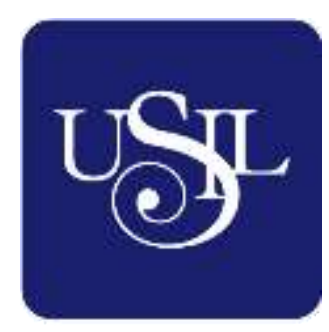

UNIVERSIDAD

SAN IGNACIO

DE LOYOLA

ESCUELA DE POSTGRADO

Maestría en Educación con Mención en Gestión de

la Educación

\title{
PROGRAMA DE FORMACIÓN CONTINUA DE DIRECTIVOS PARA ACTIVAR A LOS PUESTOS CLAVES EN UNA INSTITUCIÓN EDUCATIVA PRIVADA DE EDUCACIÓN BÁSICA REGULAR
}

Tesis para optar el grado de Maestro en Educación con Mención en Gestión de la Educación

JOSE FERNANDO CHICOMA CASTRO

Asesor:

Patricia Medina Zuta

Lima - Perú 


\section{Dedicatoria}

Dedico este trabajo a mis padres por darme el don de la vida y la fortaleza para no desistir en alcanzar mis metas profesionales; y a mis hermanos, por ser mi verdadero motor y motivo en la vida. 


\section{Agradecimiento}

Quiero extender mi agradecimiento a los Dres. Patricia Medina Zuta y José Manuel Muñoz Salazar, asesores de la presente investigación, por su alto grado de compromiso, dedicación y apoyo incondicional. 


\section{Índice}

Introducción $\quad 1$

Planteamiento del problema de la investigación 2

$\begin{array}{ll}\text { Formulación del problema } & 3\end{array}$

Preguntas científicas. 3

Objetivos de la investigación $\quad 4$

Objetivo general. $\quad 4$

Paradigma, enfoque, tipo y diseño de investigación 4

Población y muestra $\quad 5$

Población. $\quad 5$

$\begin{array}{ll}\text { Muestra. } & 6\end{array}$

$\begin{array}{ll}\text { Métodos de la investigación } & 7\end{array}$

$\begin{array}{ll}\text { Métodos teóricos. } & 7\end{array}$

Métodos empíricos. $\quad 8$

Métodos estadísticos y matemáticos. $\quad 9$

$\begin{array}{lr}\text { Categorías apriorísticas de la investigación } & 9\end{array}$

$\begin{array}{ll}\text { Justificación teórica, metodológica y práctica } & 10\end{array}$

$\begin{array}{ll}\text { Teórica. } & 10\end{array}$

$\begin{array}{ll}\text { Metodológica. } & 10\end{array}$

$\begin{array}{ll}\text { Práctica. } & 11\end{array}$

Estructura general del informe 11

Capítulo I 12

Marco Teórico 12

Antecedentes de la investigación 12

$\begin{array}{ll}\text { Antecedentes internacionales. } & 12\end{array}$

Antecedentes nacionales. $\quad 14$

Fundamentos Teóricos 16

Formación Continua de Directivos. $\quad 16$

$\begin{array}{lr}\text { Talleres de formación. } & 17\end{array}$

$\begin{array}{lr}\text { Encuentros de redes educativas. } & 18\end{array}$

$\begin{array}{lr}\text { Actividades virtuales a distancia. } & 19\end{array}$

Activación de Puestos Claves. 20

$\begin{array}{lr}\text { Reclutamiento. } & 20\end{array}$

Sistema de incentivos personales.

Capacitación. 23

Capítulo II $\quad 24$

Diagnóstico o Trabajo de Campo $\quad 24$

Características del campo de estudio $\quad 24$ 
$\begin{array}{ll}\text { Análisis de la encuesta a estudiantes. } & 24\end{array}$

$\begin{array}{lr}\text { Análisis de la entrevista a directivos. } & 27\end{array}$

$\begin{array}{lr}\text { Análisis de la entrevista a puestos claves. } & 29\end{array}$

Proceso de categorización e interpretación 31

$\begin{array}{ll}\text { Procesamiento de la información. } & 31\end{array}$

Relaciones analíticas e interpretativas entre datos y categorías emergentes 32

Necesidad de actualización de conocimientos y mejora continua de la gestión del directivo. 32

Desconocimiento y falta de experticia en el uso de TICS por parte de los gestores educativos. 32

Necesidad de reconocimiento del perfil de los puestos claves por parte de los directivos. 33

$\begin{array}{ll}\text { Conclusiones aproximativas } & 34\end{array}$

Capítulo III 36

Modelación, validación y aplicación de la propuesta 36

Propósito de la investigación $\quad 36$

$\begin{array}{ll}\text { Fundamentación pedagógica. } & 36\end{array}$

$\begin{array}{ll}\text { Fundamentación psicológica. } & 39\end{array}$

$\begin{array}{ll}\text { Fundamentación socio - educativa. } & 41\end{array}$

$\begin{array}{lr}\text { Fundamentación administrativa. } & 43\end{array}$

$\begin{array}{ll}\text { Fundamentación normativa. } & 45\end{array}$

$\begin{array}{lr}\text { Diseño gráfico funcional de la propuesta } & 47\end{array}$

Desarrollo e implementación del programa de formación continua 47

$\begin{array}{lr}\text { Programa de Formación Continua de Directivos. } & 48\end{array}$

$\begin{array}{lr}\text { Objetivo General. } & 48\end{array}$

$\begin{array}{lr}\text { Objetivos específicos. } & 48\end{array}$

$\begin{array}{ll}\text { Módulos. } & 48\end{array}$

$\begin{array}{ll}\text { Enfoques. } & 49\end{array}$

Ejecución del programa de formación continua.

$\begin{array}{ll}\text { Duración. } & 50\end{array}$

$\begin{array}{ll}\text { Organización. } & 51\end{array}$

$\begin{array}{ll}\text { Temarios. } & 52\end{array}$

$\begin{array}{ll}\text { Normas y Compromisos. } & 53\end{array}$

$\begin{array}{ll}\text { Certificación. } & 54\end{array}$

$\begin{array}{ll}\text { Evaluación. } & 54\end{array}$

$\begin{array}{lr}\text { Perfil del Egresado. } & 54\end{array}$

Validación del programa de formación continua $\quad 55$

$\begin{array}{ll}\text { Valoración Interna. } & 56\end{array}$

$\begin{array}{ll}\text { Valoración Externa. } & 58\end{array}$

Resultados de la Valoración Interna y Externa. $\quad 59$

$\begin{array}{ll}\text { Conclusiones } & 61\end{array}$ 
Recomendaciones

Referencias

Anexos

Anexo 1. Matriz de Categorización

Anexo 2. Matriz Metodológica

Anexo 3. Cuestionario a estudiantes

Anexo 4. Ficha de entrevista a directivos

Anexo 5. Ficha de entrevista a puestos claves

Anexo 6. Tabulación de encuesta a estudiantes

Anexo 7. Carta de presentación a expertos

Anexo 8. Carta de presentación a la Institución Educativa

Anexo 9. Validación de instrumentos por criterio de expertos

Anexo 10. Validación del programa de formación continua 


\section{Índice de Tablas}

TABLA 1. POBLACIÓN 6

TABLA 2. UNIDAD DE ANÁLISIS 6

TABLA 3. CATEGORÍAS Y SUBCATEGORÍAS ....................................................... 9

TABLA 4. FUNDAMENTOS TEÓRICOS PARA LA CREACIÓN DEL PFC ................. 46

TABLA 5. PROGRAMACIÓN DE ACTIVIDADES DEL PFC........................................ 51

TABLA 6. SYLABUS DEL PROGRAMA DE FORMACIÓN CONTINUA................... 52

TABLA 7. PERFIL DEL EGRESADO ………………......................................... 54

TABLA 8. ESPECIALISTAS DE LA VALIDACIÓN ... …………………………...... 56

TABLA 9. ESCALA DE CALIFICACIÓN................................................................. 57

TABLA 10. VALIDACIÓN INTERNA POR JUICIO DE EXPERTOS ………………..... 57

TABLA 11. VALIDACIÓN EXTERNA POR JUICIO DE EXPERTOS... …………....... 58

TABLA 12. RESUMEN DE VALIDACIÓN INTERNA Y EXTERNA........................... 58 


\section{Índice de figuras}

FIGURA 1. RESULTADO DEL PROCESO DE DIAGNÓSTICO DE CAMPO............... 31

FIGURA 2. TIPOS DE APRENDIZAJE ....................................................................... 37

FIGURA 3. MÉTODOS DE APRENDIZAJE POR FORMA DE RAZONAMIENTO..... 38

FIGURA 4. MÉTODOS DE APRENDIZAJE BASADOS EN LA ORGANIZACIÓN .... 39

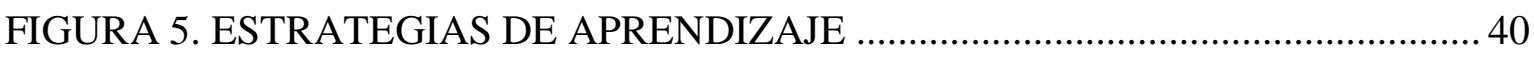

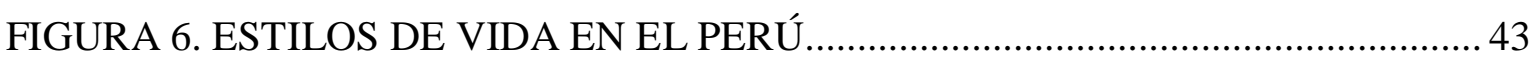

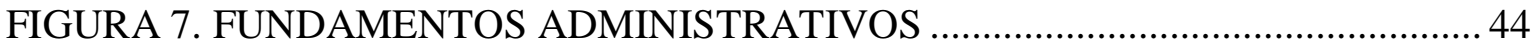

FIGURA 8. VENTAJAS DEL PROGRAMA DE FORMACIÓN CONTINUA ................ 51 


\section{Resumen}

En el ámbito educativo, existen cargos considerados claves o de alta importancia para el adecuado funcionamiento de toda la organización. Pero ¿qué pasa cuando no es ocupado por una persona talentosa? Sin duda, este es uno de los problemas que enfrentan muchas instituciones educativas, y en particular los gestores educativos, cuando se ven frente a la renuncia o despido de un profesional talentoso que ocupa una posición considerada clave. Por lo general, los directores recurren al reemplazo de un puesto clave a través del reclutamiento externo, pero ¿es esto lo correcto?, ¿no existe un colaborador interno que pueda asumir dicha posición?, ¿existe un adecuado plan de sucesión?, ¿se sabe qué hacer ante esta eventualidad?, ¿el gestor educativo está preparado para ello? La presente investigación ha logrado desarrollar con éxito un programa de formación continua de directivos que permita saber qué hacer y qué no hacer para activar y/o retener a los puestos claves dentro de las instituciones educativas. Para ello se han consultado más de 50 fuentes académicas en donde se ha podido investigar a profundidad y delimitar la forma en las que los gestores educativos pueden ser capacitados para poder enfrentar con habilidad este tipo de problemas. Se han establecido para ello dos categorías de investigación: formación continua de directivos y activación de puestos claves que a su vez presentan las siguientes sub categorías: talleres de formación, encuentros de redes educativas, actividades virtuales a distancia, reclutamiento, sistema de incentivos personalizados y capacitación respectivamente; con la intención de tener un panorama claro de la forma en la que un gestor educativo puede dar solución rápida y planificada a la ausencia de un puesto clave.

Palabras Clave: formación continua, puestos claves, activación de puestos, retención de puestos, capacitación del gestor educativo. 


\begin{abstract}
In the educational field, there are positions considered key or of high importance for the proper functioning of the entire organization. But what happens when it is not occupied by a talented person? Undoubtedly, this is one of the problems faced by many educational institutions, and in particular educational managers, when faced with the resignation or dismissal of a talented professional who occupies a position considered key. In general, the directors resort to the replacement of a key position through external recruitment, but is this the right thing? Is there not an internal collaborator who can assume that position? Is there an adequate succession plan? Do you know what to do about this eventuality? Is the education manager prepared for it? This research aims to propose a continuous training program for managers that allows knowing what to do and what not to do to activate and / or retain the key positions within educational institutions. For this purpose, more than 50 academic sources have been consulted where it has been possible to investigate in depth and delimit the way in which educational managers can be trained to be able to face this type of eventuality with skill. Three research categories have been established for this: continuous training of managers, activation of key positions, which in turn present the following sub categories: training workshops, educational network meetings, virtual activities distance, internal and external recruitment, personalized incentive system and training respectively; with the intention of having a clear picture of the way in which an educational manager can provide a quick and planned solution to the absence of a key position.
\end{abstract}

Key words: continuous training, key positions, activation of posts, retention of posts, training of the educational manager. 


\section{Introducción}

Las instituciones educativas en el siglo XXI viven cambios estratégicos, culturales, pedagógicos y organizativos para adaptarse a los requerimientos del mercado. Hoy en día la educación ha revolucionado en el tiempo a tal punto que está obligando a los colegios de casi todo el mundo a reinventarse invirtiendo en infraestructura, tecnología, convenios y sobre todo en profesionales altamente calificados, con el único afán de brindar un servicio de calidad diferenciado.

La Organización de las Naciones Unidas para la Educación, la Ciencia y la Cultura (Unesco, 2019) considera que la educación es un derecho humano para todos, a lo largo de toda la vida, y que el acceso a la instrucción debe ir acompañado de una cuota importante de calidad que depende principalmente de los educadores. Son los docentes quienes a través de sus conocimientos, habilidades y actitudes pueden garantizar o no el éxito educativo de sus estudiantes. La Organización para la Cooperación y el Desarrollo Económico (OCDE, 2014) por su parte sostiene, en su Programa País, que la educación de calidad depende de dos factores: del nivel de competencia de los docentes y la habilidad del directivo para saber administrar los recursos con los que cuenta.

Según Wolk (2009), en la actualidad, no sólo basta con tener una carrera profesional para ser competente, el mercado exige un segundo idioma, una especialización o máster, habilidades blandas bien trabajadas y un nivel alto de liderazgo que permita ser solvente a la hora de asumir un puesto de trabajo. Esto es prácticamente un requisito para cualquier profesión y se acrecienta cuando nos referimos a los profesionales del Sector Educación, quienes se entiende deben ser personas probas e intachables.

Para Mintzberg (2013), las personas son las que hacen a las organizaciones y no organizaciones a las personas, entendiéndose que el talento humano puede determinar el éxito o fracaso de toda la organización, en este sentido tal como explica Deroncele (2015, 2017) las organizaciones son sistemas humanos que se configuran desde la relación entre el proyecto organizacional (misión, visión, valores, objetivos, objeto social) y las motivaciones, necesidades, expectativas e intereses de los directivos y trabajadores, siendo el ser humano el factor más importante en la concreción de los procesos claves, estratégicos y de apoyo.

En el ámbito educativo, resulta fundamental que los directivos sean capaces de identificar cuáles son aquellos puestos claves en donde la toma de decisiones, solución de problemas, 
pensamiento crítico y creativo sean desarrollados por personas con talento. Identificar a los profesionales más talentosos y asignarlos a puestos claves es sin duda uno de los retos más ambiciosos al que se enfrentan permanentemente los directivos de las instituciones educativas.

\section{Planteamiento del problema de la investigación}

Los puestos claves en una institución educativa son aquellos que son neurálgicos para la operación (en número de dimensiones); no tener a colaboradores idóneos en estos puestos acarrea serios problemas para el funcionamiento de áreas específicas o de toda la organización en general. Por lo tanto, la gestión exitosa del directivo es una función esencial. Ésta consiste en dos aspectos básicos: la identificación del puesto clave y el cuidado de las personas que lo desempeñan, desde su activación hasta su posible reemplazo (Escudero y Gómez, 2006).

Gestionar exitosamente un puesto clave implica cuidar a los puestos que tienen impacto en la organización. Desde la incorporación de una persona a ese puesto, asegurando así su compatibilidad con las exigencias del mismo y la cultura de la organización; hasta la asignación de un mimo, que implica otorgarle beneficios y atenciones diferenciadas. Existen dos preocupaciones respecto a los puestos claves: ¿Cómo se atraen? y ¿Cómo se retienen? La respuesta es distinta para cada caso. La atracción y retención tiene características distintas, la primera es más estructurada, mientras que la segunda es más emergente u orgánica. El manejo de cada uno de estos procesos se da de forma distinta en las organizaciones educativas (Zerilli, 2003).

Pero, ¿Qué técnicas o herramientas utiliza un directivo para identificar los puestos y las personas claves en la organización educativa?, ¿Existe alguna metodología formal para hacerlo?, ¿Todos los puestos claves son ocupados por personas claves?, ¿Se cuenta con personas claves en posiciones no claves? Éstas son sólo algunas de las interrogantes a las cuales daremos respuesta en la presente investigación.

Todo lo expuesto anteriormente, nos permite analizar la realidad de un colegio de Lima Metropolitana ubicado en el distrito de San Miguel. Dicha institución cuenta con una población que supera los 1300 estudiantes en los niveles de Inicial, Primaria y Secundaria. Actualmente, es considerado referente en su distrito por los múltiples servicios diferenciados que ofrece en sus más de 50 aulas; entre ellos, el Programa del Diploma del 
Bachillerato Internacional, que permite que sus egresados puedan acceder a la convalidación de cursos del colegio con la universidad.

Dicha institución cuenta con una estructura jerárquica diseñada para que sus colaboradores (casi 200 personas) ejerzan sus funciones con proactividad y dinamismo dentro de un organigrama vertical; sin embargo, cuando se ha presentado una renuncia voluntaria o se ha desvinculado a algún miembro de su personal por falta grave, toda la organización se ve afectada cuando se trata de un puesto clave, pues nadie sabe cómo desempeñar dichas funciones por falta de un adecuado plan de sucesión o la escasez de recursos humanos con el talento necesario para poder reemplazarlo.

Es por esta necesidad que el presente estudio, plantea el diseño de un programa de formación continua de directivos para activar a los puestos claves en una institución educativa privada de educación básica regular, con la intención de contar con herramientas y estrategias de gestión que permitan identificar quiénes deberían ocupar puestos claves, cómo se debería efectuar su retención en el tiempo o quiénes deberían reemplazarlo en caso se presente una renuncia voluntaria o una desvinculación por falta grave.

\section{Formulación del problema}

¿Cómo los directivos podrían activar a los puestos claves en una institución educativa privada de educación básica regular?

\section{Preguntas científicas.}

¿Cuál es el estado actual de los programas de formación continua de directivos para activar a los puestos claves en una institución educativa privadas de educación básica regular?

¿Cuáles son los fundamentos teóricos y metodológicos de un programa de formación continua de directivos que permita activar a los puestos claves en una institución educativa privada de educación básica regular?

¿Qué criterios se deben considerar para la modelación de un programa de formación continua de directivos que permita activar a los puestos claves en una institución educativa privada de educación básica regular?

¿Cómo se puede validar la efectividad de la modelación de un programa de formación continua de directivos que permita activar a los puestos claves en una institución educativa privada de educación básica regular? 


\section{Objetivos de la investigación}

\section{Objetivo general.}

Diseñar un programa de formación continua de directivos para activar a los puestos claves en una institución educativa privada de educación básica regular.

\section{Objetivos específicos o tareas específicas de la investigación.}

Diagnosticar el estado actual de los programas de formación continua de directivos para activar a los puestos claves en una institución educativa privada de educación básica regular.

Sistematizar los fundamentos teóricos y metodológicos que sustentan los programas de formación continua de directivos para activar a os puestos claves en una institución educativa privadas de educación básica regular.

Determinar los criterios teóricos y didácticos que sirven de base para la modelación de un programa de formación continua de directivos para activar a los puestos claves en una institución educativa privada de educación básica regular.

Validar la modelación de un programa de formación continua de directivos para activar a los puestos claves en una institución educativa privada de educación básica regular.

\section{Paradigma, enfoque, tipo y diseño de investigación}

El presente estudio sigue el paradigma socio crítico, pues se fundamenta en la crítica social con un marcado carácter auto reflexivo, considerando que el conocimiento se construye por intereses que parten de necesidades reales actuales. La intención del presente trabajo es superar todo reduccionismo y conservadurismo de la sociedad, tomando como referencia la “teoría crítica” de Theodor Adorno y Max Horkheimer (2003), en la que se pone énfasis en la evaluación y la crítica de la sociedad a partir del estudio de las ciencias humanas y sociales. Asimismo, sigue el paradigma interpretativo pues se centra en la fenomenología, distinguiendo como son las cosas a partir del cómo pensamos que realmente son, tomando como referencia la "teoría interpretativa" de Edmundo Husserl (1900), en la que se sostiene que las cosas existen porque queremos que estén allí. La investigación tendrá un proceso dinámico que intentará unir la teoría con la práctica teniendo como objetivo principal la mejora del ser humano a partir de la comprensión de su realidad. 
El enfoque de la investigación presenta un diseño no experimental que se basa en la observación de una realidad educativa en su contexto natural. Se entiende por diseño no experimental a aquel en la que no es necesario manipular deliberadamente las variables y cuya intención es principalmente observar un problema para analizarlo con posterioridad (Hernández, Fernández y Baptista, 2006). Asimismo, presentará un corte transversal puesto que recogerá la información en un solo momento a través de diversos instrumentos de aplicación. El presente trabajo plantea recoger datos reales "in situ” (en su lugar de origen) para luego procesarlos y plantear una posible solución a través del diseño de un programa de formación continua para directivos.

La presente investigación es de tipo aplicada educacional, pues se orienta a la comprensión, profundización y resolución de un problema real que se presenta con frecuencia en el sector educación: la activación y retención de personas con talento en puestos claves. Entendemos por investigación aplicada educacional a aquella búsqueda sistemática de "algo nuevo" que se da a través del diagnóstico, fundamentación, modelamiento y validación de información (Albert, 2009). Ese "algo" producto de esta investigación será el diseño de un programa de formación continua de directivos para activar a los puestos claves en una institución educativa privada de educación básica regular.

\section{Población y muestra}

\section{Población.}

En el presente trabajo de investigación, la población está conformada por todos aquellos gestores educativos y/o directivos de instituciones educativas de educación básica regular ubicadas en los distritos de San Miguel y Magdalena. Entendemos por población a aquel número finito de personas que comparten elementos o características comunes (Balestrini, 2006). Se estima que la población estaría por encima de los 100 directivos de colegios privados ubicados en dichos distritos, considerando que en el 2016, según el Instituto Nacional de Estadística e Informática, se contaba con 37 escuelas registradas y que en los últimos años se han otorgado 11 licencias de funcionamiento para nuevos colegios (Ver Tabla 1). 
Tabla 1

Población

\begin{tabular}{cc}
\hline $\begin{array}{c}\mathbf{N}^{\circ} \text { colegios privados en los distritos de } \\
\text { San miguel } \mathbf{y} \text { Magdalena }\end{array}$ \\
\hline Distrito & $\mathbf{N}^{\circ}$ Colegios \\
San Miguel & 34 \\
Magdalena & 14 \\
Total & 48 \\
\hline
\end{tabular}

Fuente: INEI 2016

\section{Muestra.}

La unidad de análisis de la presente investigación está conformada por el personal directivo de una institución educativa particular, la cual está conformado por los siguientes perfiles directivos: Directora General y Subdirector; tres profesionales considerados puestos claves (coordinadores) y 23 estudiantes de 5to año de Secundaria. Dicha institución cuenta con un organigrama vertical a través del cual existen diversos niveles de jefatura donde se organizan de manera bastante dinámica un aproximado de 200 colaboradores, quienes atienden a una población de 1300 estudiantes. Entendemos por unidad de análisis a aquella fracción de la población a la cual estudiaremos de manera objetiva y/o subjetiva (Balestrini, 2006). El muestreo aplicado fue de tipo no probabilístico intencional, es decir que la muestra fue deliberadamente elegida por el autor de la presente investigación (Ver Tabla 2).

Tabla 2

Unidad de Análisis

\begin{tabular}{cc}
\hline Unidad de análisis & Cargos \\
\hline Directivos & 01 Directora General \\
& 01 Subdirector \\
Puestos Claves & 03 Coordinadores \\
Estudiantes & 23 Alumnos \\
& \\
\hline
\end{tabular}

Fuente: Elaboración propia 


\section{Métodos de la investigación}

La presente investigación es principalmente cualitativa, pues sus bases están sentadas sobre la interpretación de los fenómenos sociales a través de la vivencia del investigador (autor), quien se encuentra inmerso en el contexto de estudio. Ello implica un alto porcentaje de intersubjetividad en la elección de las categorías de investigación, las cuáles podrían tener cierto sesgo en la interpretación de la realidad. Los actores principales que podemos evidenciar en esta investigación son el investigador y el objeto de estudio. (Balestrini, 2002).

\section{Métodos teóricos.}

Los métodos teóricos aplicados en la presente investigación fueron:

\section{Método histórico-lógico.}

Según Martinez (2014), un método histórico lógico se enfoca en el estudio de acontecimientos que se han dado en una determinada etapa o periodo de tiempo de manera que se puede medir su causa y efecto. Es así que en el presente estudio, se ha ejecutado un despliegue teórico en torno al origen, evolución y estado actual de los puestos claves dentro de las instituciones educativas de educación básica regular de los últimos 20 años.

\section{Método análisis síntesis.}

Porras (2016), sostiene que el método de análisis síntesis permite investigar una realidad enfocándose en un tema específico considerado relevante, el mismo que se analizará por partes hasta llegar a una conclusión lógica. En ese sentido, el presente estudio abordó el análisis de la realidad de manera segmentada, en sus múltiples relaciones y componentes. La síntesis del presente estudio estableció la unión entre las categorías de investigación y determinó sus relaciones, apoyándose en la abstracción y generalización del objeto de estudio.

\section{Método por modelación.}

Rodriguez (2001), afirma que el método por modelación es un modelo científico que permite explicar la realidad de manera teórica a través de abstracciones. Bajo esa premisa, la presente investigación ha descubierto nuevas relaciones entre las categorías de investigación y cualidades del objeto de estudio y las ha esquematizado a fin de diseñar un 
programa de formación continua para directivos. Todo ello dentro de una secuencia lógica aplicada.

\section{Método de abstracción e integración.}

Martinez (2014), afirma que el método de abstracción e integración o concreción presenta una estructura delimitada por dos escenarios consecutivos. El primero hace alusión a la comprensión de hechos abstractos y el segundo a su análisis para llevarlos a resultados concretos. Bajo esa perspectiva, los contenidos teóricos y prácticos de la presente investigación han sido analizados al detalle por parte del autor de la tesis, apoyándose de literatura existente - sobre los puestos claves - de los principales centros de recursos de investigación y bibliotecas de las universidades más importantes de Lima Metropolitana.

\section{Método inductivo - deductivo.}

Porras (2016), sostiene que el método inductivo - deductivo responde a un razonamiento lógico por parte del autor, que le permite llegar a conclusiones generales y específicas. En ese contexto, la presente investigación ha pretendido obtener conclusiones generales a partir de premisas particulares y viceversa. Se aplicó para ello una etapa de observación y otra de análisis y clasificación de los hechos que permitieron modelar una posible solución al problema de investigación.

\section{Métodos empíricos.}

Los métodos empíricos aplicados en la presente investigación fueron:

\section{Entrevista.}

Según Rodriguez (2001), la entrevista es una técnica que consiste en la recolección de datos de forma oral a través de un diálogo programado. El objetivo es que el interrogador conozca la opinión del entrevistado sobre un tema en particular. En el presente estudio se aplicó esta técnica a través de varias sesiones de preguntas y respuestas. Se contó para ello con una guía de preguntas (instrumento) que permitió conocer al detalle la forma de pensar del entrevistado. Los agentes a entrevistar fueron principalmente el directivo y los puestos claves. 


\section{Encuesta.}

Para Porras (2016), la encuesta es una técnica y/o procedimiento que permite recopilar información veraz por parte del encuestado que pueda ser tabulada y/o analizada estadísticamente con el fin de obtener resultados objetivos en una investigación descriptiva. En el presente estudio, se aplicó un cuestionario para recoger la opinión de un número finto de estudiantes, quienes representan una muestra importante para la identificación y/o reconocimiento de las características que tienen en común los puestos claves dentro de su organización. Dicha información resultó fundamental y/o clave para la modelación, validación y/o propuesta de una categoría de investigación emergente.

\section{Métodos estadísticos y matemáticos.}

Para Eyssautier (2011), la aplicación de métodos estadísticos y matemáticos representan sin duda, los mejores procedimientos para procesar datos cualitativos y cuantitativos. Esta técnica permite comprobar o negar supuestos o establecer relaciones entre los mismos. En la presente investigación se tabuló la información obtenida a través del uso de tablas de Excel que luego fueron procesados en el paquete estadístico SPSS. Todo ello con la intención de obtener una estadística descriptiva que le de soporte objetivo al presente estudio.

\section{Categorías apriorísticas de la investigación}

Tabla 3

Categorías y Subcategorías

\begin{tabular}{ll}
\hline Categorías & Subcategorías \\
\hline
\end{tabular}

\section{Formación Continua de Directivos:}

Es aquella capacitación constante y sostenida en

Talleres de formación

la que los gestores de la educación logran

aprender nuevas estrategias y herramientas de

Encuentros de redes educativas

gestión que les ayudan a ejercer con autonomía y

solvencia sus funciones administrativas y

Actividades virtuales a distancia

pedagógicas (Escudero y Gómez, 2006).

Activación de Puestos Claves:

Reclutamiento 
Proceso mediante el cual se capta y/o retiene a

los puestos claves para desempeñar funciones

Sistema de incentivos personalizados

críticas que garanticen el éxito de toda la

organización (Roig, 2006).

Capacitación

Fuente: Elaboración propia

\section{Justificación teórica, metodológica y práctica}

\section{Teórica.}

La presente investigación se justifica desde el punto de vista teórico porque el mercado exige que los gestores de la educación se mantengan en constante formación dado que son los responsables directos de la planificación, organización, dirección y control del proyecto educativo. Saber gestionar implica tener claro el cómo se debe actuar para dar solución a un problema, ello incluye la capacidad de saber cómo administrar al personal que tiene a su cargo; el no contar con personas claves en puestos claves puede repercutir seriamente en la calidad del servicio, la cultura y/o la rentabilidad de toda la organización, es por ello que la formación continua de los directivos resulta crucial para garantizar su continuidad y éxito.

Resulta muy difícil perfeccionar la labor del dirigente sin perfeccionar su capacitación. Las posibilidades de ejercer con efectividad sus funciones están vinculadas con la calidad y objetividad en el desarrollo de su capacitación. Es necesario que un directivo sea experto en coordinar los talentos y ello solo se logra con la actualización constante de capacidades. El proceso de enseñanza - aprendizaje con dirigentes tiene la finalidad de producir un cambio en estos, que debe expresarse - siempre - en una mejor gestión de recursos humanos.

\section{Metodológica.}

El presente trabajo de investigación tiene justificación metodológica porque su estructura es sistémica cualitativa, aplicada y educacional; estando orientada principalmente al diseño de un programa de mejora continua para directivos que les permita activar y retener a los puestos claves dentro de sus organizaciones educativas. 
Es sistémica cualitativa, porque incluye entrevistas individuales, focus group y observaciones directas; las mismas que recogen información valiosa que permite entender los motivos por los cuáles cuesta tanto buscar, captar y retener a los puestos claves en el sector educativo.

Es aplicada, porque tiene como objetivo resolver uno de los problemas más álgidos que presentan el día hoy las organizaciones educativas: la activación y retención de los puestos claves.

Es educacional, porque se enmarca dentro del contexto educativo, dando respuesta a uno de los problemas más críticos que enfrentan los gestores educativos y directores: la activación y retención del personal con talento.

\section{Práctica.}

El presente estudio tiene pertinencia y justificación práctica porque recoge la realidad un colegio particular de Lima Metropolitana, la cual no es ajena a la de otras escuelas de educación básica regular del sector público y privado que podamos encontrar en el Perú. La intención de la presente investigación es diseñar un Programa de Formación Continua de Directivos que le permita a los directores, gestores, promotores y/o investigadores aplicar estrategias reales que impulsen la activación y/o retención de los puestos claves que se encuentran bajo su gestión.

\section{Estructura general del informe}

La presente investigación iniciará describiendo los antecedentes internacionales y nacionales del objeto de estudio, para luego sentar las bases teóricas sobre las categorías de investigación: Formación Continua de Directivos y Activación de Puestos Claves. Posteriormente a ello se procederá con la ejecución de un diagnóstico inicial que permita levantar información de campo a través de la aplicación y validación de instrumentos. Luego de la recolección datos, se analizará la muestra de estudio a fin de obtener resultados que nos conduzcan a un análisis y conclusiones aproximativas. Finalmente, se presentarán y discutirán los resultados con la intención de modelar y validar una propuesta que servirá de aporte para todas aquellas instituciones educativas de Educación Básica Regular ubicadas en los distritos de San Miguel y Magdalena que deseen implementar un Programa de Formación Continua de Directivos para Activar a sus Puestos Claves. 


\section{Capítulo I: Marco Teórico}

\section{Antecedentes de la investigación}

\section{Antecedentes internacionales.}

Albert (2018), tras investigar el rol del directivo en los cinco continentes, en su tesis doctoral alega que la aplicación de planes de mejora continua es el único y mejor camino para el éxito de las organizaciones educativas. Albert demostró a través de seis artículos publicados en reconocidos medios como el New York Times de Nueva York que las instituciones educativas, a través de sus directivos, deben implementar áreas especializadas que garanticen la calidad educativa. Él llama a este proceso "mejora continua sostenida". Y es que las instituciones que no superan sus errores y se proyectan al futuro están condenadas a caer en la obsolescencia. Hoy en día la demanda del mercado estudiantil se centra en buscar más y mejores servicios que solo puede ser resuelta con la implementación de planes de mejora continua en el tiempo.

Newstrom (2016), asegura que el un buen gestor debe ser un experto en comportamiento organizacional para poder así comprender mejor a las personas en situaciones diversas. Él concluyó en sus investigaciones aplicadas en 83 escuelas de todo Latinoamérica, incluyendo países como Perú, Argentina, Chile, Brasil, Colombia y Ecuador, que los directivos más exitosos son los que dominan los siguientes procesos: la reflexión, el pensamiento crítico, los elementos de valor y el análisis de la causa. Se le atribuye especial significación a los procesos reflexivos del directivo en tanto "la capacidad de reflexión permite la atención y estado de alerta frente al otro, al propio entorno, y a lo que supone interpretarlos y configurarlos de modo constante" (Medina y Deroncele, 2019, p. 600).

De la misma manera Deroncele (2017, p.212) plantea la importancia de fomentar como parte de la formación continua de los directivos elementos como: "el dominio del estrés laboral, habilidades de trabajo en equipo, mediación en la resolución de conflictos; sentido ético en la actividad directiva, motivación laboral, habilidades comunicativas, habilidades para el desarrollo de grupos laborales saludables; todo lo cual se concreta en la potenciación de competencias directivas para la gestión integrada del talento humano" 
Ello nos lleva a concluir que los gestores deben esforzarse permanentemente por adquirir y reforzar competencias y destrezas que les ayuden a liderar con solvencia al equipo que tienen a su cargo.

Valledor (2013), también investigó sobre este tema en 11 países de 4 continentes, concluyendo de manera categórica que el éxito de una organización educativa está estrechamente vinculado a la capacidad de gestión del directivo. Él afirma que un gestor debe tener clara la misión, visión y plan estratégico de la institución a fin de llevar a buen puerto a toda la comunidad educativa. Valledor pone énfasis en que los gestores deben ser líderes por excelencia y deben estar en constante formación y capacitación. Estas afirmaciones nos permiten concluir que los gestores educativos cumplen un rol protagónico en el desarrollo de sus organizaciones, por ende, su formación resulta ser un elemento clave para alcanzar el éxito.

Wolk (2009) por su lado, argumenta que un líder debe conocer a su equipo, debe ser un estratega al momento de asignar funciones y debe ser un coach a tiempo completo. Si lo llevamos al ámbito educativo, podemos afirmar que el gestor educativo es quien debe asumir ese rol de liderazgo, identificando las cualidades y limitaciones del personal que tiene a su cargo para poder asignarlo de forma estratégica a las posiciones en donde pueda tener mejores resultados que se verán reflejados tanto a nivel individual como colectivo. Esta asignación estratégica permite que las funciones críticas de la organización sean asumidas por personas talentosas, garantizando de alguna manera un servicio educativo diferenciado.

Roig (2006), realizó una investigación sobre los puestos de trabajo bajo el título "El estudio de los puestos de trabajo, la valoración de tareas y la valoración del personal”. En dicho estudio, a modo de línea del tiempo, se señala que existe evidencia del análisis de los puestos de trabajo a partir de 1910, con Taylor y Ford, quienes implantaron en Francia - cada uno a su estilo - técnicas en sus factorías Citroen y Renault a través de las cuales lograron “identificar y analizar el trabajo y consideración de las exigencias personales requeridas para el adecuado desempeño o ejecución de los diversos puestos”. Es decir, que antes de la era industrial y la aparición de las disciplinas científicas que tienen como objeto el trabajo como actividad humana, ya se podía hablar de puestos de trabajo y de características de las personas para poder ocuparlos. Para Roig, los puestos claves deben ser ocupados por personas con talento, las mismas que deben pasar por un proceso de identificación por parte del director o gestor educativo. 
Escudero y Gómez (2006), en su tesis doctoral, sostienen que en el sector educación, resulta crucial que los puestos claves sean ocupados por profesionales altamente calificados, pues serán ellos el motor de toda la organización. Dichos autores afirman que es competencia de cada directivo identificar, activar y retener a los mejores talentos para garantizar la calidad educativa. El sustento para esta afirmación fue la tabulación de más de 100 entrevistas a directivos de escuelas públicas y privadas de ocho países latinoamericanos. Esto nos permite afirmar nuevamente que los puestos claves resultan ser el eje central de la escuela, pues ellos y su talento son los que van a establecer los cimientos para poder establecer un servicio diferenciado.

\section{Antecedentes nacionales.}

Díaz (2019), sostiene que los gestores o directores deben capacitarse constantemente para aprender a gestionar de manera profesional a los recursos humanos. Atraer y retener al talento es sin duda uno de los retos más ambiciosos que todas las organizaciones pretenden alcanzar dado que estamos viviendo en tiempos de transformación en donde las personas están en constante búsqueda de nuevas y mejores oportunidades laborales. Díaz logró demostrar en sus investigaciones que los gestores que se capacitan de manera constante, no sólo logran ubicar a sus organizaciones como las mejores del mercado, tras aplicar políticas de mejora continua, sino que también logran mantener motivado al personal que tienen a su cargo. Y es que mantener altos niveles de motivación en el personal podrían minimizar la rotación y garantizar de cierto modo la calidad educativa.

Medina (2019), por su parte, afirma que los profesionales deben poner un especial cuidado en su formación y adentrarse en una cultura con pautas y valores nuevos que exigen cambios incluso en su identidad. Sostiene además que la exigencia de uno mismo es un compromiso personal que incide directamente en el crecimiento profesional, desarrollo personal y progreso.

Rest (2018), investigó de cerca a los gestores de escuelas públicas del Perú en los años 2016, 2017 y 2018, aseverando que las instituciones educativas son como tableros de ajedrez, en donde el gestor representa al jugador quien debe decidir el cómo, cuándo y hacia dónde mover sus piezas, que en este caso son los colaboradores, para poder alcanzar un servicio de calidad en la escuela. Y es que un buen gestor debe ser un estratega por excelencia, un profesional que pueda adelantarse a los problemas y darles solución de manera inteligente y sostenida. 
Poiry (2018), concluyó en sus artículos de reforma en educación que los profesionales del sector educación deben ocupar cargos de acuerdo a sus competencias y capacidades. Él hace una fuerte crítica a los directivos que permiten que sus docentes ocupen cargos para los cuáles no han sido formados. Poiry, afirma que en muchas escuelas del Perú, tanto públicas como privadas, se les exige a los docentes ocupar posiciones por necesidad, afectando la calidad educativa y limitando las capacidades de los estudiantes que podrían tener una mejor educación. Y es que nadie puede dar lo que no tiene, es decir que una persona que no cumple con el perfil para un determinado puesto no debería asumir tal posición pues podría repercutir en la calidad educativa que se pretende alcanzar.

Abarca (2013), por su parte sostiene, que un verdadero líder es aquel que está en la búsqueda constante de nuevos aprendizajes. Este autor alega categóricamente que el éxito de las organizaciones depende, en gran medida, de la capacidad de los directores para mantenerse a la vanguardia en su propio sistema, marcando el camino para su competencia. Esta afirmación nos permite concluir que los verdaderos líderes deberían invertir permanentemente en su formación y el desarrollo de sus capacidades.

Renton (2010), por su parte afirma que los directores de las escuelas que no están en constante formación están condenados a llevar a sus instituciones educativas a la obsolescencia, este autor sostiene que la educación permanentemente está sufriendo cambios y que los gestores educativos deben estar en una constante búsqueda de la mejora continua de sus organizaciones. Y es que la mejora continua es la mejor inversión que un gestor educativo puede hacer, pues permite que la organización se mantenga a la vanguardia y se diferencie de la competencia.

Espinoza (2006), afirma categóricamente que los líderes educativos deben estar en permanente formación, pues es la única forma en la que se puede garantizar la calidad educativa. Dicho autor logró demostrar que un gestor educativo que se mantiene en constante capacitación es $76 \%$ más productivo en sus funciones pedagógicas y administrativas y $45 \%$ más eficiente en la conducción del equipo humano que tiene a su cargo. Espinoza evaluó a 73 directivos de manera cualitativa, logrando identificar que aquellos que habían recibido programas de actualización, tenían mejores resultados con su equipo en términos activación y retención de puestos claves. Ello nos lleva a la conclusión que la productividad del gestor educativo está estrechamente relacionada a la actualización de sus conocimientos y desarrollo de habilidades y actitudes. 
Al revisar las investigaciones anteriores, podemos afirmar que si bien todos los autores coinciden es que es de vital importancia que los directivos desarrollen competencias para activar y retener a los puestos claves dentro de sus organizaciones educativas; existe escasa o poca evidencia de ¿cómo retener? y/o ¿cómo activar? al personal con talento, así como el ¿cómo diseñar y qué contenido debería tener un programa de formación continua para directivos que les permita activar y retener a los puestos claves en instituciones educativas de educación básica regular?, lo que hace que los resultados obtenidos de la presente investigación sean muy útiles para otras organizaciones educativas.

\section{Fundamentos Teóricos}

\section{Formación Continua de Directivos.}

Se entiende por formación continua de directivos a aquella capacitación constante y sostenida en la que los gestores de la educación logran aprender nuevas estrategias y herramientas de gestión que les ayudan a ejercer con autonomía y solvencia sus funciones administrativas y pedagógicas. Dicha instrucción, habilitación, entrenamiento o preparación debe perseguir un objetivo específico en donde el participante refuerce sus habilidades y competencias con el fin de mejorar su labor en términos de dirección y liderazgo (Escudero y Gómez, 2006).

La formación continua, capacitación continua, formación permanente, educación continua, también conocida como educación por extensión, son términos que encierran múltiples actividades de aprendizaje teórico práctico que se realizan después de la formación tradicional (básica regular, técnica o universitaria), y que pueden extenderse durante toda la vida (Schuler, 2017).

La formación continua de los directivos debe partir del reconocimiento de la "gestión de potencialidades formativas" ubicando al sujeto como protagonista del proceso de formación" (Deroncele, Medina y Gross, 2020), lo cual se inscribe como pauta para el diseño del programa de formación continua de directivos para activar a los puestos claves, siendo parte implícita de los criterios teóricos y didácticos consuderados.

La formación continua facilita el aprendizaje de nuevos conocimientos, explora nuevos modelos educativos, favorece la interacción con personas de otros entornos, ayuda a obtener reconocimientos laborales y/o a aplicar a mejoras económicas, refuerza el 
liderazgo y potencia las capacidades para conducir con solvencia a los equipos. En otras palabras, la formación continua se convierte en una oportunidad para que los gestores educativos y/o directivos se conviertan en agentes altamente competitivos (Villa y Caperán, 2015)

La educación continua puede impartirse en modalidad presencial o a distancia, suele tener un bajo costo lo que se hace que se vuelva atractiva, se puede impartir a través de programas, cursos, talleres o seminarios, constituyendo la mejor forma de mantenerse actualizado y altamente calificado (Roig, 2006).

La formación continua en el sector educación, en Latinoamérica, ha dado muy buenos resultados a través de talleres de formación, encuentros de redes educativas y actividades virtuales a distancia. La UNESCO presentó en el año 2017, en su informe bianual, estas cuatro modalidades como las más efectivas de los últimos 20 años (Rentón, 2010).

La formación continua de directivos representa sin duda uno de los mejores caminos para atraer y retener al talento humano. La administración eficiente y eficaz de los recursos humanos está estrechamente vinculada con el éxito de toda la organización educativa (Chiavenato, 2011).

\section{Talleres de formación.}

La palabra taller proviene del francés "atelier" y hace referencia al lugar donde se trabaja con las manos. En el campo de la educación, se habla de talleres para referirse a una cierta metodología de enseñanza que combinan la teoría y la práctica. Los talleres de formación tiene la filosofía de "aprender haciendo", entendiéndose a que las personas suelen ser kinestésicas, es decir que aprender más y mejor haciendo, viendo y escuchando (Villa y Caperán, 2015).

Los talleres de formación pueden variar de acuerdo a los objetivos que se persiguen. Por lo general, suelen ser de corta duración y suelen acreditarse a través de constancias de participación y/o certificados. Existe evidencia que sostiene que las personas aprenden mejor cuando se combina la teoría con la práctica, esta afirmación alcanza a cualquier individuo sin importar su profesión, es decir que puede ser aplicado perfectamente a cualquier gestor y/o director en el ámbito educativo (Chiavenato, 2011).

Los talleres de formación pueden darse a través de diferentes modalidades, entre ellas podemos citar: encuentros, cursos, seminarios y/o jornadas. Los talleres de formación 
siempre estarán enfocados desde una óptica en donde el directivo es el líder del equipo. En donde sus acciones estarán estrechamente vinculadas con el éxito de la organización y en donde él es el actor principal, una especie de director de orquesta que sabe qué es lo que debe y qué es lo que no debe hacer con el talento humano que tiene a su cargo (David, 2013).

\section{Encuentros de redes educativas.}

La educación en nuestros tiempos se encuentra en constante cambio y actualización gracias a la globalización. Desde ese enfoque, podemos afirmar que los objetivos e intereses en la transmisión de conocimientos entre gestores educativos son muchas veces comunes entre uno o más países. Los encuentros de redes educativas permiten establecer criterios unificados de una región a otra con la intención de optimizar la gestión educativa en las escuelas. Dicho intercambio cultural se puede dar, dependiendo el caso, a través de reuniones diarias, interdiarias, semanales, mensuales, anuales, bianuales, etc. (Robbins, 2013).

Los encuentros de redes educativas suponen un compromiso en el que el director o gestor educativo se retira por unas horas, días, semanas y/o meses de sus labores cotidianas para conocer experiencias exitosas de otras organizaciones que puedan ser replicadas en la suya. Es conocido en el mercado educativo metodologías como el Proyecto Optimist, el Método Singapur, el Método Reggio Emilia, el Modelo Educativo Finlandés, entre otros, en donde los estudiantes aprenden más y mejor. Pero, ¿es esto posible sin que el directivo evalúe de forma rápida su viabilidad de acuerdo a los recursos humanos con los que cuenta? ¿Se podrán hacer cambios en la educación sin considerar los recursos con los que se cuenta? Sin duda, los encuentros de redes educativas traen consigo nuevos aprendizajes para el gestor y con ello posibles mejoras considerables para su escuela (Gómez, 2018).

Los encuentros de redes educativas abren la mente del directivo, lo hacen salir de la “caja" y pensar de manera distinta. Hay autores que afirman que éstos encuentros ayudan a reinventar el pensamiento de los líderes de la educación, los ayudan a salir del área de confort para ubicarse en un lugar distinto y diferenciarse de la competencia. El mercado educativo se está volviendo cada día más exigente y si los directores no se preparan para dar la talla, sin duda podrían caer en la obsolescencia y llevar al fracaso a toda la organización educativa (Dessler, 2014). 


\section{Actividades virtuales a distancia.}

La educación a distancia es una forma de enseñanza en la cual los directivos no requieren asistir físicamente a un lugar de estudios. En ese sistema muy usado en las últimas décadas, los gestores reciben el material de estudio (personalmente, por correo postal, correo electrónico u otras posibilidades que ofrece el internet) y se convierte automáticamente en un autodidacta. Esta modalidad resulta ser muy económica y práctica pues abarata los costos de enseñanza tradicional (pago de local, honorarios al docente, impresión de material, etc.) y el tiempo de traslado del participante (Villa y Caperán, 2015).

La educación a distancia es una forma de educación en la que se puede aprender de manera autónoma y bajo el ritmo que se le acomode al gestor. Permite que el aprendizaje sea personalizado favoreciendo la proactividad del participante. Desarrolla no solo la expresión escrita y las habilidades digitales, sino por sobre todo la responsabilidad y la comprensión profunda de diversos materiales (Gómez, 2018).

Este tipo de formación no solo está orientada a aprender nuevos conocimientos, también permite aprender técnicas de gestión que permitan que el directivo sepa cómo motivar a sus subordinados. Le ayuda a liderar con autonomía. Le permite aprender técnicas para saber planificar, organizar, dirigir y controlar los recursos que tiene a su disposición (Hill, 2018).

Tanto los talleres de formación, como los encuentros de redes educativas y las actividades virtuales a distancia representan excelentes alternativas para capacitar y/o entrenar a los gestores educativos, dotándolos de herramientas de gestión que les permitan activar y retener a los puestos claves dentro de sus organizaciones educativas (Roig, 2006). Los gestores educativos al concluir un proceso de formación continua deberían ser capaces

de: comprender al detalle las implicancias de su gestión y sus acciones, planear una secuencia estratégica evaluando su impacto y viabilidad, comprender la realidad de su localidad e identificar las teorías que le permitan efectuar un plan de acción razonable, saber competir con un valor agregado diferenciado, auditar el trabajo de sus puestos claves de manera periódica, cuantificar el efecto de sus decisiones y ser buscar en todo momento cumplir con su misión hasta alcanzar su visión. (D Alessio, 2016). 


\section{Activación de Puestos Claves.}

Un puesto clave es aquella posición considerada de gran importancia para la organización. Los puestos claves regularmente demandan un alto juicio crítico y creativo, solución de problemas y toma de decisiones por parte del candidato por lo que se espera que la persona o el colaborador que lo ocupe cuente con altos niveles de competencia en términos de experiencia, actitud, habilidad y conocimientos (Castro y Ocampo, 2006).

En el ámbito educativo, competencia de la presente investigación, existen cargos o jefaturas (ejemplo: coordinadores de nivel, coordinadores de área, jefes de línea, jefes de departamento, etc.) que deberían ser ocupado por personas especialmente talentosas para garantizar la calidad educativa y el éxito de la organización (Whitemore, 2017).

Cuando un puesto queda vacante (por renuncia o despido) se requiere un candidato que calce en él en el menor tiempo posible. Ello se suele dar en periodos que oscilan entre 3 y 6 meses. Muchas organizaciones utilizan la figura conocida como "periodo de prueba" a fin de asegurarse de que el candidato haga "fit" (sea idóneo) con el puesto y la empresa. La activación de un puesto clave es precisamente ello, lograr que el candidato cubra las expectativas de la organización educativa al haber cumplido satisfactoriamente con el periodo de prueba (Dolan, 2012).

Los motivos por los cuales las personas no logran activar con una organización son principalmente porque son agentes contaminantes, influyen negativamente en sus compañeros, no tiene visión estratégica, no son coherentes, son egoístas para compartir información, no han trabajado adecuadamente sus habilidades blandas, tiene poca predisposición, tiene nulo o escaso liderazgo y ascendencia y/o muestran poco compromiso con el trabajo (Dolan, 2013).

La retención de un puesto clave por su parte supone el conjunto de acciones que un gestor educativo debe considerar para lograr que el personal con talento logre permanecer en la organización por muchos años garantizando así el éxito de la misma (Dolan, 2012).

\section{Reclutamiento.}

El reclutamiento interno hace referencia a la promoción de trabajadores dentro de la organización. En este tipo reclutamiento, el empleado entiende a la perfección el modelo de negocio, el tiempo de adaptación es más rápido, se minimizan los costos de captación y publicación de posiciones y se motiva - de manera tácita - a todos los demás miembros del 
equipo al encontrar que existe una línea profesional a la cual se puede acceder con esfuerzo y constancia (Dolan, 2012).

El reclutamiento externo hace alusión a la captación de nuevos colaboradores y está normalmente está cargo del Departamento de Recursos Humanos. Dicha área buscará de manera sistemática a los candidatos fuera de sus propios empleados para cubrir los puestos. Muchas empresas utilizan anuncios en revistas y periódicos, páginas de ofertas laborales (Bumeran, Computrabajo, Laborum, Aptitus, entre otros.) El valor agregado del reclutamiento externo es la aportación de nuevas ideas por parte del nuevo candidato, la nueva información y metodologías traídas del antiguo su empleador y la estabilidad del equipo al no tener que rotar ninguna posición existente (Dolan, 2013).

Estos dos tipos de reclutamiento que si bien se parecen y tienen el mismo objetivo, que es principalmente cubrir un puesto vacante, son diferentes entre sí. El primero siempre tendrá un bajo costo y un mayor impacto sobre los colaboradores internos pues sentirán que hay oportunidades de crecimiento dentro de la organización educativa; mientras que el segundo, traerá consigo nuevos aprendizajes permitiendo la implementación de mejoras académicas y administrativas a corto, mediano y largo plazo.

La mayoría de organizaciones educativas no identifica formalmente a sus puestos claves, no establece parámetros que definan sus funciones e importancia y no asigna un presupuesto para ellos, generando un perjuicio tácito para las mismas cuando se presenta un despido por falta grave o una renuncia voluntaria al no saber qué persona debería ocupar tal posición. No obstante, existen instituciones educativas que sí aplican políticas para retener a sus mejores talentos, haciéndose casi imposible que puedan ser tentados por la competencia para dejar sus posiciones (Rentón, 2010).

Para Roig (2006), retener a un puesto clave en el sector educación, responde a tres estrategias fundamentales: creación de su propia marca, aplicación de un sistema de incentivos personales y ejecución de programas de capacitación. Estos aspectos son los más valorados por los profesionales de la educación. Será un reto para el gestor educativo poder aplicarlos para garantizar su retención en el tiempo y por ende el éxito de toda la organización.

Se entiende por retención de un puesto clave a los esfuerzos que realiza una organización educativa para poder evitar la pérdida de profesionales talentosos. Pagar bien, reconocer el talento, brindar un grato ambiente de trabajo, tener objetivos colectivos, dar 
confianza, ofrecer y recibir feedback son sólo algunas de las prácticas más comunes por muchas empresas (Robbins, 2013).

\section{Sistema de incentivos personales.}

Para retener a un puesto clave, muchas organizaciones aplican un sistema de incentivos personales también llamados "mimos" entre sus colaboradores talentosos. Un mimo es algo único, es una excepción o exclusividad que responde a los intereses o gustos de una persona que ocupa un puesto clave y que generó la activación deseada; es un mecanismo de retención que no está relacionado con su función o puesto sino a una preferencia o capricho. Este puede surgir como una petición de la persona que activa un puesto clave o de la empresa en su afán de cautivarlo. También es reconocido como "gollería". El objetivo del mimo, es generar un ambiente cálido, cómodo y personalizado, para las personas que son reconocidas como claves, es decir que activan un puesto clave en la organización (Roig, 2006)

El mimo busca minimizar el riesgo de pérdida o fuga de estas personas, pretende retener y motivar. El mimo intenta garantizar la permanencia de la persona en el puesto clave. Algunas empresas sólo muestran esta práctica una vez que la persona activó el puesto clave y no al momento de la contratación. En ocasiones, el mimo puede no ser merecido ante los ojos del grupo, pero al ser una persona valiosa por la activación que genera en el puesto clave, la empresa decide mimarlo para retenerlo y mantenerlo contento (Bisquerra, 2002).

Los incentivos personalizados muchas veces responden a la necesidad del puesto clave y no representan necesariamente un gasto para la entidad educativa. El reconocimiento público es una de las formas que muchos directivos emplean para mantener motivados a sus subordinados. Para ello es fundamental que el directivo conozca a su equipo y sepa cuáles son las fortalezas y debilidades de cada uno. (Tobón, 2008).

Entre los incentivos personalizados más comunes se encuentran; la asignación de un asistente o personal de apoyo, la asignación de alguna responsabilidad que demande poder sobre los demás, el reconocimiento público, la entrega de activos, el cambio de horario de trabajo, entre otros (Roig, 2006).

Si bien los incentivos personalizados ayudan a mantener motivados al personal, resulta crucial que el directivo sepa cuándo, a quién y cómo otorgarlos. El exceso de incentivos puede traer como consecuencia en el tiempo que el nivel de desempeño de los 
puestos claves únicamente responda a esos incentivos y se pierda el objetivo principal que es su alto rendimiento e impacto en la organización. Será importante entonces que el gestor se convierta en una especie de cazatalentos y sepa qué es lo que motiva a cada una de las personas que tiene a su cargo (Toro, 2010).

\section{Capacitación.}

Se extiende por capacitación al proceso educativo corto a través del cual se aprenden nuevos conocimientos. Es la forma clásica de aprendizaje para afinar un determinado aprendizaje. Existen múltiples formas de capacitarse y los costos varían de acuerdo al expositor, lugar, cantidad de horas, certificación, entre otros (Espinoza, 2006).

El objetivo principal de la capacitación es no caer en la obsolescencia y mantenerse siempre actualizado. Como sabemos la educación es sumamente cambiante y es prácticamente una obligación para el gestor o líder educativo mantenerse actualizado en conocimientos y técnicas que le permitan dirigir con autonomía y solvencia la institución educativa que tiene a su cargo (Abarca, 2013).

La capacitación permanente de un gestor educativo contribuye a que éste conozca sus responsabilidades y desarrolle un "sexto sentido" que le permita adelantarse en soluciones a los posibles problemas que se puedan presentar dentro de su organización en términos de rotación, activación y retención de puestos claves (Espinoza, 2006).

Aplicar estrategias de retención de un puesto clave es sin duda uno de los recursos más utilizados por las organizaciones educativas del país. Asignar un presupuesto para ello podría lograr un mejor clima institucional que se verá traducido en colaboradores más motivados y comprometidos que a su vez recaerá sobre el servicio educativo y prestigio de la institución (Chiavenato, 2011). 


\section{Capítulo II: Diagnóstico o Trabajo de Campo}

\section{Características del campo de estudio}

Los datos obtenidos en el trabajo de campo fueron analizados e interpretados a través de algunos métodos empíricos como lo son la entrevista y las encuesta. La información obtenida a través de dichos procedimientos fue debidamente clasificada a través de códigos, memos y familias permitiéndonos obtener categorías emergentes a partir de un minucioso análisis o triangulación que explicaremos al detalle líneas más adelante.

En la presente investigación se aplicaron entrevistas a directivos, entrevistas a puestos claves y se encuestaron a un grupo representativo de estudiantes.

\section{Análisis, interpretación y discusión de resultados}

\section{Análisis de la encuesta a estudiantes.}

Iniciamos el trabajo de campo encuestando a veintitrés estudiantes de quinto de secundaria de una Institución Educativa Particular ubicada en el distrito de San Miguel. Entiéndase por estudiante a aquel sujeto que cursa estudios y/o aprende algo nuevo a través de un medio formativo definido (Poiry, 2018). Dicha encuesta tuvo una duración de 20 minutos aproximadamente, las misma que se ejecutó en un aula debidamente ventilada, libre de bulla y/o distractores. Se contó para ello con la aprobación de los encuestados para tomar una fotografía a modo de evidencia a través de un equipo móvil de alta gama (Iphone X). La información fue recolectada a través de un cuestionario (instrumento) previamente diseñado para tal fin.

En la pregunta número 1 ¿Considera que los directivos que laboran en su institución están debidamente capacitados para ejercer sus funciones?, se identificó que 8 estudiantes (34.8\%) consideran que casi siempre los directivos que laboran en su institución están debidamente capacitados para ejercer sus funciones, 5 estudiantes $(21.7 \%)$ consideran que siempre los directivos que laboran en su institución están debidamente capacitados para ejercer sus funciones, 5 estudiantes $(21.7 \%)$ consideran que a veces los directivos que laboran en su institución están debidamente capacitados para ejercer sus funciones, 3 estudiantes (13\%) consideran que pocas veces los directivos que laboran en su 
institución están debidamente capacitados para ejercer sus funciones y 2 estudiantes (8.7\%) consideran que nunca los directivos que laboran en su institución están debidamente capacitados para ejercer sus funciones.

En la pregunta número 3 ¿Considera que las mejoras aplicadas en la institución por parte de los directivos después de asistir a encuentros de redes educativas han sido favorables para mejorar el aprendizaje de los estudiantes?, se corroboró que 10 estudiantes (43.5\%) consideran que a veces las mejoras aplicadas en la institución por parte de los directivos después de asistir a encuentros de redes educativas han sido favorables para mejorar el aprendizaje de los estudiantes, 6 estudiantes $(26.1 \%)$ consideran que casi siempre las mejoras aplicadas en la institución por parte de los directivos después de asistir a encuentros de redes educativas han sido favorables para mejorar el aprendizaje de los estudiantes, 3 estudiantes $(13 \%)$ consideran que nunca las mejoras aplicadas en la institución por parte de los directivos después de asistir a encuentros de redes educativas han sido favorables para mejorar el aprendizaje de los estudiantes, 3 estudiantes (13\%) consideran que pocas veces las mejoras aplicadas en la institución por parte de los directivos después de asistir a encuentros de redes educativas han sido favorables para mejorar el aprendizaje de los estudiantes y 1 estudiante $(4,3 \%)$ considera que siempre las mejoras aplicadas en la institución por parte de los directivos después de asistir a encuentros de redes educativas han sido favorables para mejorar el aprendizaje de los estudiantes.

En la pregunta número 4 ¿Considera que los directivos de su institución hacen uso de las TICS para potenciar su gestión?, se evidenció que 15 estudiantes (65.2\%) consideran que casi siempre los directivos de su institución hacen uso de las TICS para potenciar su gestión, 3 estudiantes (13\%) consideran que siempre los directivos de su institución hacen uso de las TICS para potenciar su gestión, 2 estudiantes $(8.7 \%)$ consideran que nunca los directivos de su institución hacen uso de las TICS para potenciar su gestión, 2 estudiantes $(8.7 \%)$ consideran que pocas veces los directivos de su institución hacen uso de las TICS para potenciar su gestión y 1 estudiante $(4.3 \%)$ considera que a veces los directivos de su institución hacen uso de las TICS para potenciar su gestión.

En la pregunta número 7 ¿Considera adecuados los procedimientos que emplea la organización para la contratación de personal nuevo?, se demostró que 9 estudiantes $(39.1 \%)$ consideran que a veces son adecuados los procedimientos que emplea la organización para la contratación de personal nuevo, 7 estudiantes (30.4\%) consideran que 
casi siempre son adecuados los procedimientos que emplea la organización para la contratación de personal nuevo, 3 estudiantes (13\%) consideran que nunca son adecuados los procedimientos que emplea la organización para la contratación de personal nuevo, 2 estudiantes $(8.7 \%)$ consideran que pocas veces son adecuados los procedimientos que emplea la organización para la contratación de personal nuevo y 2 estudiantes $(8.7 \%)$ consideran que siempre son adecuados los procedimientos que emplea la organización para la contratación de personal nuevo.

En la pregunta número 10 ¿Considera Ud. que sus docentes están bien capacitados para ejercer sus funciones?, se halló que 13 estudiantes $(56.5 \%)$ consideran que la mayoría de docentes están bien capacitados para ejercer sus funciones, 5 estudiantes $(21.7 \%)$ consideran que todos los docentes están bien capacitados para ejercer sus funciones, 2 estudiantes $(13 \%)$ consideran que ninguno de los docentes están bien capacitados para ejercer sus funciones, 1 estudiante $(4.3 \%)$ considera que muy pocos docentes están bien capacitados para ejercer sus funciones y 1 estudiante $(4.3 \%)$ considera que algunos docentes están bien capacitados para ejercer sus funciones.

En la pregunta número 11 ¿Considera que los docentes presentan mejoras considerables en su gestión después de recibir capacitación?, se evidenció que 12 estudiantes (52.2\%) consideran que siempre los docentes presentan mejoras considerables en su gestión después de recibir capacitación, 6 estudiantes (26.1\%) consideran que casi siempre los docentes presentan mejoras considerables en su gestión después de recibir capacitación, 2 estudiantes $(8.7 \%)$ consideran que pocas veces los docentes presentan mejoras considerables en su gestión después de recibir capacitación, 2 estudiantes $(8.7 \%)$ consideran que a veces los docentes presentan mejoras considerables en su gestión después de recibir capacitación y 1 estudiante $(4.3 \%)$ considera que pocas veces los docentes presentan mejoras considerables en su gestión después de recibir capacitación.

La información obtenida en dicha encuesta nos permite afirmar que los estudiantes identifican con claridad los cambios que se presentan en su escuela cuando los directivos participan de programas de formación continua. Asimismo, logran destacar la labor de los puestos claves y su impacto dentro de la organización y logran describir, aunque de manera muy general, el perfil de los puestos claves dentro de su institución. 


\section{Análisis de la entrevista a directivos.}

Continuamos el trabajo de campo entrevistando a dos directivos de la misma Educativa Particular ubicada en el distrito de San Miguel. Entiéndase por directivo a aquel gestor que tiene a su cargo la dirección parcial o general de una entidad educativa (Roig, 2006). Las entrevistas tuvieron una duración de 31 y 39 minutos respectivamente, las mismas que se dieron en ambientes relativamente confortables (oficinas) libres de bulla y/o distractores. Se contó para ello con la aprobación de los entrevistados para grabar dicha acción a través de un equipo móvil de alta gama (Iphone X). La información fue recolectada a través de una guía de entrevista (instrumento) previamente diseñada para tal fin.

En la pregunta 1 ¿Cuáles considera Ud. que son los principales beneficios para el directivo de una organización al inscribirse en talleres de formación continua? los entrevistados manifestaron que mantenerse activos en temas de formación y actualizarse constantemente mejora la empleabilidad, la productividad y la gestión educativa generando así una repercusión positiva en la calidad educativa de la institución educativa.

En la pregunta 2 ¿Qué características deberían tener los talleres de formación continua para que Ud. se interese en inscribirse en alguno de ellos? los encuestados concluyeron que los talleres de formación continua deberían tener información relacionada con conocimiento global, uso de metodologías ágiles y flexibilidad horaria.

En la pregunta 5 ¿Considera que el uso de las TICS representa un aliado estratégico en su labor como directivo? los directivos aseveraron que las TICS permiten optimizar tiempo, reducir recursos, gestionar más y mejor la información y mejorar la comunicación entre una o más sedes educativas.

En la pregunta 6 ¿Qué tiempo al mes estaría dispuesto a invertir de inscribirse en alguna de ellas? ¿Cómo le gustaría que fuesen esas actividades? los encuestados concluyeron que estarían dispuestos a dedicar de 1 a 2 horas diarias para actividades de formación de 2 a 4 días de la semana. Agregaron además que dichas actividades deberían ser flexibles y en modalidad online.

En la pregunta $7 i \mathrm{Ud}$. toma en cuenta las buenas prácticas de otras organizaciones para considerarlas en el plan operativo de su institución? los entrevistados respondieron que el sector educación está algo atrasado en temas de innovación, afirmando que la implementación de buenas prácticas debería ser una medida impulsada desde el Ministerio de Educación. Manifestaron que a veces copian modelos educativos locales pero que muchas veces no se obtienen los resultados esperados. 
En la pregunta 11 ¿Existe alguna política para retener a los colaboradores más talentosos? los entrevistados manifestaron que algunos colaboradores talentosos cuentan con ciertos beneficios o mimos que se traducen en mejoras salariales, accesos a capacitación, empowerment, entre otros.

La entrevista a directivos tuvo la finalidad de conocer la frecuencia o interés de los mismos por su formación continua y su posible impacto en su gestión educativa. Se planteó para ello una docena de preguntas y repreguntas que intentaron descubrir si los sujetos entrevistados son conscientes y/o identifican la importancia de invertir en su formación para potenciar de esta manera su gestión y con ello a los puestos claves.

Sorprendentemente la información obtenida de los sujetos entrevistados fue bastante similar. Ambos reconocieron que invertir en su formación genera un impacto positivo en su labor pero a la vez manifestaron que, debido a sus múltiples funciones y responsabilidades, la falta de tiempo se convierte en su peor enemigo.

La entrevista recogió información relevante. Los sujetos manifestaron su preferencia por las actividades de formación periódicas como lo son los encuentros de redes educativas y las actividades virtuales a distancia. Pusieron mucho énfasis en que el aprendizaje en puestos directivos debe darse a través del análisis de casos reales, imitación de experiencias exitosas y con el soporte de la mayor cantidad de recursos tecnológicos posibles. Este último punto llamó mucho la atención pues fue sin duda uno de los aspectos que no se habían considerado dentro de las categorías apriorísticas de la presente investigación.

La entrevista a directivos nos permitió conocer el nivel de cercanía de los gestores educativos con los colaboradores que tienen a su cargo y su expertise por identificar, activar y retener a los puestos considerados claves. Los resultados en este sentido arrojaron que los gestores educativos, aunque de manera inconsciente, generalmente confían y/o delegan las funciones consideradas críticas a los colaboradores más empeñosos, líderes y responsables, también llamados por ellos, puestos claves.

Se pudo identificar además que ambos entrevistados coinciden en que es relativamente sencillo reconocer a los puestos claves, en la medida que mantienen un mismo patrón de comportamiento, destacándose por su liderazgo, pensamiento crítico, pensamiento creativo, toma de decisiones y solución de problemas. Este punto también aportó mucho en el objeto de estudio, pues pudimos reconocer que los directivos tienen un perfil ideal de puesto clave, sin haberlo leído y/o obtenido de la literatura existente. 


\section{Análisis de la entrevista a puestos claves.}

Finalizamos el trabajo de campo entrevistando a tres puestos claves de la misma Institución Educativa Particular ubicada en el distrito de San Miguel. Entiéndase por puesto clave a aquella posición dentro de la organización que genera mayor impacto en el éxito de la misma (Roig, 2006). Dichas entrevistas tuvieron una duración de 33, 35 y 41 minutos respectivamente, las mismas que se dieron en ambientes relativamente confortables (aulas) libres de alumnos, bulla y/o distractores. Se contó para ello con la aprobación de los entrevistados para grabar dicha acción a través de un equipo móvil de alta gama (Iphone X). La información fue recolectada a través de una guía de entrevista (instrumento) previamente diseñada para tal fin.

En la pregunta 1 ¿En qué medida los directivos de su institución mejoran su gestión después de asistir a talleres de formación continua? los encuestados afirmaron que los directivos son sumamente reservados en su formación. Pocas veces comentan si están estudiando algún curso, taller o capacitación. No obstante, cambian de actitud después de asistir a talleres de formación, mostrando una mejor disposición que se traduce en la implementación de mejoras funcionales que en algunos casos se dan de forma creativa e innovadora.

En la pregunta 2 ¿En qué medida los directivos de su institución mejoran su gestión después de asistir a encuentros de redes educativas? los entrevistados manifestaron que los encuentros de redes educativas mejoran el estado de ánimo de los directivos logrando en ellos ideas de cambio y flexibilidad para poner en marcha nuevas ideas e implementar proyectos educativos. Los puestos claves afirmaron además que se marca de forma muy notable un antes y un después en los directivos, logrando una renovación importante que impacta positivamente en su gestión educativa.

En la pregunta 4 ¿Cuáles son las diferencias que existen entre un puesto clave y una persona con talento? los entrevistaron coincidieron en que un puesto clave es aquel que tiene mayores responsabilidades mientras que una persona talentosa es aquella que se destaca en su trabajo con cualidades como la responsabilidad, lealtad, compromiso y dedicación.

En la pregunta 8 ¿Existe una política clara de incentivos personalizados en su institución? los entrevistados manifestaron que si bien no existe una banda salarial establecida, los colaboradores que más se esfuerzan cuentan con una mejor remuneración. Afirmaron además, que los puestos claves son el motor de la organización. 
La entrevista a puestos claves tuvo la finalidad de conocer su apreciación en referencia al impacto que generan los programas de formación continua en los directivos a través de la formulación de trece preguntas y repreguntas semiestructuradas. La intención de la entrevista era conocer si los puestos claves valoran este tipo de actividades dirigidas a los gestores y si tienen o no alguna repercusión en su gestión educativa y/o en su rol como colaboradores.

En ese sentido, pudimos identificar que el $100 \%$ de puestos claves consideran que los programas de formación continua aportan en la gestión del directivo e impactan positivamente en su rol directivo. Algunos puestos claves mencionaron palabras como “cambio de actitud", "reinvención", "cambio de 360 grados", haciendo alusión a lo que percibían cuando alguno de sus jefes asistía a programas de formación continua.

Pusieron mucho énfasis en que los directivos más eficaces son los que logran incorporar la tecnología en su formación. Los puestos claves consideran que este es el mejor aliado de la formación pues acorta distancias, reduce el tiempo de aprendizaje, lo vuelve más significativo y permite que la educación sea más dinámica. Asimismo, reconocieron que el rol de los puestos claves es muy valioso y que debería reconocerse su esfuerzo de alguna manera. No pidieron necesariamente una mejor remuneración pero si un mejor trato o mejores condiciones laborales.

También se pudo apreciar que los puestos claves no logran identificar las diferencias entre un puesto clave y una persona con talento, pues consideran que ambos conceptos son iguales y/o responden a una sinonimia. Se evidenció además que todos los puestos claves son de alguna manera líderes por excelencia y conocen y dominan a la perfección las funciones que tienen asignadas. 


\section{Proceso de categorización e interpretación}

Procesamiento de la información.

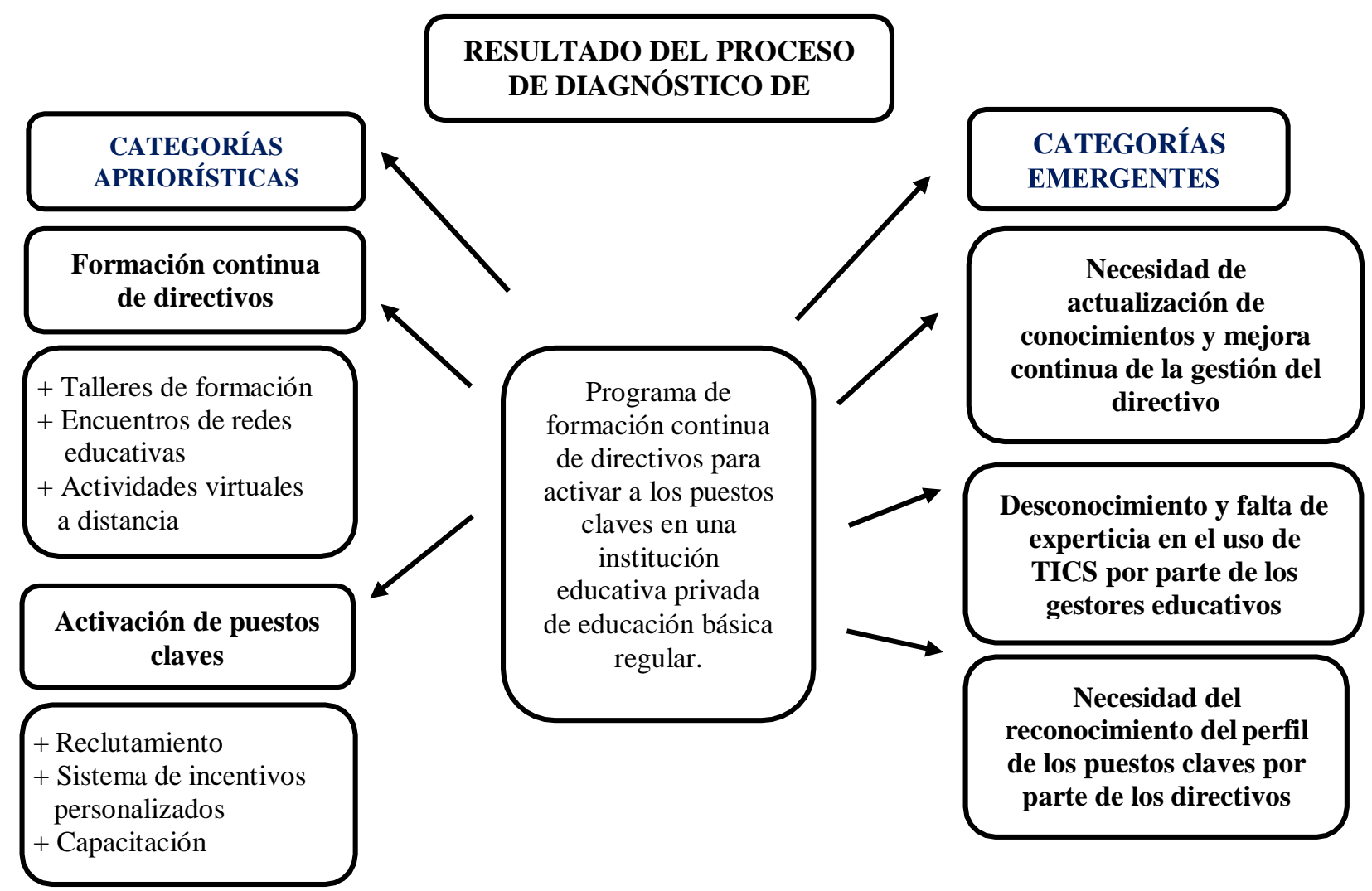

Fuente: Elaboración propia

Figura 1. Resultado del proceso de diagnóstico de campo

En la figura 1, se puede apreciar que las categorías apriorísticas son: formación continua de directivos y activación de puestos claves, que a su vez se subdividen en las subcategorías talleres de formación continua, encuentros de redes educativas, actividades virtuales a distancia, reclutamiento, sistema de incentivos personalizados y capacitación respectivamente. Se puede observar también que las categorías emergentes obtenidas luego de haber realizado el proceso de triangulación a través de la aplicación de métodos empíricos que se cristalizaron a través de las entrevistas a directivos y puestos claves y la encuesta a estudiantes son: actualización de conocimientos y mejora continua de la gestión del directivo, experticia en el uso de TICS por parte de los gestores educativos y reconocimiento del perfil de los puestos claves por parte de los directivos. 


\section{Relaciones analíticas e interpretativas entre datos y categorías emergentes}

\section{Necesidad de actualización de conocimientos y mejora continua de la gestión del directivo.}

En el trabajo de campo se pudo identificar que son muy pocos los directores y/o gestores educativos que se mantienen en constante formación y/o mejora continua. Muchos de ellos no han actualizado sus conocimientos en los últimos años y por ende no han desarrollado competencias profesionales que les permitan cumplir con su rol directivo de manera eficiente e innovadora. Se identificó que, si bien todos reconocen que la formación continua es valiosa, la falta de tiempo y las múltiples responsabilidades hacen que su inversión en ella sea escasa, por no decir nula.

Salit (2011), afirma que la actualización de conocimientos por parte de los directivos de una organización educativa es la única forma de mantener y/o garantizar la calidad educativa. Dicho autor hace una crítica bastante fuerte a los gestores educativos que no se preocupan por su formación poniendo énfasis que un verdadero líder no puede dar lo que no tiene, haciendo referencia a que un director no puede exigir que los docentes que tiene a su cargo se capaciten si primero él no lo ha hecho. Sin duda, un buen gestor debería preocuparse por actualizar sus aprendizajes de forma permanente, pues como lo afirmamos al inicio de esta investigación, las instituciones educativas en el siglo XXI viven cambios estratégicos, culturales, pedagógicos y organizativos de forma constante para poder adaptarse a los requerimientos del mercado.

En línea con esa idea, Zapata (2012) sostiene que la mejora continua implica un cambio de actitud de todos los miembros de la organización con miras a la búsqueda permanente de la calidad educativa. Se entiende por calidad educativa al conjunto de factores que permiten que los estudiantes aprendan más y mejor, alineando sus capacidades, habilidades y competencias con las exigencias del mercado global. Es por esta razón que los directivos deberían contar con un plan de vida personal alineado a procesos de actualización profesional y formación continua.

\section{Desconocimiento y falta de experticia en el uso de TICS por parte de los gestores educativos.}

En la presente investigación se pudo identificar que los directivos y/o gestores educativos han sido formados y/o educados en tiempos en los que no existían mayores recursos 
tecnológicos. Ello ha originado que se marquen brechas importantes que sin duda se ven reflejadas en el día a día, dado que muchos docentes jóvenes han encontrado en la tecnología su mejor aliado para poder transmitir conocimientos y desarrollar competencias y capacidades en los estudiantes, metodologías que se ven ralentizadas al no contar con la aprobación y/o visto bueno de los directivos que muchas veces se muestran renuentes al cambio. Este desconocimiento y falta de experticia en el uso de TICS por parte de los gestores educativos no solo retrasa el trabajo sino que lo condena a una educación tradicional que en la actualidad se considera obsoleta dado el dinamismo de la educación del siglo XXI. Pimienta (2012), sostiene que en la actualidad el mejor aliado de la globalización es la tecnología. Dicho autor demostró que las instituciones más exitosas en el mundo de educación básica regular son las que han incluido en su propuesta académica el uso de las TICS como estrategia. Ello sin duda genera una controversia y cierta negación por parte de los gestores educativos, pues al ser de una generación en donde no se aprendía con tecnología, muchas veces se duda de su eficacia y efectividad. Ello sumado a los altos costos de la implementación de las TICS hace que muchas escuelas tradicionales no se mantengan a la vanguardia, perjudicando a los estudiantes cuando egresan de las aulas y se ven inmersos en un mercado que exige el dominio de ciertas competencias digitales.

Por su lado, Rico (2003) afirma que los líderes del futuro son los que han logrado entender que hoy en día no se puede vivir sin tecnología. Dicho autor asevera categóricamente que los gestores de la educación están obligados a formarse en tecnología y dominar ciertas competencias para poder ser solventes en la conducción de la organización educativa que tienen a su cargo. Un gestor debería estar abierto al cambio y salir del área de confort si realmente quiere garantizar la calidad educativa. El uso de las TICS es sin duda una necesidad del mercado y una tendencia que seguirá incrementándose con creces en las próximas generaciones.

\section{Necesidad de reconocimiento del perfil de los puestos claves por parte de los directivos.}

La investigación también identificó serios problemas en relación al reconocimiento y/o identificación del perfil de los puestos claves por parte de los directivos. Se observó que los puestos claves muchas veces no son identificados correctamente lo que se ve reflejado en la omisión o duplicidad de funciones, contratación de mayor número de profesionales, 
ejecución de procesos burocráticos, entre otros. Y es que el reconocimiento adecuado de un puesto clave no solo contribuye a la creación de una estructura jerárquica sólida sino que también permite desarrollar un adecuado sistema de gestión que sin duda se verá reflejado en la calidad educativa que toda institución pretende brindar.

Roig (2006), analizó de cerca el rol de los puestos claves concluyendo que las organizaciones deberían delimitar un perfil ideal de los mismos. Ello con la intención de alinear los intereses personales de los puestos claves con los de la organización. Como lo afirmamos anteriormente, los puestos claves son aquellos que cumplen funciones neurálgicas para la operación, por ende debería existir un interés particular del directivo en delimitar su perfil e impulsar su activación y retención en el tiempo.

Por su parte, Mclelland (1999), sostiene que para que el directivo pueda delimitar adecuadamente el perfil de un puesto en la escuela que dirige, resulta fundamental identificar cuáles son las competencias requeridas para tal posición. Los puestos claves requieren dominar ciertas habilidades que deben ser verificadas para poder garantizar el cumplimiento adecuado de sus funciones. Es responsabilidad del directivo delimitar el perfil que debe tener cada posición, fomentar el cumplimiento de dicho perfil en los procesos de reclutamiento interno y/o externo y efectuar políticas de activación y retención. Entiéndase por retención al conjunto de acciones que realiza el gestor para mantener al colaborador motivado y comprometido con su trabajo (Keller, 2008).

\section{Conclusiones aproximativas}

Los gestores educativos deberían programar de forma anual y/o bianual, a través de un diagrama de Gantt u otra herramienta de gestión, las actividades de formación y/o actualización profesional a las que podría asistir. Ello les permitiría aplicar una política de mejora continua que imite experiencias exitosas en otras entidades educativas.

La mejora continua debería ser un tema prioritario por las escuelas para poder garantizar la calidad educativa que se verá reflejada en el aprendizaje significativo de los estudiantes. Trazar metas y ejecutar acciones concretas a corto, mediano y largo plazo podría ser uno de los mejores caminos para poder lograrlo.

El uso de las TICS debería ser una política definida e impulsada en toda la comunidad educativa. El gestor educativo o directivo debería establecer un presupuesto para la elaboración y ejecución de un proyecto que vaya alineado a la realidad de su 
institución, considerando que vivimos en un siglo en donde los estudiantes son nativos digitales y vivimos en un mundo cada vez más globalizado y cambiante.

La identificación o delimitación de un perfil del puesto clave le permitiría a los directivos apoyarse en ellos para cumplir con el plan estratégico de la institución. Saber activar y retener a los puestos claves resulta sin duda una de las acciones que todo buen directivo debería saber aplicar. 


\section{Capítulo III: Modelación, validación y aplicación de la propuesta}

El proceso de investigación obtuvo como resultado la identificación de tres categorías emergentes que al ser analizadas de manera integral, desde un punto de vista holístico, permitieron diseñar y modelar un programa de formación continua de directivos que les ayude a saber qué y cómo hacer para activar y retener a los puestos claves dentro de su organización educativa.

\section{Propósito de la investigación}

El propósito del programa de formación continua centra su atención en desarrollar competencias profesionales y otorgar herramientas de gestión a los directivos o gestores educativos a fin de saber cómo activar y retener a los puestos claves en sus organizaciones educativas. Es importante resaltar que una adecuada política de activación y retención de puestos claves debería incidir directamente en el crecimiento de la institución educativa así como en su sistema de gestión de calidad (Dominguez, 2015).

\section{Fundamentación pedagógica.}

La pedagogía es una metodología que se basa en la transmisión de conocimientos de una persona a otra. Con esta afirmación, resulta fundamental que el programa de formación continua, objetivo de la presente investigación, cuente con un soporte pedagógico en donde el directivo pueda aprender nuevos conocimientos y desarrollar competencias que luego se verán reflejadas en su gestión educativa.

Dominguez (2015) en sus múltiples investigaciones y publicaciones sostiene que nadie puede enseñar lo que no ha aprendido. Él afirma que todos los seres humanos nacen sin conocimientos y que poco a poco, a través de su experiencia de vida y educación, van desarrollando nuevos conocimientos. Dicho autor afirma categóricamente que todas las personas aprenden de manera distinta, haciendo hincapié en que algunos aprenden de manera visual, otros de modo auditivo y la mayoría de forma kinestésica. (Ver figura 2). 


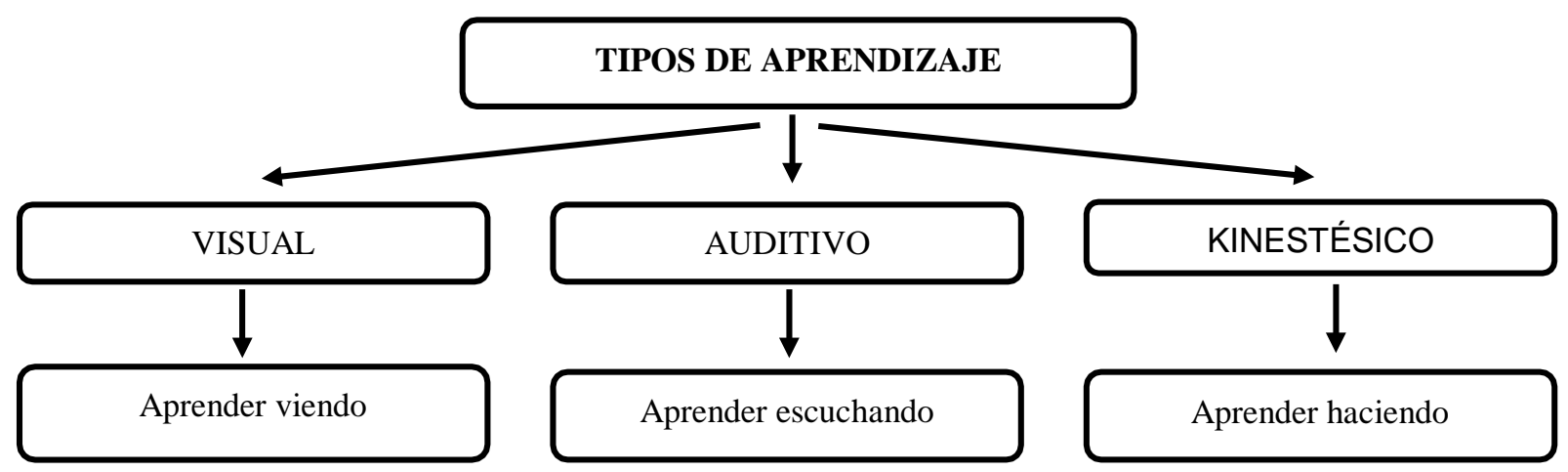

Fuente: Elaboración propia

Figura 2. Tipos de aprendizaje

Ello nos lleva a concluir que el programa de formación continua que plantearemos debería tener los tres tipos de aprendizaje señalados dado que nuestro público objetivo, directivos y/o gestores educativos, podrían tener distintas formas de aprender nuevos conocimientos.

Delors (1996) por su parte, identifica algunos métodos pedagógicos a través de los cuáles los adultos aprenden más y mejor de acuerdo a su forma de razonamiento. Este autor concluyó que los directivos por lo general son personas que creen saberlo todo, pues en su gran mayoría no solo han concluido sus estudios superiores, sino que, por lo general, cuentan con estudios específicos, especializaciones y/o maestrías, que los hacen un tanto renuentes y/o soberbios cuando se trata de aprender algo nuevo. Este autor afirma que existen tres métodos eficaces, dirigidos a público adulto, que se podrían plantear en el programa de formación continua. El método deductivo, cuando el nuevo aprendizaje se da a través de definiciones, afirmaciones o conceptos (de lo general a lo particular); el método inductivo, cuando se aprende analizando casos reales o experiencias significativas y el método comparativo o analógico, cuando se aprende comparando de manera vertical dos posibles soluciones. (Ver figura 3) 


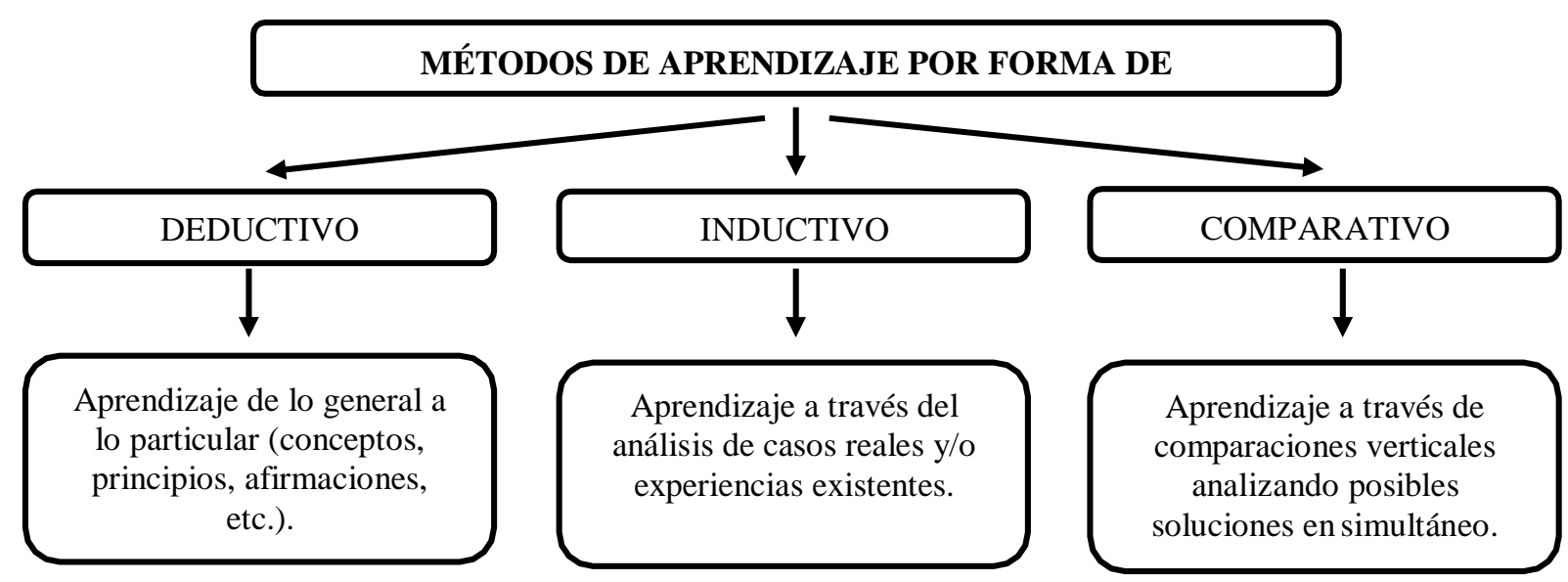

Fuente: Elaboración propia

Figura 3. Métodos de aprendizaje por forma de razonamiento

Estas afirmaciones nos permiten entender que el programa de formación continua, resultado de la presente investigación, debería considerar al menos dos de los métodos antes descritos pues facilitarían que los directivos aprendan de manera significativa nuevos conceptos que les permitan activar y retener a los puestos claves en sus instituciones educativas.

Filloux (2009) también demostró, desde el campo de la pedagogía, que las personas adultas aprenden a través de métodos basados en la organización. Este autor afirma que existen dos métodos que permiten que las personas cumplan con su objetivo sin importar lo ambicioso que este sea. El método basado en la lógica, cuando se ordenan los hechos de forma ascendente siguiendo una secuencia en el tiempo, y el método basado en la psicología del sujeto, cuando el orden de los eventos responde a los intereses de la persona. Filoux afirma que nadie aprende lo que no le interesa, haciendo una crítica bastante rigurosa a los aprendizajes que no se conectan con el sujeto participante. (Ver figura 4) 


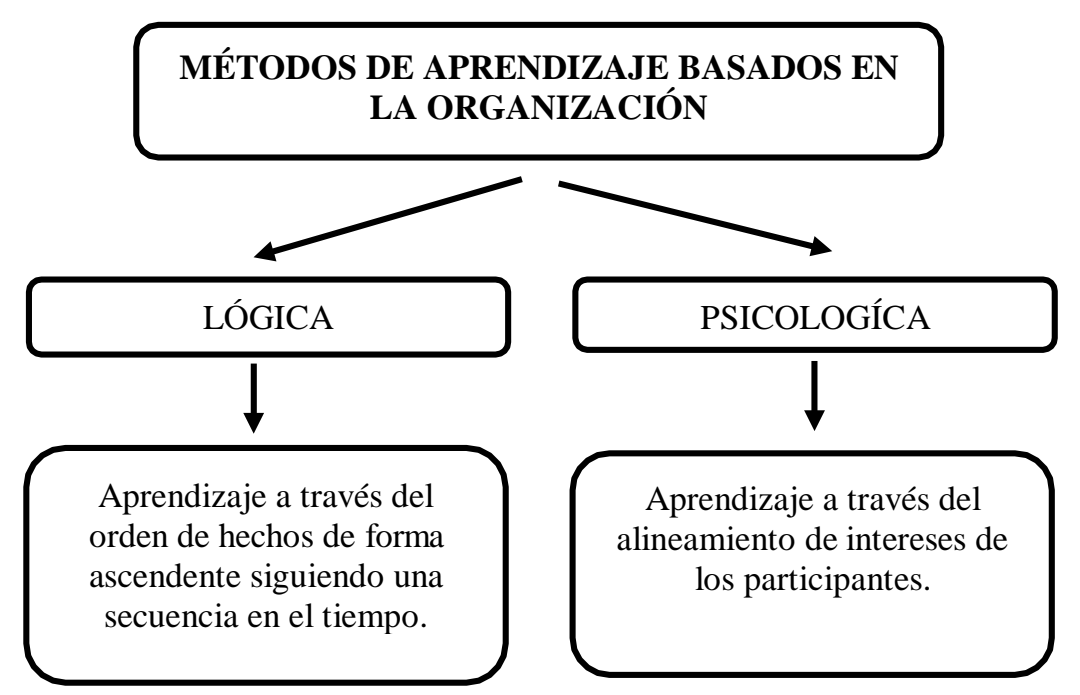

Fuente: Elaboración propia

Figura 4. Métodos de aprendizaje basados en la organización

Estas aseveraciones, basadas en argumentos pedagógicos sólidos, nos permiten elaborar, implementar y ejecutar un programa de formación continua de directivos de forma coherente y seria, que responda a la necesidad existente en las instituciones educativas privadas de educación básica regular de Lima Metropolitana en temas relacionados a la activación de puestos claves.

\section{Fundamentación psicológica.}

El programa de formación continua está dirigido a los gestores educativos de una institución privada ubicada en el distrito de San Miguel. Los participantes son docentes de profesión y cuentan con más de 10 años de experiencia liderando equipos multidisciplinarios en entidades públicas y privadas de educación básica regular. Son personas bien preparadas, con valores éticos sólidos y con metas ambiciosas en el ámbito profesional e institucional.

Díaz (2004) afirma que todos los seres humanos, conscientes o no, tienen un norte en la vida. Una meta a la cual quieren llegar. Un objetivo de vida real. Una luz al final del camino. Desde esa premisa, dicho autor sostiene, desde el punto de vista psicológico, que las personas son capaces de aprender cuando encuentran un sentido en lo que hacen. Responder a la pregunta del para qué debo hacer y/o aprender tal o cual cosa es la única y mejor manera de lograr que una persona se comprometa con su aprendizaje y haga su 
mejor esfuerzo. Cuando un niño sabe que si se esfuerza va a obtener una recompensa a cambio, lo hace bien. De igual modo, cuando a un adulto se le explica cuáles serán los beneficios de aprender algo nuevo, sin duda hará todo lo que esté a su alcance para poder lograrlo. Es por esta razón, que el programa de formación continua debería tener un objetivo claro que les permita a los participantes imaginar un escenario ideal aplicando estrategias de gestión educativa.

Aguilar y González (2016) por su parte, sostienen que el aprendizaje de los individuos se da a través de la activación de tres mecanismos o estrategias psicológicas. El primero basado en la adquisición de información, en la que se aprende por primera vez algo nuevo, el segundo basado en la retención de la información, en la que se recuerda la información ya aprendida en el mediano plazo, y la tercera en la recuperación de la información en la que busca combinar conocimientos aprendidos durante toda la vida del individuo. (Ver figura 5)

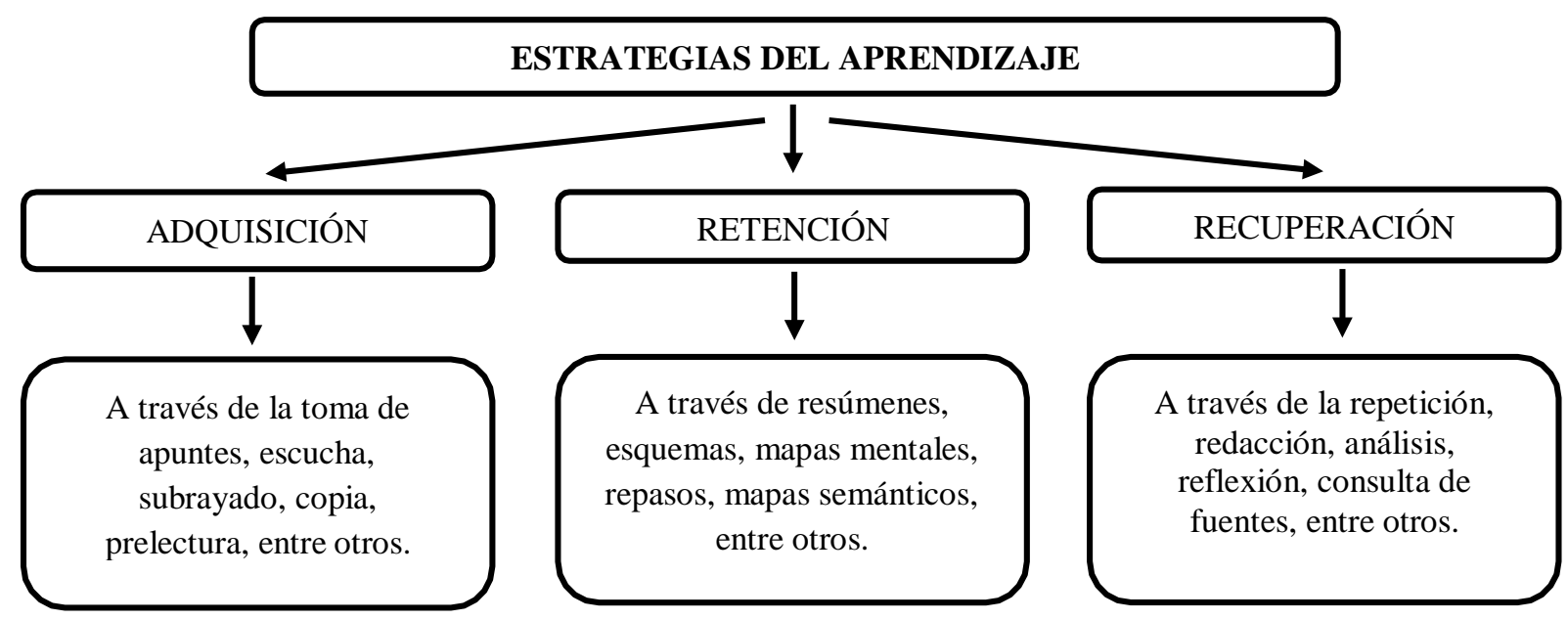

Fuente: Elaboración propia

Figura 5. Estrategias de aprendizaje

Estas estrategias nos permiten tener claro que la información a impartir en el programa de formación continua a directivos debería ser validada a través de una encuesta previa a los participantes para saber qué tanto podrían conocer y/o dominar los temas a tratar. Ello permitiría adaptar el programa de formación a la realidad del directivo y/o gestor educativo y por qué no decirlo también al contexto de la institución educativa. 
Por su lado, Mitchell (2013) afirma que la motivación es un agente indispensable para el aprendizaje del individuo. Dicho autor sostiene y enfatiza que no se puede aprender algo nuevo si no se ha considerado aspectos de la psicología del individuo como lo son: su edad, su formación, su nivel sociocultural, su situación económica, su credo, su profesión, su estado emocional, entre otros. Y es que no es lo mismo motivar a un joven que a un adulto, ni es lo mismo motivar a una persona con solvencia económica que a una persona cuyo pensamiento está en si su familia pudo alimentarse o no ese día. Considerar a qué publico estaría dirigido el programa de formación continua y que lo motiva a activar y retener a sus puestos claves, son sin duda elementos que se deben considerar en su elaboración para garantizar de alguna manera su ejecución con éxito.

\section{Fundamentación socio - educativa.}

Los directivos y/o gestores educativos participantes de la presente investigación son personas cuyas edades oscilan entre los 45 y 60 años. Son directivos que perciben remuneraciones que superan los trece mil soles mensuales. Son casados con 2 y 3 hijos respectivamente y viven zonas residenciales de Lima en casas propias. Cuentan con grado de maestro y más de 10 años de experiencia en gestión educativa. Gozan de buena salud y se muestran firmes en sus convicciones. Mostraron en todo momento facilidad de palabra y liderazgo. Asimismo, se pudo evidenciar que son personas bastante ocupadas por lo que se les encontró resolviendo diversos problemas a la vez, todos relacionados a su rol como gestores educativos.

Por su parte, la institución educativa se encuentra en una de las mejores zonas del distrito de San Miguel, cuenta con más de 40 mil metros cuadrados, 80 docentes, 1300 alumnos y un sinnúmero de convenios con diversas entidades y universidades. Brinda servicios diferenciados y cuenta con una infraestructura muy bien cuidada y moderna. Las pensiones se encuentran bordeando los mil soles mensuales y se cuenta con la autorización para impartir el Programa del Diploma del Bachillerato Internacional.

Chiang (2010) por su parte afirma que en temas de formación, el público objetivo debe ser validado. No validar a las personas a las cuáles está dirigido el programa de formación podría generar que el objetivo no se cumpla al presentarse dificultades como: la falta de interés de los participantes, la duplicidad de temas, el nivel de dificultad del contenido a dictarse, el enfoque, el idioma, la duración, los ejemplos, entre otros. Y es que lo que funciona en un determinado contexto educativo no necesariamente va a funcionar en 
otra escuela, pues cada institución tiene su propia realidad. Estas afirmaciones nos permiten entender que el programa de formación continua debe adaptarse a cada escuela y no cada escuela debe adaptarse al programa de formación continua.

Cruz y Velásquez (2016) por su lado, afirman que la realidad del sector privado es muy distinta al sector público. En el sector privado generalmente, las personas pueden cubrir sus necesidades básicas sin problemas lo que les permite concentrarse en su formación y educación, mientras que en el sector público, la satisfacción de necesidades primarias se convierte en un tema prioritario que no puede ser desatendido por motivos de formación, capacitación y/o entrenamiento. Con ello podemos concluir que no será lo mismo, dependiendo cada caso por supuesto, intentar formar a un directivo del sector público de la misma manera en la que se podría formar a un directivo del sector privado. Estas aseveraciones pueden sonar discriminatorias, de ahí la importancia de delimitar con objetividad quiénes serán los participantes de un eventual programa de formación continua para activar y retener a los puestos claves.

Cuenca (2000) por su lado sugiere que para ejecutar un programa de formación se debe agrupar a los participantes de manera homogénea e inteligente. Dicho autor pone una especial atención en que no todas las personas pueden ser formadas de la misma manera. Para ello, él recomienda empadronar a las personas delimitando al menos su nivel sociocultural y grado de instrucción. Esta delimitación permitiría un mejor enfoque de los temas a trabajar, y un mejor nivel de satisfacción de los participantes que se verá reflejado en mejores resultados en términos de gestión educativa.

Arellano (2000) identificó seis estilos de vida en el Perú del cómo los ciudadanos piensan y se comportan. Esta clasificación sin duda puede aplicarse a los directivos de las diferentes instituciones educativas en Lima Metropolitana para poder agruparlos en dos o más programas de formación continua que puedan ser ejecutados en simultáneo.

En primer lugar se encuentran los afortunados, aquellos que tienen instrucción superior completa y sus ingresos son altos. En segundo lugar se encuentran los progresistas, aquellos cuya instrucción es similar al promedio de personas y sus ingresos son constantes. En tercer lugar se encuentran las modernas, aquellas que buscan superarse constantemente y buscan ser aceptadas por la sociedad y cuyos ingresos son relativos. En cuarto lugar se encuentran los adaptados, aquellos que se acomodan a su realidad, buscan superarse y cuyos ingresos pueden ser variados. En quinto lugar se encuentran las conservadoras, aquellas cuyos hijos y hogar son su prioridad y sus ingresos son bajos. 
Finalmente se encuentran los modestos, cuyo nivel socioeducativo y cultural es inferior al promedio. (Ver figura 6)

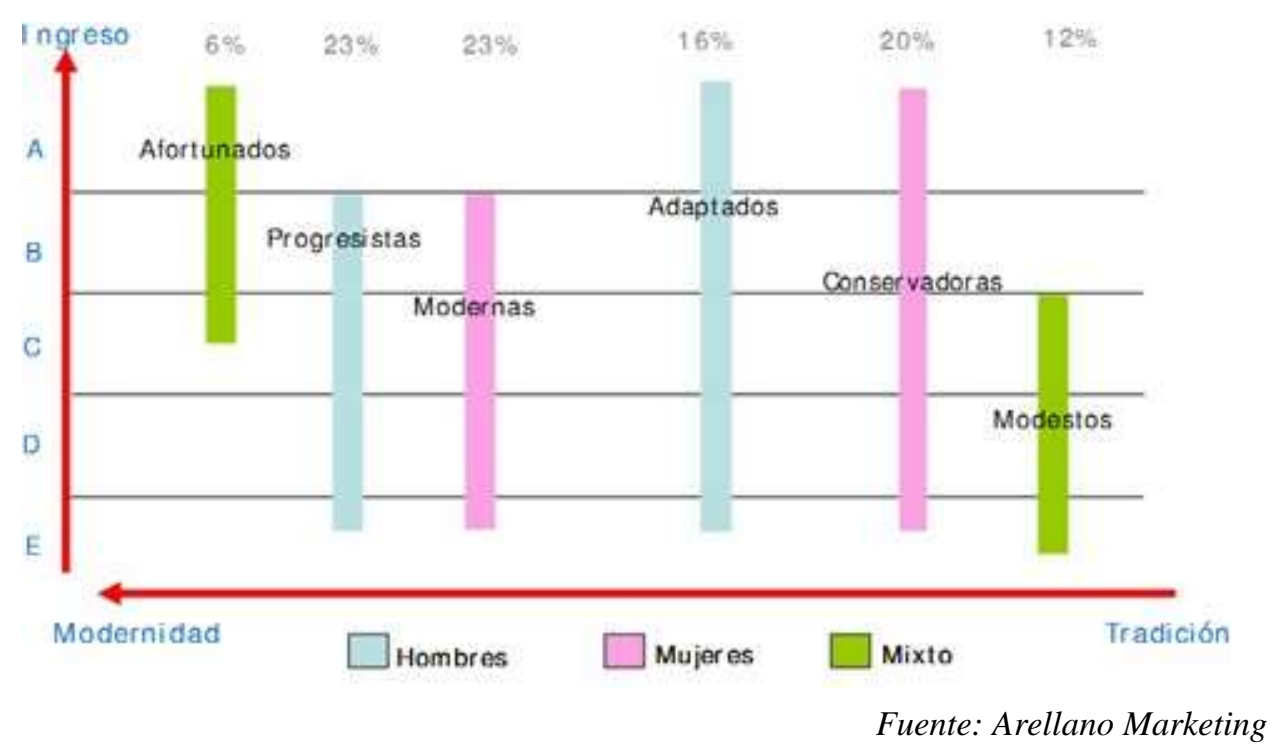

Figura 6. Estilos de vida en el Perú

Según los estilos de vida de Arellano, los directivos a los cuáles está dirigido el programa de formación continua son personas afortunadas, progresistas y modernas, es decir que cuentan con formación profesional completa y tienen una situación económica estable

\section{Fundamentación administrativa.}

Para poder garantizar el éxito del programa de formación continua de directivos resulta indispensable seguir algunos principios administrativos que ayuden a mantener un orden en el proceso y medir de cierta forma su impacto en la institución.

Herrera (2015) recurre a los cuatro principios de la administración para garantizar que el aprendizaje de los gestores educativos sea significativo. La planificación, que consiste en diseñar un programa ajustado a la realidad de los participantes en términos de duración, horarios, número de participantes, experiencia de expositores, entre otros; la organización, que consiste en implementar una secuencia lógica de temas con objetivos concretos; la dirección, que marcará el rumbo del programa de formación continua y su impacto en cuanto a los resultados esperados y finalmente el control, que consistirá en 
medir de alguna manera si la propuesta de la presente investigación, es decir el programa de formación continua ha mejorado la gestión educativa del directivo.

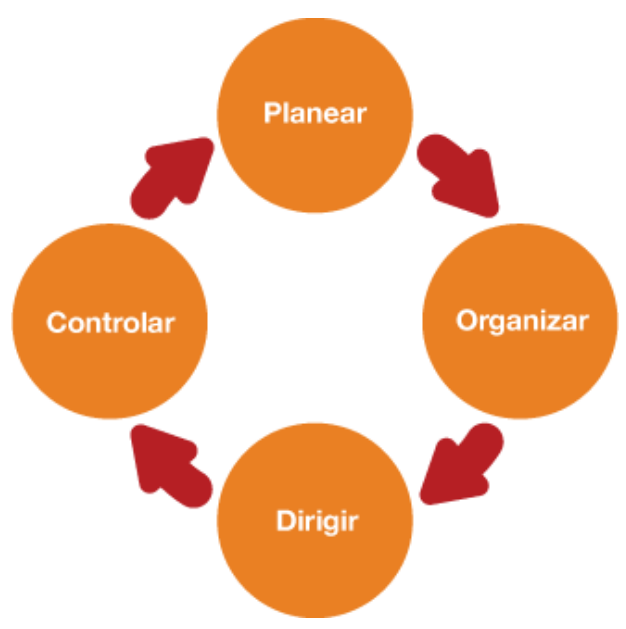

Fuente: Elaboración Propia

Figura 7. Fundamentos administrativos

Petry (2006) por su lado, sostiene que los programas de formación continua deberían estar enmarcados considerando los tipos de administración a los cuáles los directivos están inmersos. Dicho autor afirma que existen tres tipos de administración educativa. La administración pública, haciendo referencia a los colegios nacionales cuyo ente gestor es el Estado; la administración privada, cuando los fines son lucrativos y el capital es propio por parte de personas particulares o naturales; y la administración mixta, cuando el colegio recibe algún tipo de subvención como por ejemplo los colegios pastorales. Petry considera que los gestores educativos pueden ser agrupados de acuerdo al tipo de administración al cual se encuentran inmersos, pues ello les permitiría compartir una misma realidad y por ende una misma solución en cuanto a la activación y retención de puestos claves.

Tobón (2013) por su parte enfatiza en que los programas de formación de directivos deben poner un especial énfasis en el aprovechamiento informático. Este autor asevera que los directivos del siglo XXI debe ser capaces de integrar en sus aprendizajes el uso de las TICS dada su falta de tiempo a consecuencia de sus recargadas agendas. Tobón sostiene que los programas de formación continua deben incluir una cuota tecnológica importante para facilitar a los gestores educativos a acortar distancias y maximizar resultados. 


\section{Fundamentación normativa.}

El MINEDU (2014) con $N^{\circ}$ Resolución de Secretaría General ํㅜ 304-2014 creó hace algunos años un documento normativo titulado "Marco del Buen Desempeño Directivo"; en él se establece que los directivos son agentes que deben preocuparse permanentemente por su formación, su capacitación y su adaptación a la realidad educativa del centro que tienen a su cargo. El MINEDU pone un especial interés en que los gestores educativos se nutran constantemente de competencias y herramientas de gestión que les ayuden a alcanzar altos estándares de calidad educativa. Esta iniciativa, impulsada por el ente máximo de nuestro país, es sin duda el mejor cimiento para la creación de un programa de formación continua de directivos que permita activar y retener a los puestos claves de su institución educativa.

Hofer (2017), publicó múltiples artículos en los cuáles respalda la iniciativa del MINEDU. Este autor sostiene que el rol del directivo se basa principalmente en conducir al equipo docente con solvencia y autoridad implementando estrategias de mejora continua. Y es que la mejora continua es el único camino para alcanzar altos estándares de gestión educativa que se verán reflejados sin duda en la calidad educativa a la que nuestra sociedad aspira. Será tácito entonces entender que el directivo debe invertir tiempo y dinero en su formación continua de manera sostenida, mientras se encuentre al frente de una organización educativa.

Marquez (2019), por su lado hizo un estudio en diversos países de Latinoamérica como Argentina, Perú, Colombia, Brasil, Bolivia, Uruguay y Cuba, concluyendo que si bien no hay una ley que exija a los directivos de las escuelas capacitarse de forma anual, se ha demostrado en países como Australia y Corea del Sur, que los directivos que han logrado un cambio importante en sus escuelas, son los que se actualizan, usan tecnología y copian modelos exitosos de otras partes del mundo. Marquez pone como ejemplo el exitoso modelo educativo que se imparte en Finlandia. En donde los educandos, profesores y directivos son libres de elegir cuándo y cómo desean aprender. Aquí abunda la tecnología y no existen modelos estructurados en donde a cada quien se le dice lo que tiene o debe de hacer. Esta es sin duda una de las mejores formas de aprendizaje que se puede replicar en el planteamiento de un programa de formación continua para directivos. Un modelo de aprendizaje que se ajuste a las necesidades de cada participante y se vea enmarcado junto a ese silencioso aliado estratégico llamado tecnología. 
A continuación se muestra el resumen de los fundamentos teóricos que se han considerado en la elaboración del programa de formación continua de directivos para activar a los puestos claves en una institución educativa de educación básica regular.

Tabla 4

Fundamentos teóricos para la creación del PFC

\begin{tabular}{ccc}
\hline TIPO & AUTOR & DESCRIPCIÓN \\
\hline Fundamentación Pedagógica & Dominguez (2015) & Tipos de aprendizaje \\
& Delors (1996) & Métodos de aprendizaje \\
Filoux (2009) & Métodos de organización \\
Fundamentación Psicológica & Díaz (2004) & Planteamiento de un objetivo concreto \\
& Mitchel (2013) & Estrategias de aprendizaje \\
Fundamentación Socio & Chiang (2010) & Motivación del individuo \\
Educativa & Cruz y Velásquez (2016) & Validación del directivo \\
& Cuenca (2000) & Realidad del directivo \\
Fundamentación & Arellano (2000) & Agrupación homogénea de participantes \\
Administrativa & Herrera (2015) & Estilos de vida de los directivos \\
& Petry (2006) & Principios de la administración \\
& Tobón (2013) & Tipos de administración \\
& MINEDU (2014) & Aprovechamiento informático
\end{tabular}

Fuente: Elaboración Propia 


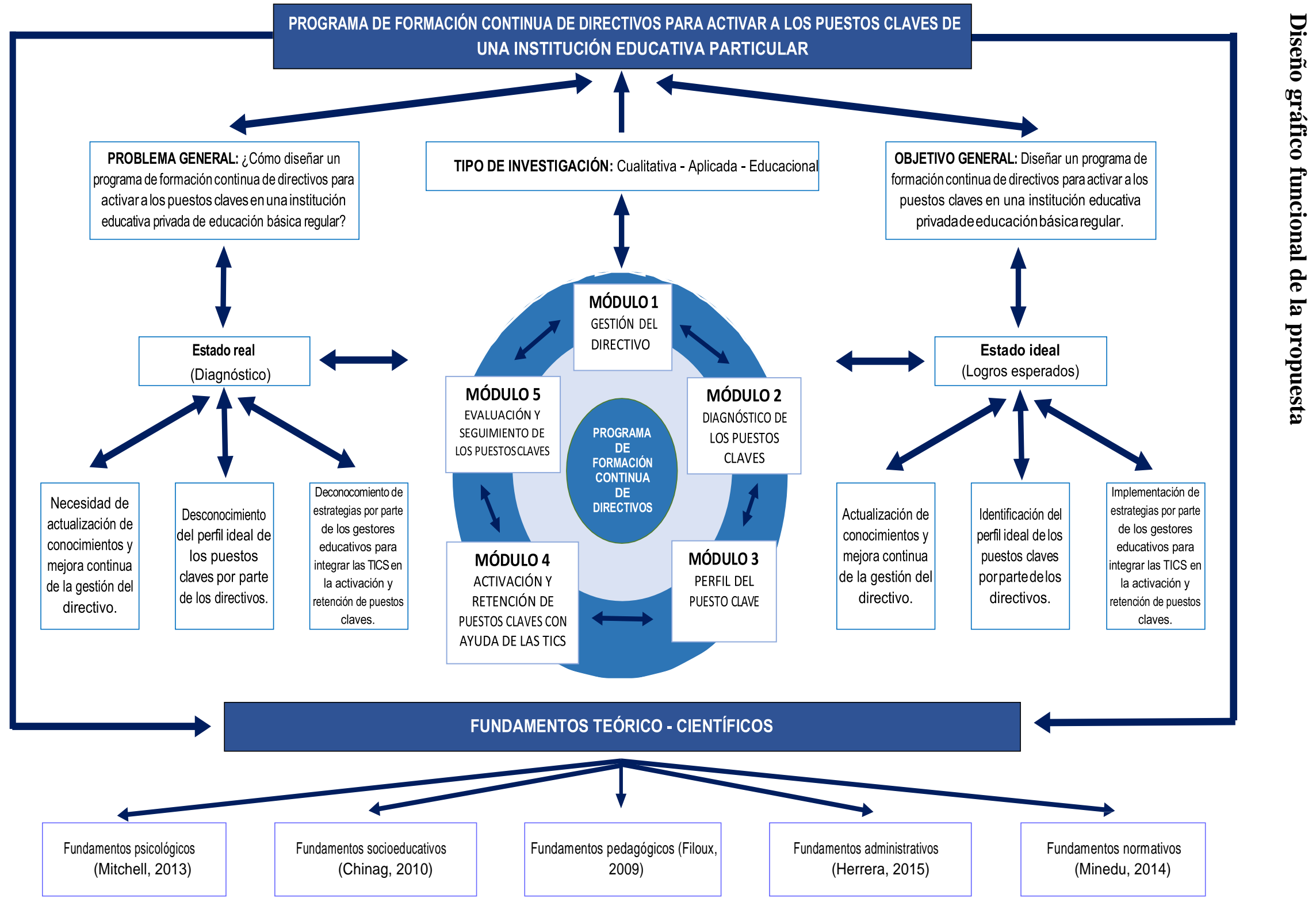

Fuente: Elaboración propia 


\section{Programa de Formación Continua de Directivos.}

Tras el proceso de modelamiento y cruce de información entre la literatura existente y el trabajo de campo, el autor de la presente tesis propone el siguiente Programa de Formación Continua de Directivos para Activar a los Puestos Claves en una institución educativa de educación básica regular.

\section{Objetivo General.}

Fortalecer las competencias y capacidades de los gestores educativos para desarrollar estrategias que le permitan activar y retener a los puestos claves dentro de sus organizaciones educativas.

\section{Objetivos específicos.}

Diseñar el módulo gestión del directivo para lograr la competencia de autoevaluación de los directivos.

Diseñar el módulo diagnóstico de los puestos claves para lograr la competencia de interpretación de la realidad de los directivos.

Diseñar el módulo perfil del puesto clave para lograr la competencia de creatividad de los directivos.

Diseñar el módulo activación y retención de puestos claves con ayuda de las TICS para lograr la competencia de comunicación digital y optimización de recursos de los directivos.

Diseñar el módulo evaluación y seguimiento de los puestos claves para lograr la competencia de supervisión y monitoreo de personal por parte del directivo.

\section{Módulos.}

El programa de formación continua contará con 5 módulos cuyo objetivo es desarrollar competencias profesionales en los gestores educativos y/o directores.

El módulo I: Gestión del directivo, pretende que los directivos comprendan cuál es su rol pedagógico y administrativo dentro de la institución educativa que dirigen. Este módulo está diseñado para que cada gestor pueda autoevaluarse y pueda identificar aspectos de mejora en su gestión.

El módulo II: Diagnóstico de los puestos claves, permitirá que los directivos interpreten la realidad de su institución y el impacto que los puestos claves ejercen sobre la 
misma, ello con miras a tener un diagnóstico que les permitan establecer metas a corto, mediano y largo plazo.

El módulo III: Perfil del puesto clave, está diseñado para que cada gestor pueda de manera creativa establecer un perfil ideal de los puestos claves. Ello ayudará a identificar a los profesionales más talentosos y ubicarlos en posiciones estratégicas dentro de la institución.

El módulo IV: Activación y retención de puestos claves, está orientado a desarrollar estrategias que permitan mantener a los puestos claves motivados. Para ellos se buscará que los gestores educativos desarrollen ciertas competencias digitales de retención.

El módulo V: Evaluación y seguimiento de puestos claves, está diseñado para que los gestores educativos sepan monitorear a los puestos claves. Este módulo permitirá que los directivos desarrollen competencias de seguimiento, control y evaluación.

\section{Enfoques.}

El programa de formación continua de directivos, producto de la presente investigación, plantea cuatro enfoques educativos que permitirán alcanzar el objetivo antes descrito: el enfoque humanista, el enfoque por competencias, el enfoque inclusivo y el enfoque intercultural.

El enfoque humanista permitirá que los directivos no sean vistos como entes únicamente cognitivos en donde no se tome en cuenta sus afectos, necesidades, preocupaciones, emociones, entre otros; sino que por el contrario, le dará una mirada holística que permita integrar las competencias de cada gestor educativo de manera individual.

El enfoque por competencias contribuirá notablemente para que los gestores educativos resuelvan problemas reales y logren sus propósitos, aquí resulta conveniente citar el Marco del Buen Desempeño Docente, el cual asevera que los líderes educativos deben desarrollar dos competencias fundamentales: la facultad para poner en práctica nuevos saberes y la habilidad para leer la realidad y las posibilidades que tiene a la mano para poder intervenir en ella.

El enfoque inclusivo aportará en la reducción de barreras de aprendizaje y participación, con la clara intención de satisfacer las necesidades de cualquier gestor educativo, sin importar el sector en el que se encuentre, la ciudad, las condiciones y/o las personas que tenga a su cargo. 
El enfoque intercultural permitirá dialogar con otras culturas de distintas partes del mundo. Ello aportará notablemente en el reconocimiento de la diversidad educativa, estructuras, modelos educativos, entre otros. La imitación de experiencias educativas exitosas permite adelantarnos a posibles resultados. A veces es mejor aprender de otros, pues nos permite proyectar la inversión y medir resultados de manera tangible.

\section{Ejecución del programa de formación continua.}

El programa de formación continua tendrá como eje transversal la implementación de tres líneas de acción formativas: los talleres de formación, los encuentros de redes educativas y las actividades virtuales a distancia.

Los talleres de formación no son más que una metodología de enseñanza que combina eficientemente la teoría con la práctica, identificando, reconociendo y determinando sus características, objetivos y diferencias respectivamente (Escudero y Gómez, 2006). Se ejecutarán a través de cursos y seminarios que serán descritos líneas más abajo.

Los encuentros de redes educativas Son reuniones de intercambio de experiencias educativas que permiten aplicar, reconocer y proponer mejoras en la gestión del directivo (Escudero y Gómez, 2006). Se han diseñado a través de 1 o más encuentros entre diversos gestores educativos de distintos sectores, ciudades y países.

Las actividades virtuales a distancia consisten en una forma de enseñanza en la cual no se requiere asistir físicamente a una o más sesiones de clase, identificando, reconociendo y determinando las formas de aprendizaje existentes en el mercado a través del uso de las TICS. (Escudero y Gómez, 2006). Aquí será indispensable que los directores, cuenten con recursos tecnológicos (tablets, laptops, celulares, entre otros), acceso a internet y un conocimiento mínimo en el uso de herramientas digitales.

\section{Duración.}

El programa de formación continua está diseñado para ser ejecutado durante 5 meses de forma consecutiva bajo la modalidad blended (a distancia) con escasas actividades presenciales. La idea es que los gestores educativos no descuiden sus funciones pero a su vez dispongan de al menos 5 meses al año para poder formarse en temas de activación y retención de puestos claves en horarios $100 \%$ flexibles. La propuesta del programa de 
formación continua de directivos está adaptada para ser ejecutada en los "tiempos libres" de los participantes (Ver figura 7).

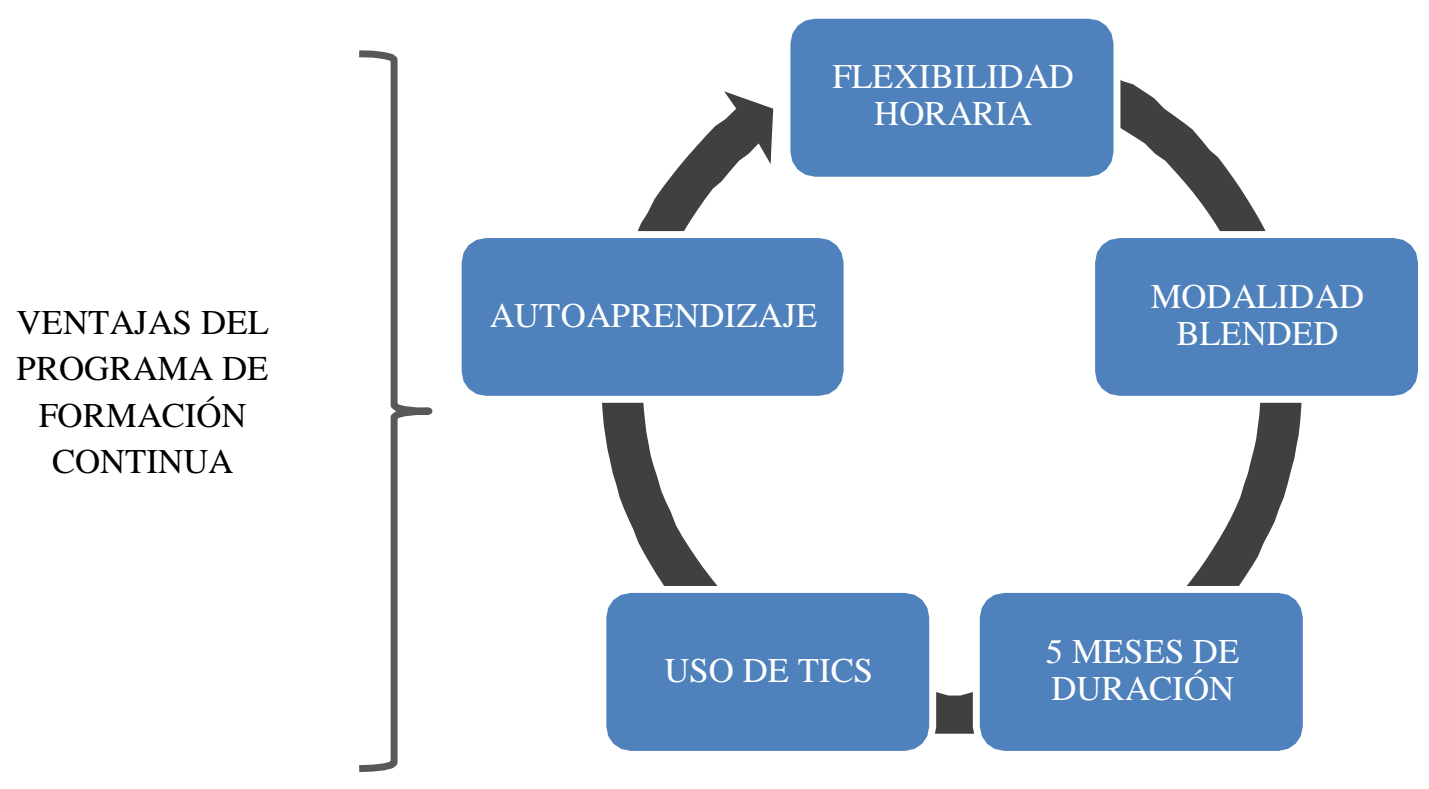

Fuente: Elaboración propia

Figura 8. Ventajas del programa de formación continua

\section{Organización.}

El programa de formación continua (PFC) de directivos para activar a los puestos claves está compuesto por cinco módulos que responden a un orden lógico de actividades en donde los participantes podrán aplicar el autoaprendizaje e interactuar de forma eventual con gestores educativos de otras escuelas del país y el extranjero a través de talleres de formación, actividades virtuales a distancia y encuentros de redes educativas (Ver tabla 5). Tabla 5

Programación de actividades del PFC

\begin{tabular}{cccl}
\hline \multicolumn{4}{c}{ Módulo I: Gestión del directivo } \\
\hline 1 & Taller 1 & 3 horas & Presencial \\
2 & Actividad Virtual 1 & 45 minutos & Blended \\
3 & Actividad Virtual 2 & 45 minutos & Blended \\
4 & Actividad Virtual 3 & 45 minutos & Blended \\
\hline
\end{tabular}

Módulo II: Diagnóstico de los puestos claves

\begin{tabular}{llll}
\hline 5 & Taller 2 & 3 horas & Presencial
\end{tabular}




\begin{tabular}{cccc}
6 & Actividad Virtual 4 & 45 minutos & Blended \\
7 & Actividad Virtual 5 & 45 minutos & Blended \\
8 & Actividad Virtual 6 & 45 minutos & Blended \\
\hline 9 & Módulo III: Perfil del puestos clave & Presencial \\
10 & Taller 3 & 3 horas & Blended \\
11 & Actividad Virtual 7 & 45 minutos & Blended \\
12 & Actividad Virtual 8 & 45 minutos & Blended \\
\hline & Actividad Virtual 9 & 45 minutos & Presencial \\
\hline 13 & Módulo IV: Uso de tics en la activación y retención de puestos claves \\
14 & Taller 4 & 3 horas & Blended \\
15 & Actividad Virtual 10 & 45 minutos & Blended \\
16 & Actividad Virtual 11 & 45 minutos & Blended \\
\hline 18 & Actividad Virtual 12 & 45 minutos & Presencial \\
\hline 19 & Módulo V: Evaluación y Seguimiento de los puestos claves & \\
\hline
\end{tabular}

Fuente: Elaboración propia

Temarios.

El programa de formación continua de directivos contiene un total de 4 talleres de formación, 14 actividades virtuales a distancia y 01 encuentro de redes educativas (Ver tabla 6)

\section{Tabla 6}

Sylabus del programa de formación continua

\begin{tabular}{ccc}
\hline SEM & ACTIVIDAD & TEMA \\
\hline 1 & Taller 1 & Bienvenida al Programa de Formación Continua \\
2 & Actividad Virtual 1 & El rol del directivo \\
3 & Actividad Virtual 2 & Liderazgo pedagógico y administrativo \\
4 & Actividad Virtual 3 & Autoevaluación \\
5 & Taller 2 & La importancia de los puestos claves \\
6 & Actividad Virtual 4 & El talento en las organizaciones educativas \\
7 & Actividad Virtual 5 & Análisis FODA de los puestos claves
\end{tabular}




$\begin{array}{ccc}8 & \text { Actividad Virtual 6 } & \text { Detección de necesidades } \\ 9 & \text { Taller 3 } & \text { El perfil del puesto clave } \\ 10 & \text { Actividad Virtual 7 } & \text { Persona talentosa VS Puesto clave } \\ 11 & \text { Actividad Virtual } 8 & \text { Manual de Funciones de los Puestos Claves } \\ 12 & \text { Actividad Virtual 9 } & \text { El empowerment } \\ 13 & \text { Taller 4 } & \text { Activación y retención } \\ 14 & \text { Actividad Virtual 10 } & \text { Reclutamiento interno } \\ 15 & \text { Actividad Virtual 11 } & \text { Reclutamiento Externo } \\ 16 & \text { Actividad Virtual 12 } & \text { Capacitación de puestos claves } \\ 17 & \text { Encuentro de redes 1 } & \text { Evaluación y seguimiento de puestos claves } \\ 18 & \text { Actividad Virtual 13 } & \text { Sistema de Incentivos Personalizados } \\ 19 & \text { Actividad Virtual 14 } & \text { Uso de portafolios de seguimiento } \\ 20 & \text { Clausura del Programa } & \text { Cierre y entrega de certificados }\end{array}$

Fuente: Elaboración propia

\section{Normas y Compromisos.}

El programa de formación continua de directivos es un aporte, en la modalidad de programa de capacitación, al artículo $\mathrm{N}^{\circ} 56$, literal d, de la Ley General de Educación y el artículo $\mathrm{N}^{\circ} 40$, literal g, de la Ley de Reforma Magisterial, que establece que los directivos deben ser formados de manera permanente y obligatoria.

El programa de formación continua está dirigido únicamente a directores, gestores educativos y/o personal directivo de cualquier institución pública y/o privada ubicada en el territorio nacional, ello incluye a peruanos y extranjeros.

Los participantes se comprometen a cumplir con un mínimo del $70 \%$ de asistencia a las actividades planteadas en el programa de formación continua, caso contrario no recibirán su certificado de participación por un total de 50 horas pedagógicas.

Los participantes deberán justificar sus inasistencias con la documentación pertinente en casos de salud, viaje, duelo o emergencia dentro del mes en curso.

Todos los participantes recibirán un manual con las normas de convivencia, compromisos, obligaciones, derechos, deberes, términos y condiciones del presente programa de formación continua. 


\section{Certificación.}

Los participantes que acrediten una asistencia superior al $70 \%$ de actividades planteadas en el programa de formación continua de directivos, recibirán un certificado por 50 horas pedagógicas por concepto de capacitación, el mismo que estará sellado y validado por el autor de a presente tesis, el Licenciado José Fernando Chicoma Castro, el mismo que está inscrito y habilitado en el Colegio de Licenciados en Administración de Lima con registro único de colegiatura $\mathrm{N}^{\circ} 028448$.

\section{Evaluación.}

La evaluación de los participantes será de forma permanente; para tal efecto, se le entregará de forma oportuna la rúbrica y criterios de evaluación correspondientes. La calificación se dará de forma vigesimal y con promedios ponderados.

\section{Perfil del Egresado.}

El programa de formación continua de directivos está diseñado para fortalecer las competencias y desempeños priorizados según el Marco del Buen Desempeño Directivo (Minedu 2014).

\section{Tabla 7}

Perfil del egresado

\section{Gestión para las condiciones de las mejoras de los aprendizajes}

\section{COMPETENCIA 1}

Conduce de manera participativa la planificación institucional sobre la base del conocimiento de los procesos pedagógicos, el clima escolar, las características de los estudiantes y su entorno y la orienta hacia el logro de metas de aprendizaje.

\section{COMPETENCIA 2}

Promueve y sostiene la participación democrática de los diversos actores de la IE y la comunidad a favor de los aprendizajes, así como un clima escolar basado en el respeto, el estímulo, la colaboración mutua y el reconocimiento de la diversidad.

\section{DESEMPEÑ̃ 1}

Diagnostica las características del entorno institucional, familiar y social que influyen en el logro de las metas de aprendizaje.

\section{DESEMPEÑO 2}

Diseña de manera participativa los instrumentos de gestión escolar.

\section{DESEMPEÑO 3}

Genera un clima escolar basado en la diversidad y comunicación permanente.

\section{DESEMPEÑO 4}

Maneja estrategias de resolución de problemas. 


\section{COMPETENCIA 3}

Promueve y lidera una comunidad de aprendizaje con las y los docentes de su institución educativa basada en la colaboración mutua, la autoevaluación profesional y la formación continua orientada a mejorar la práctica pedagógica y asegurar logros de aprendizaje.

\section{COMPETENCIA 4}

Gestiona la calidad de los procesos pedagógicos al interior de su institución educativa a través del acompañamiento sistemático a las y los docentes y la reflexión conjunta con el fin de alcanzar las metas de aprendizaje.

\section{DESEMPEÑO 5}

Demuestra conocimientos pedagógicos actualizados y comprensión de los conceptos fundamentales.

\section{DESEMPEÑO 6}

Genera mecanismos para el trabajo colaborativo.

\section{DESEMPEÑO 7}

Diseña con creatividad actividades que se ajustan a la realidad educativa en la que vive.

\section{DESEMPEÑO 8}

Monitorea y orienta el proceso de evaluación.

Fuente: Elaboración propia

\section{Validación del programa de formación continua}

El programa de formación continua de directivos para activar a los puestos claves en una institución educativa de educación básica regular fue validado por tres docentes expertos del Programa de Posgrado en Educación de la Universidad San Ignacio de Loyola. Se utilizó para ello la técnica de consulta de juicio de expertos a través de la aplicación de indicadores de validación interna y externa. Los docentes fueron elegidos por el autor de la presente tesis debido a su amplia experiencia en el campo metodológico y temático afines a la presente investigación.

\section{Características de los especialistas.}

Los profesionales que validación de la presente tesis fueron el Dr. José Manuel Muñoz Salazar (experto 1), el Mg. Sc. Hélwis César Moreno Bardales (experto 2) y la Mg. María Teresa Herrera Montoya (experto 3). El Dr. José Salazar cuenta con más de 35 años de experiencia profesional, es Ingeniero Electrónico de profesión por la Universidad Ricardo Palma, Especialista en Estadística de la Investigación por la Universidad Peruana Cayetano Heredia, Magister en Ciencias de la Educación con mención en Gestión de Innovación Educativa y Doctor en Ciencias de la Educación por la Universidad Nacional de Educación Enrique Guzmán y Valle. Por su parte, el Mg. Cesar Moreno cuenta con más de 20 años de experiencia profesional, es Licenciado en Administración de Empresas por la Universidad San Ignacio de Loyola y Magíster Scientiae en Administración por la Universidad Agraria 
la Molina. Finalmente, la Dra. María Teresa Herrera cuenta con más de 33 años de experiencia profesional, es Licenciada en Educación por la Universidad Nacional de Educación Enrique Guzmán y Valle y Maestra en Educación con mención en Psicopedagogía por la Universidad San Ignacio de Loyola. (Ver tabla 6).

Tabla 8

Especialistas de la validación

\begin{tabular}{|c|c|c|c|c|}
\hline $\begin{array}{c}\text { Apellidos y } \\
\text { Nombres }\end{array}$ & $\begin{array}{c}\text { Grado } \\
\text { Académico }\end{array}$ & $\begin{array}{l}\text { Especialidad / } \\
\text { Profesión }\end{array}$ & Ocupación & $\begin{array}{c}\text { Años de } \\
\text { experiencia }\end{array}$ \\
\hline $\begin{array}{l}\text { Herrera Montoya, } \\
\text { María Teresa }\end{array}$ & Maestra & Educadora & $\begin{array}{c}\text { Docente } \\
\text { Universitario e } \\
\text { Investigadora }\end{array}$ & 33 \\
\hline $\begin{array}{l}\text { Moreno Bardales, } \\
\text { Hélwis César }\end{array}$ & Magíster & Administrador & $\begin{array}{l}\text { Docente } \\
\text { Universitario y } \\
\text { Consultor de } \\
\text { Soluciones } \\
\text { Tecnológicas }\end{array}$ & 20 \\
\hline $\begin{array}{c}\text { Muñoz Salazar, } \\
\text { José Manuel }\end{array}$ & Doctor & $\begin{array}{c}\text { Ingeniero } \\
\text { Electrónico }\end{array}$ & $\begin{array}{c}\text { Docente } \\
\text { Universitario e } \\
\text { Investigador }\end{array}$ & 35 \\
\hline
\end{tabular}

Fuente: Elaboración Propia

\section{Valoración Interna.}

La validación interna efectuada por los expertos consideró los siguientes indicadores: factibilidad de la aplicación de la propuesta, claridad de la propuesta, posibilidad de extensión a contextos semejantes, correspondencia con las necesidades actuales, novedad en el uso de procedimientos y conceptos, congruencia entre el resultado y los objetivos de la propuesta, la modelación y sus propósitos de acuerdo a los fundamentos psicológicos, pedagógicos, administrativos, socioeducativos y normativos, la contextualización de la propuesta con la realidad, la coherencia de los objetivos y la existencia de un adecuado plan de acción.

La escala de calificación en dicha validación se ejecutó a través de la aplicación de los siguientes puntajes: Deficiente (1), Bajo (2), Regular (3), Bueno (4) y Muy Bueno (5). Los mismos que en sumatoria pueden alcanzar los 50 puntos. Dicha escala presenta a su vez presenta rangos de frecuencia y porcentaje que ayudan a visualizar mejor los resultados obtenidos (Ver tabla 7). 
Los resultados de la validación interna arrojaron los siguientes puntajes: 48 puntos (experto 1), 48 puntos (experto 2) y 49 puntos (experto 3 ); y los siguientes porcentajes: 96\% (experto 1), $96 \%$ (experto 2) y $98 \%$ (experto 3), es decir que la calificación final obtenida resulta ser: Muy buena (Ver tabla 10).

\section{Tabla 9}

Escala de calificación

\begin{tabular}{ccc}
\hline Escala & Rango de frecuencia & Rango de porcentaje \\
\hline Deficiente & $(10-17)$ & $(20 \%-35 \%)$ \\
Bajo & $(18-25)$ & $(36 \%-51 \%)$ \\
Regular & $(26-33)$ & $(52 \%-67 \%)$ \\
Buena & $(34-41)$ & $(68 \%-83 \%)$ \\
Muy buena & $(42-50)$ & $(84 \%-100 \%)$ \\
\hline
\end{tabular}

Fuente: Elaboración Propia

Tabla 10

Validación interna por juicio de expertos

\begin{tabular}{|c|c|c|c|c|c|c|}
\hline \multirow[t]{2}{*}{ Indicadores } & \multicolumn{2}{|c|}{ Experto 1} & \multicolumn{2}{|c|}{ Experto 2} & \multicolumn{2}{|c|}{ Experto 3} \\
\hline & Puntaje & $\%$ & Puntaje & $\%$ & Puntaje & $\%$ \\
\hline $\begin{array}{l}\text { Factibilidad de aplicación del resultado que se } \\
\text { presenta. }\end{array}$ & 5 & 10 & 5 & 10 & 5 & 10 \\
\hline $\begin{array}{l}\text { Claridad de la propuesta para ser aplicado por } \\
\text { otros }\end{array}$ & 5 & 10 & 5 & 10 & 5 & 10 \\
\hline $\begin{array}{l}\text { Posibilidad de la propuesta de extensión a otros } \\
\text { contextos semejantes }\end{array}$ & 4 & 8 & 5 & 10 & 5 & 10 \\
\hline $\begin{array}{l}\text { Correspondencia con las necesidades sociales e } \\
\text { individuales actuales }\end{array}$ & 5 & 10 & 4 & 8 & 5 & 10 \\
\hline $\begin{array}{l}\text { Congruencia entre el resultado propuesto y el } \\
\text { objetivo fijado. }\end{array}$ & 5 & 10 & 5 & 10 & 5 & 10 \\
\hline $\begin{array}{l}\text { Novedad en el uso de conceptos y procedimientos } \\
\text { de la propuesta. }\end{array}$ & 5 & 10 & 4 & 8 & 5 & 10 \\
\hline $\begin{array}{l}\text { La modelación contiene propósitos basados en los } \\
\text { fundamentos educativos, curriculares y } \\
\text { pedagógicos, detallado, preciso y efectivo }\end{array}$ & 4 & 8 & 5 & 10 & 4 & 8 \\
\hline $\begin{array}{l}\text { La propuesta está contextualizada a la realidad en } \\
\text { estudio. }\end{array}$ & 5 & 10 & 5 & 10 & 5 & 10 \\
\hline Presenta objetivos claros, coherentes y posibles de & 5 & 10 & 5 & 10 & 5 & 10 \\
\hline
\end{tabular}


alcanzar.

Contiene un plan de acción de lo general a lo particular.

$\begin{array}{llllll}5 & 10 & 5 & 10 & 5 & 10 \\ 48 & 96 & 48 & 96 & 49 & 98\end{array}$

Fuente: Elaboración Propia

\section{Valoración Externa.}

La validación externa efectuada por los expertos consideró los siguientes indicadores: claridad, objetividad, actualidad, organización, suficiencia, intencionalidad, consistencia, coherencia, metodología y pertinencia.

La escala de calificación en dicha validación se ejecutó a través de la aplicación de los siguientes puntajes: Deficiente (1), Bajo (2), Regular (3), Bueno (4) y Muy Bueno (5). Los mismos que en sumatoria pueden alcanzar los 50 puntos.

Los resultados de la validación externa arrojaron los siguientes puntajes: 50 puntos (experto 1), 50 puntos (experto 2) y 49 puntos (experto 3); y los siguientes porcentajes: $100 \%$ (experto 1), 100\% (experto 2) y 98\% (experto 3), es decir que la calificación final obtenida resulta ser: Muy buena (Ver tabla 8).

Tabla 11

Validación externa por juicio de expertos

\begin{tabular}{|c|c|c|c|c|c|c|c|}
\hline \multicolumn{2}{|c|}{ Indicadores } & \multicolumn{2}{|c|}{ Experto 1} & \multicolumn{2}{|c|}{ Experto 2} & \multicolumn{2}{|c|}{ Experto 3} \\
\hline & & Puntaje & $\%$ & Puntaje & $\%$ & Puntaje & $\%$ \\
\hline Claridad & $\begin{array}{l}\text { Es formulado con lenguaje } \\
\text { apropiado }\end{array}$ & 5 & 10 & 5 & 10 & 5 & 10 \\
\hline Objetividad & $\begin{array}{l}\text { Está expresado en } \\
\text { conductas observables }\end{array}$ & 5 & 10 & 5 & 10 & 5 & 10 \\
\hline Actualidad & $\begin{array}{l}\text { Adecuado al avance de la } \\
\text { ciencia pedagógica }\end{array}$ & 5 & 10 & 5 & 10 & 4 & 8 \\
\hline Organización & $\begin{array}{l}\text { Existe una organización } \\
\text { lógica }\end{array}$ & 5 & 10 & 5 & 10 & 5 & 10 \\
\hline Suficiencia & $\begin{array}{l}\text { Comprende los aspectos de } \\
\text { cantidad y calidad }\end{array}$ & 5 & 10 & 5 & 10 & 5 & 10 \\
\hline Intencionalidad & $\begin{array}{l}\text { Adecuado para valorar los } \\
\text { aspectos de las categorías }\end{array}$ & 5 & 10 & 5 & 10 & 5 & 10 \\
\hline Consistencia & $\begin{array}{l}\text { Basado en aspectos } \\
\text { teóricos científicos de la } \\
\text { educación }\end{array}$ & 5 & 10 & 5 & 10 & 5 & 10 \\
\hline Coherencia & $\begin{array}{l}\text { Entre el propósito, diseño } \\
\text { y la implementación de la }\end{array}$ & 5 & 10 & 5 & 10 & 5 & 10 \\
\hline
\end{tabular}


propuesta

La estrategia responde al

Metodología

propósito de la

investigación

Pertinencia

Es útil y adecuado para la investigación

TOTAL

\section{Resultados de la Valoración Interna y Externa.}

Fuente: Elaboración Propia

Tras ejecutar los procesos de validación interna y externa por juicio de expertos y promediar los resultados, se obtuvo un resultado de 49 puntos que es equivalente a $98 \%$. Esto quiere decir que la presente investigación presenta una calificación casi perfecta, es decir que el modelo planteado resulta ser aplicable a la gestión educativa. (Ver tabla 10)

Tabla 12

Resumen de valoración interna y externa

\begin{tabular}{cccc}
\hline Resultados & Experto 1 & Experto 2 & Experto 3 \\
\hline Validación interna & 48 & 48 & 49 \\
Validación externa & 50 & 50 & 49 \\
Promedio & 49 & 49 & 49 \\
Promedio Final & & 49 & \\
\hline
\end{tabular}

Fuente: Elaboración Propia

\section{Conclusiones Aproximativas.}

El programa de formación continua de directivos para activar a los puestos claves en una institución educativa de educación básica regular presenta una adecuada fundamentación psicológica, pedagógica, administrativa, socioeducativa y normativa.

La propuesta modelada denota claridad, objetividad, actualidad, organización, suficiencia, pertinencia, metodología, coherencia, consistencia e intencionalidad según la apreciación de tres expertos temáticos y metodológicos.

El programa de formación continua debe reincidir en mejorar el liderazgo pedagógico y administrativo de los gestores educativos desde una perspectiva integral e innovadora a través de talleres de formación continua, actividades virtuales a distancia y encuentros de redes educativas.

Capacitar a los gestores educativos en estrategias de activación y retención de 
puestos claves, reclutamiento interno y externo, planes de sucesión, empowerment, gestión educativa y sistemas de gestión de calidad resulta vital para desarrollar competencias de autoevaluación, interpretación de la realidad, creatividad, comunicación digital y supervisión y monitoreo del personal en los directivos o gestores educativos. 


\section{Conclusiones}

\section{Primera}

Se cumplió con el objetivo general de la investigación al modelar y validar un programa de formación continua de directivos para activar a los puestos claves en una institución educativa de educación básica regular.

\section{Segunda}

Se sistematizaron y fundamentaron de forma holística los referentes teóricos de las categorías y subcategorías apriorísticas propuestas por el autor de la presente investigación; para ello, se procedió a analizar y contrastar valiosa literatura científica obtenida de cuatro bibliotecas reconocidas de Lima. Estas acciones permitieron ampliar la perspectiva metodológica del investigador para efectuar un diagnóstico de campo con una altísima exigencia y rigor académico, cumpliendo así con la primera tarea científica.

\section{Tercera}

Se analizó y diagnosticó el estado actual de los programas de formación continua de directivos para activar a los puestos claves en una institución educativa de educación básica regular a través de la aplicación responsable de técnicas e instrumentos de la muestra seleccionada por conveniencia, obteniendo así, tras un proceso minucioso de codificación, categorías emergentes que favorecieron al cumplimiento de la segunda tarea científica.

\section{Cuarta}

Se modeló desde una perspectiva académica científica un programa de formación continua para activar a los puestos claves de una institución educativa de educación básica regular, tomándose como referencia métodos teóricos que ayudaron a explicar la realidad a través de abstracciones. Ello permitió descubrir las relaciones existentes entre las categorías apriorísticas y emergentes dentro de una secuencia lógica aplicada, cumpliéndose de esta manera con la tercera tarea científica. 


\section{Quinta}

Se validaron los aspectos positivos y negativos de la nueva propuesta de programa de formación continua de directivos para activar a los puestos claves en una institución educativa de educación básica regular, desde una perspectiva científica de tipo aplicada educacional, cumpliéndose así con la quinta tarea científica. 


\section{Recomendaciones}

\section{Primera}

Aplicar la nueva propuesta de programa de formación continua de directivos para activar a los puestos claves en una institución educativa de educación básica regular como una alternativa pedagógica innovadora que se verá reflejada en la mejora continua de la organización y la calidad educativa.

\section{Segunda}

Validar y medir los impactos que puedan presentarse tras la aplicación de la nueva propuesta de programa de formación continua de directivos para activar a los puestos claves en una institución educativa de educación básica regular. Para ello se sugiere aplicar el análisis Foda, herramienta de gestión que estudia la situación real de la institución analizando sus aspectos internos y externos; el diagrama de Gantt, cuyo objetivo es programar las actividades o tareas a lo largo de un determinado periodo de tiempo; el balanced scorecard, sistema integrado de gestión que permite el control de los factores directos que inciden en la gestión del directivo; y la matriz EFE y EFI, instrumentos que permiten evaluar las relaciones que existen entre los aspectos internos y externos de la institución educativa.

\section{Tercera}

Registrar y presentar los resultados de la aplicación de la nueva propuesta de programa de formación continua de directivos para activar a los puestos claves en una institución educativa de educación básica regular en eventos científicos, encuentros de redes educativas, talleres de formación continua, entre otros, como aporte a posibles problemas de activación y retención de puestos claves. 


\section{Referencias}

Abarca, J. (2013). El coach como líder. Lima, Perú: Editorial Pie de Trigo Editores

Adorno, T. y Horkheimer, M. (2003). Dialéctica de la ilustración. Fragmentos filosóficos. Madrid - Trotta, España: ISBN

Albert, G. (2018). La Investigación Educativa. Claves Teóricas. Madrid, España: Mc Graw-Hill.

Aguilar, J. y González, D. (2016). Un modelo estructural de la motivación intrínseca. Ciudad de México, México: Editorial Hermosillo

Álvarez, C. (1995). La escuela de la vida. La Habana, Cuba: Educación Superior

Álvarez, R. (2012). Hacia un currículo integral y contextualizado. Honduras: Editorial Universalia

Amorín, A. (2012). La motivación como herramienta de mejora escolar. Fortaleza, Brasil: Universidade de Fortaleza

Arellano, R. (2000). Estilos de Vida. Lima, Perú: Non Comercial

Balestrini, Miriam. (2002). Cómo se elabora un Proyecto de Investigación. Caracas Venezuela: BI Consultores Asociados

Balestrini, Miriam. (2006). Metodología de la Investigación para Administración, Economía, Humanidades y Ciencias Sociales. México D.F., México: Editorial Prentice Hall.

Barriga, C. (2010). Enseñar a aprender. Homo Sapiens. Rosario, Argentina: Editorial Santa Fe

Bisquerra, R. (2002). Modelos de orientación e intervención psicopedagógica. Barcelona, España: Editorial Praxis

Bueno, D. (2017). Neurociencia para educadores. Todo lo que los educadores siempre han querido saber sobre el cerebro. Barcelona, España. Editorial Octoedro

Bunge, M. (1981). La investigación científica aplicada. Barcelona, España: Editorial Ariel

Castañeda, J. (1966). Valoración del rendimiento del personal. Madrid, España: Editorial Iberconsult S.A.

Castellanos, D. y Reinoso, C. (2007). Para promover un aprendizaje desarrollador. La Habana, Cuba: Colección de proyector 
Castro, M. y Ocampo, S. (2010). Coaching multidimensional: teoría y práctica. D.F., México: Editorial Trillas.

Chiavenato, I. (2011). Administración de recursos humanos. Rio de Janeiro, Brasil: Elsevier Editora Ltda.

Chiang, M. (2010). How does pre service teachers learning. Salt Lake City, Estados Unidos: University of Utah

Cruz, O. y Velásquez, M. (2016). Metodología para el aprendizaje significativo. Buenos Aires, Argentina: Revista de Educación

Cuenca, F. (2000). Factores psicológicos y sociales relacionados con la motivación. D.F., México: Editorial Paidos

D Alessio, F. (2016). El Proceso Estratégico. Un enfoque de gerencia. Lima, Péru: Pearson Educación de Perú S.A.

David. F. (2013). Administración Estratégica. Naucalpan de Juárez, México: Editorial Pearson Educación S.A.

Delors, J. (1996). La educación encierra un tesoro que debemos saber valorar. Unesco: Editorial Santillana

Deroncele, A., Medina, P., y Gross, R. (2020). Gestión de potencialidades formativas en la persona: reflexión epistémica y pautas metodológicas. Universidad y Sociedad, 12(1), 97-104.

Deroncele, A. (2017). Dinámica de la intervención psicosocial en el contexto organizacional. En el Libro: "Herramientas para la Intervención Psicosocial en el Desarrollo Humano en el Oriente Cubano, desde una Perspectiva Integradora”. ISBN: 978-3-6685-0565-0. Editorial GRIN VERLAG. Alemania.

Deroncele, A. (2015). Estrategia educativa para la formación profesional integral del psicólogo en el contexto organizacional. Tesis de doctorado. Universidad de Oriente, Cuba.

Dessler, G. (2014). Administración de Personal. Naucalpan de Juárez, México: Editorial Prentice Hall Hispanoamericana S.A.

Dirección Regional de Educación de Lima Metropolitana (2019). Recuperado de http://www.drelm.gob.pe/drelm/revalorizacion-docente/

Díaz. A (2019). El secreto de una buena educación. Lima, Perú: Editorial Pie de Trigo Editores S.A. 
Díaz. F. (2004). Estrategias docentes para el aprendizaje. D.F., México: McGraw Hill

Dolan. S. (2012). Coaching por valores en la escuela. Bogotá, Colombia: Editorial Buena Semilla.

Dolan, S. (2013). Coaching por valores en la escuela. Bogotá, Colombia: Editorial Buena Semilla.

Dominguez, J. (2015). Manual de metodología de la investigación científica. Chimbote, Perú: Universitat Autónoma de Barcelona

Escudero J. y Gómez A. (2006). La formación del profesorado y la mejora de la Educación. Madrid, España: Editorial Octaedro, S.L.

Espinoza N. (1995). Administración documentaria para empresas e instituciones. Lima, Perú: Editorial Universo

Espinoza N. (2006). Ciencia y Tecnología para el desarrollo del Perú. Lima, Perú: Editorial Universo

Eyssautier, M. (2011). Metodología de la Investigación. D.D, México: Editorial Paraninfo

Filloux, J. (2009). La personalidad según la profesión. D.F., México: Imprenta Lito Arte S.A.

Freire, P. (2018). Pedagogía de la autonomía: saberes necesarios para la práctica educativa y la buena gestión en las escuelas. Buenos Aires, Argentina: Siglo veintiuno

García H. (1994). La educación personalizada en el mundo del trabajo. Madrid, España: Editorial Rialp S.A.

García, L. (2007). De la educación a distancia a la educación virtual. Barcelona, España: Ariel Educación

Gardner, R. (2005). Integrative motivation and second language. Ottawa, Canada: Canadian Association of Apilled Linguistics

Gallego, J. (2002). Implicaciones pedagógicas de los entornos virtuales en la educación a distancia: espacio de reflexión. Lima, Perú: Consorcio de universidades

Gómez L., Balkin D. y Cardy. R (2018). Gestión de Recursos Humanos. Madrid, España: Editorial Pearson Educación S.A. 
Goleman, D., Boyatzis, R. y Mckee, A. (2002). The new leaders: transforming the art of leadership into the science of results. Londrés, Inglaterra: Little brown editions Hernández, R., Fernández, C. y Baptista, P. (2006). Metodología de la Investigación. México. D.F., México: Editorial Mc Graw-Hill

Herrera. A (2015). Uso de recursos abiertos en el desarrollo de las habilidades comunicativas en una institución educativa particular de Lima Metropolitana. Lima, Perú: Pontificia Universidad Católica del Perú

Hill, C. y Jones. G. (2018). Administración Estratégica. México D.F., México: Editorial McGraw - Hill / Interamericana Editores S.A.

Hofer, M. (2017). Manejo de aula y desempeño docente. Guadalajara, México: McGraw - Hill

Instituto Nacional de Estadística e Informática (2019). Recuperado de https://www.inei.gob.pe/

Keller, J. (2008). First principles of motivación. Washington, Estados Unidos: Editorial McMilland

La Organización de las Naciones Unidas para la Educación, la Ciencia y la Cultura (2019). Recuperado de https://es.unesco.org/themes/education

Mclelland, D. (1999). El estudio de la motivación humana. Madrid, España: Foresman \& Company

Martínez, H. (2014). Metodología de la Investigación. D.F., México: Editorial Cengage

Marquez, A. (2019). Las habilidades, reflexiones y proposiciones para su evaluación. Santiago, Cuba: Editorial VG

Medina, P. (2019). ¿Qué hay detrás de una tesis? Ideele Revista N²84

Medina, P., Deroncele, A. (2019). La evaluación formativa desde el rol del docente reflexivo. Revista Maestro y Sociedad, 16(3), 597-610.

Ministerio de Educación del Perú. (2009). Diseño Curricular Nacional de la Educación Básica Regular. Lima, Perú: Minedu

Ministerio de Educación del Perú. (2009). Manual de gestión para directores de instituciones educativas. Lima, Perú: Minedu

Ministerio de Educación del Perú. (2014). Marco del buen desempeño directivo. Lima, Perú: Minedu 
Ministerio de Educación del Perú. (2014). Marco del buen desempeño directivo. Lima, Perú: Minedu

Ministerio de Educación del Perú. (2019). Recuperado de http://www.minedu.gob.pe/politicas/docencia/

Ministerio de Educación del Perú. (2020) Recuperado de http://repositorio.minedu.gob.pe/bitstream/handle/MINEDU

Mintzberg, H. (2013). Simply Mananging. What Managers Do \# and Can Do Better. San Francisco, USA: Editorial Berrett-Koehler.

Mitchell, H. (2013). El estudio de los puestos claves en las organizaciones más exitosas de Inglaterra. Londrés, Inglaterra: MM Publications

Newstrom, J. (2016). Comportamiento Humano en el trabajo. D.F., México: Editorial McGraw - Hill / Interamericana Editores S.A.

Organización para la Cooperación y el Desarrollo Económico (2019). Recuperado de http://www.oecd.org/centrodemexico/laocde/peru-y-la-ocde.htm

Ortiz, A. (2012). Didáctica problematizadora y aprendizaje basado en valores éticos y morales. Cali, Colombia; Ediciones Litoral

Ortiz, A. (2015). Neuroeducación: ¿cómo aprende el cerebro humano y cómo deberían enseñar los docentes? Bogotá, Colombia: Ediciones unidas

Petry, G. (2006). La motivación en secundaria, un estudio empírico. Madrid, España: Revita complutense

Porras, J. (2016). La organización: enfoques, tipologías y perspectiva. Bogotá, Colombia: Editorial Libero Ediciones

Pimienta, J. (2012). Estrategia de enseñanza - aprendizaje. D.F., México: Editorial Pearson

Poiry I. (2018). La Reforma de la Educación. Lima, Perú: Editorial Karter

Renton, J. (2010). Coaching y Mentoring. Técnicas para el desarrollo de los recursos humanos. Perú: Producciones Cantabria.

Rest, A. (2018). La gestión del director. Lima, Perú: Editorial PTE

Rico, P. (2013). Procedimientos y tareas de aprendizaje. La Habana, Cuba: Editorial Pueblo y Educación

Robbins, S. y Judge, T. (2013). Comportamiento Organizacional. D.F., México: Editorial Pearson. 
Rodiguez, G. (2001). Metodología de la Investigación cualitativa. Granada, España: Ediciones Díaz de Santos

Roig J. (2006). El estudio de los Puestos de Trabajo. La valoración de tareas y la valoración del personal. Madrid, España: Ediciones Díaz de Santos.

Rusell, Jane. (1995). La comunicación científica a inicios del siglo XX. Minnesota, Estado Unidos: Ediciones Franklin Watts.

Salit, C. (2011). Procesos de cambio curricular en la universidad. Buenos Aires, Argentina : Editorial Buen Pastor

Schuler R. (2017). La gestión de los recursos humanos. Madrid, España: Editorial Amelia Nieva.

Sistema Nacional de Evaluación, Acreditación y Certificación de la Calidad Educativa (2019). Recuperado de https://www.sineace.gob.pe/

Skinner, B. (1985). Aprendizaje y comportamiento. Barcelona, España: Ediciones Martinez Roca

Tobón, S. (2008). Formación basada en competencias. Bogotá, Colombia: AB Ediciones

Tobón. S. (2013). Estrategias didácticas para la formación de competencias. Bogotá, Colombia: AB Ediciones

Tobón, S., Pimienta, J. y García J. (2010). Secuencias didácticas, aprendizaje y evaluación por competencias en las instituciones educativas. Ciudad de México. México: Pearson Education

Toro, F. (2010). Clima organizacional. Una aproximación a su dinámica en la empresa latinoamericana. Medellín, Colombia: Editorial Universo

Valledor, R (2013). El tema de la investigación educacional en la formación de docentes - investigadores. Recuperado de http://roa.ult.ed.cu/bitstream

Vygotsky, L (1930). El desarrollo de los procesos psicológicos superiores. Barcelona, España: Editorial Austral

Villa, J. y Caperán, J. (2015). Manual del Coaching. Cómo mejorar el rendimiento de las personas. Madrid, España: Gráficas Rey

Whitmore J. (2017). Coaching. Barcelona, España: Paidos.

Whitehead, Alfred (1947). Science and Philosophy. Londrés, Inglaterra: Philosophical Library 
Wolk, L. (2009). Coaching El arte de soplar palabras. Buenos Aires, Argentina: Gran Aldea Editores.

Vigotsky, L. (1978). El desarrollo de los procesos psicológicos superiores. Barcelona, España: Editorial Cítica

Zapata, R. (2017). Mocs, una visión crítica y una alternativa complementaria. Unesco: Unesco de educación a distancia

Zerilli, A. (2003). Valoración del personal. Bilbao, Portugal: Ediciones Deusto. 
Anexos 
Anexo 1. Matriz de Categorización

\begin{tabular}{|c|c|c|c|}
\hline OBJETIVOS ESPECÍFICOS & CATEGORÍA & SUB CATEGORÍAS & INDICADORES \\
\hline \multirow{4}{*}{$\begin{array}{l}\text { Diagnosticar cuál es el } \\
\text { estado actual de los } \\
\text { programas de Formación } \\
\text { Continua de Directivos para } \\
\text { Activar a los Puestos Claves } \\
\text { en una institución educativa } \\
\text { privada de Educación } \\
\text { Básica Regular. }\end{array}$} & \multirow{9}{*}{$\begin{array}{c}\text { Formación Continua de } \\
\text { Directivos: Es aquella } \\
\text { capacitación constante y } \\
\text { sostenida en la que los gestores } \\
\text { de la educación logran aprender } \\
\text { nuevas estrategias y } \\
\text { herramientas de gestión que les } \\
\text { ayudan a ejercer con autonomía } \\
\text { y solvencia sus funciones } \\
\text { administrativas y pedagógicas. } \\
\text { (Escudero y Gómez, 2006). }\end{array}$} & \multirow{3}{*}{$\begin{array}{l}\text { Talleres de formación: Es una } \\
\text { metodología de enseñanza que } \\
\text { combina eficientemente la teoría } \\
\text { con la práctica, identificando, } \\
\text { reconociendo y determinando sus } \\
\text { características, objetivos y } \\
\text { diferencias respectivamente } \\
\text { (Escudero y Gómez, 2006). }\end{array}$} & $\begin{array}{l}\text { Identifica las } \\
\text { características de los } \\
\text { talleres de formación } \\
\text { existentes en el } \\
\text { mercado educativo. }\end{array}$ \\
\hline & & & $\begin{array}{l}\text { Reconoce los } \\
\text { objetivos que se } \\
\text { buscan con los } \\
\text { talleres de } \\
\text { formación. }\end{array}$ \\
\hline & & & $\begin{array}{l}\text { Determina las } \\
\text { diferencias que } \\
\text { existen entre los } \\
\text { talleres de } \\
\text { formación. }\end{array}$ \\
\hline & & \multirow{3}{*}{$\begin{array}{c}\text { Encuentros de redes } \\
\text { educativas: Son reuniones de } \\
\text { intercambio de experiencias } \\
\text { educativas que permiten aplicar, } \\
\text { reconocer y proponer mejoras en } \\
\text { la gestión del directivo (Escudero } \\
\text { y Gómez, 2006). }\end{array}$} & $\begin{array}{l}\text { Aplica mejoras en su } \\
\text { gestión después de } \\
\text { asistir a los } \\
\text { encuentros de redes } \\
\text { educativas. }\end{array}$ \\
\hline \multirow{4}{*}{$\begin{array}{c}\text { Sistematizar los } \\
\text { fundamentos teóricos y } \\
\text { metodológicos que } \\
\text { sustentan los programas de } \\
\text { Formación Continua de } \\
\text { Directivos para Activar a os } \\
\text { Puestos Claves en una } \\
\text { institución educativa } \\
\text { privadas de Educación } \\
\text { Básica Regular. }\end{array}$} & & & $\begin{array}{l}\text { Reconoce la } \\
\text { importancia del } \\
\text { intercambio de } \\
\text { experiencias. }\end{array}$ \\
\hline & & & $\begin{array}{l}\text { Propone objetivos } \\
\text { para su institución } \\
\text { tomando como } \\
\text { referencia } \\
\text { experiencias } \\
\text { exitosas en otras } \\
\text { escuelas. }\end{array}$ \\
\hline & & \multirow{3}{*}{$\begin{array}{l}\text { Actividades virtuales a } \\
\text { distancia: Es una forma de } \\
\text { enseñanza en la cual no se } \\
\text { requiere asistir físicamente a una } \\
\text { o más sesiones de clase, } \\
\text { identificando, reconociendo y } \\
\text { determinando las formas de } \\
\text { aprendizaje existentes en el } \\
\text { mercado a través del uso de las } \\
\text { TICS. (Escudero y Gómez, 2006). }\end{array}$} & $\begin{array}{l}\text { Identifica cuáles son } \\
\text { las formas de } \\
\text { aprendizaje virtual a } \\
\text { distancia. }\end{array}$ \\
\hline & & & $\begin{array}{l}\text { Reconoce el } \\
\text { desarrollo del } \\
\text { aprendizaje con el } \\
\text { uso de TICS. }\end{array}$ \\
\hline \multirow{5}{*}{$\begin{array}{c}\text { Determinar los criterios } \\
\text { teóricos y didácticos que } \\
\text { sirven de base para la } \\
\text { modelación de un programa } \\
\text { de Formación Continua de } \\
\text { Directivos para Activar a los } \\
\text { Puestos Claves en una } \\
\text { institución educativa privada } \\
\text { de Educación Básica } \\
\text { Regular. }\end{array}$} & & & $\begin{array}{c}\text { Determina las } \\
\text { diferencias que } \\
\text { existen entre las } \\
\text { actividades virtuales } \\
\text { a distancia que } \\
\text { ofrece el mercado. }\end{array}$ \\
\hline & \multirow{4}{*}{$\begin{array}{l}\text { Activación de Puestos Claves: } \\
\text { Proceso mediante el cual se } \\
\text { capta y/o retiene a los puestos } \\
\text { claves para desempeñar } \\
\text { funciones críticas que garanticen } \\
\text { el éxito de toda la organización. } \\
\text { (Roig, 2006). }\end{array}$} & \multirow{3}{*}{$\begin{array}{l}\text { Reclutamiento: Es la atracción } \\
\text { de candidatos para un puesto } \\
\text { específico dentro de la } \\
\text { organización, reconociendo e } \\
\text { identificando sus características y } \\
\text { procedimiento para su activación } \\
\text { y/o retención (Roig, 2006). }\end{array}$} & $\begin{array}{l}\text { Reconoce cuáles } \\
\text { son los puestos } \\
\text { claves dentro de la } \\
\text { organización. }\end{array}$ \\
\hline & & & $\begin{array}{l}\text { Identifica quiénes } \\
\text { son los } \\
\text { colaboradores más } \\
\text { talentosos de su } \\
\text { institución. }\end{array}$ \\
\hline & & & $\begin{array}{c}\text { Reconoce el } \\
\text { procedimiento y/o } \\
\text { políticas de la } \\
\text { institución para la } \\
\text { contratación de } \\
\text { personal nuevo. }\end{array}$ \\
\hline & & $\begin{array}{l}\text { Sistema de incentivos } \\
\text { personalizados: Es la política } \\
\text { organizacional o sistema que } \\
\text { permite o facilita la obtención de }\end{array}$ & $\begin{array}{l}\text { Propone una banda } \\
\text { salarial para los } \\
\text { colaboradores de la } \\
\text { institución educativa. }\end{array}$ \\
\hline
\end{tabular}




\begin{tabular}{|c|c|c|}
\hline \multirow{5}{*}{$\begin{array}{l}\text { Validar la modelación de un } \\
\text { Programa de Formación } \\
\text { Continua de Directivos para } \\
\text { Activar a los Puestos Claves } \\
\text { en una institución educativa } \\
\text { privada de Educación } \\
\text { Básica Regular. }\end{array}$} & \multirow[t]{2}{*}{$\begin{array}{l}\text { incentivos salariales a través de } \\
\text { la propuesta de una nueva banda } \\
\text { salarial que vaya acorde al } \\
\text { margen financiero de la institución } \\
\text { y las necesidades del personal } \\
\text { (Roig, 2006) }\end{array}$} & $\begin{array}{l}\text { Reconoce el margen } \\
\text { financiero que le } \\
\text { permita aplicar un } \\
\text { sistema de } \\
\text { incentivos } \\
\text { personalizados. }\end{array}$ \\
\hline & & $\begin{array}{l}\text { Identifica las } \\
\text { necesidades } \\
\text { económicas de los } \\
\text { colaboradores. }\end{array}$ \\
\hline & \multirow{3}{*}{$\begin{array}{l}\text { Capacitación: Es el proceso } \\
\text { educativo corto que permite } \\
\text { aprender nuevos conocimientos a } \\
\text { través del reconocimiento de las } \\
\text { debilidades, la identificación de } \\
\text { funciones y el logro de nuevos } \\
\text { saberes por parte del gestor } \\
\text { educativo (Roig, 2006). }\end{array}$} & $\begin{array}{c}\text { Reconoce la } \\
\text { importancia de la } \\
\text { capacitación en el } \\
\text { proceso educativo. }\end{array}$ \\
\hline & & $\begin{array}{l}\text { Identifica los puntos } \\
\text { débiles de su gestión } \\
\text { que podrían ser } \\
\text { reforzados a través } \\
\text { de una capacitación. }\end{array}$ \\
\hline & & $\begin{array}{l}\text { Logra nuevos } \\
\text { conocimientos } \\
\text { durante el proceso } \\
\text { de capacitación. }\end{array}$ \\
\hline
\end{tabular}


Anexo 2. Matriz Metodológica

\begin{tabular}{|c|c|c|c|c|}
\hline $\begin{array}{l}\text { OBJETIVO } \\
\text { GENERAL }\end{array}$ & $\begin{array}{l}\text { OBJETIVOS } \\
\text { ESPECÍFICOS }\end{array}$ & CATEGORÍA & SUB CATEGORÍAS & INDICADORES \\
\hline \multirow{12}{*}{$\begin{array}{c}\text { Diseñar un } \\
\text { Programa de } \\
\text { Formación } \\
\text { Continua de } \\
\text { Directivos para } \\
\text { Activar a los } \\
\text { Puestos Claves } \\
\text { en una } \\
\text { institución } \\
\text { educativa } \\
\text { privada de } \\
\text { Educación } \\
\text { Básica Regular. }\end{array}$} & \multirow{4}{*}{$\begin{array}{l}\text { Diagnosticar cuál es el } \\
\text { estado actual de los } \\
\text { programas de } \\
\text { Formación Continua de } \\
\text { Directivos para Activar } \\
\text { a los Puestos Claves } \\
\text { en una institución } \\
\text { educativa privada de } \\
\text { Educación Básica } \\
\text { Regular. }\end{array}$} & \multirow{9}{*}{$\begin{array}{l}\text { Formación Continua de } \\
\text { Directivos: Es aquella } \\
\text { capacitación constante y } \\
\text { sostenida en la que los } \\
\text { gestores de la educación } \\
\text { logran aprender nuevas } \\
\text { estrategias y herramientas } \\
\text { de gestión que les ayudan } \\
\text { a ejercer con autonomía y } \\
\text { solvencia sus funciones } \\
\text { administrativas y } \\
\text { pedagógicas. (Escudero y } \\
\text { Gómez, 2006). }\end{array}$} & \multirow{3}{*}{$\begin{array}{l}\text { Talleres de formación: Es } \\
\text { una metodología de } \\
\text { enseñanza que combina } \\
\text { eficientemente la teoría con } \\
\text { la práctica, identificando, } \\
\text { reconociendo y } \\
\text { determinando sus } \\
\text { características, objetivos y } \\
\text { diferencias respectivamente } \\
\text { (Escudero y Gómez, 2006). }\end{array}$} & $\begin{array}{c}\text { Identifica las } \\
\text { características de } \\
\text { los talleres de } \\
\text { formación } \\
\text { existentes en el } \\
\text { mercado } \\
\text { educativo. }\end{array}$ \\
\hline & & & & $\begin{array}{l}\text { Reconoce los } \\
\text { objetivos que se } \\
\text { buscan con los } \\
\text { talleres de } \\
\text { formación. }\end{array}$ \\
\hline & & & & $\begin{array}{l}\text { Determina las } \\
\text { diferencias que } \\
\text { existen entre los } \\
\text { talleres de } \\
\text { formación. }\end{array}$ \\
\hline & & & \multirow{3}{*}{$\begin{array}{l}\text { Encuentros de redes } \\
\text { educativas: Son reuniones } \\
\text { de intercambio de } \\
\text { experiencias educativas } \\
\text { que permiten aplicar, } \\
\text { reconocer y proponer } \\
\text { mejoras en la gestión del } \\
\text { directivo (Escudero y } \\
\text { Gómez, 2006). }\end{array}$} & $\begin{array}{c}\text { Aplica mejoras en } \\
\text { su gestión } \\
\text { después de asistir } \\
\text { a los encuentros } \\
\text { de redes } \\
\text { educativas. }\end{array}$ \\
\hline & \multirow{4}{*}{$\begin{array}{c}\text { Sistematizar los } \\
\text { fundamentos teóricos y } \\
\text { metodológicos que } \\
\text { sustentan los } \\
\text { programas de } \\
\text { Formación Continua de } \\
\text { Directivos para Activar } \\
\text { a os Puestos Claves en } \\
\text { una institución } \\
\text { educativa privadas de } \\
\text { Educación Básica } \\
\text { Regular. }\end{array}$} & & & $\begin{array}{c}\text { Reconoce la } \\
\text { importancia del } \\
\text { intercambio de } \\
\text { experiencias. }\end{array}$ \\
\hline & & & & $\begin{array}{l}\text { Propone objetivos } \\
\text { para su institución } \\
\text { tomando como } \\
\text { referencia } \\
\text { experiencias } \\
\text { exitosas en otras } \\
\text { escuelas. }\end{array}$ \\
\hline & & & \multirow{3}{*}{$\begin{array}{l}\text { Actividades virtuales a } \\
\text { distancia: Es una forma de } \\
\text { enseñanza en la cual no se } \\
\text { requiere asistir físicamente } \\
\text { a una o más sesiones de } \\
\text { clase, identificando, } \\
\text { reconociendo y } \\
\text { determinando las formas de } \\
\text { aprendizaje existentes en el } \\
\text { mercado a través del uso } \\
\text { de las TICS. (Escudero y } \\
\text { Gómez, 2006). }\end{array}$} & $\begin{array}{l}\text { Identifica cuáles } \\
\text { son las formas de } \\
\text { aprendizaje virtual } \\
\text { a distancia. }\end{array}$ \\
\hline & & & & $\begin{array}{c}\text { Reconoce el } \\
\text { desarrollo del } \\
\text { aprendizaje con el } \\
\text { uso de TICS. }\end{array}$ \\
\hline & \multirow{4}{*}{$\begin{array}{l}\text { Determinar los criterios } \\
\text { teóricos y didácticos } \\
\text { que sirven de base } \\
\text { para la modelación de } \\
\text { un programa de } \\
\text { Formación Continua de } \\
\text { Directivos para Activar } \\
\text { a los Puestos Claves } \\
\text { en una institución } \\
\text { educativa privada de } \\
\text { Educación Básica } \\
\text { Regular. }\end{array}$} & & & $\begin{array}{c}\text { Determina las } \\
\text { diferencias que } \\
\text { existen entre las } \\
\text { actividades } \\
\text { virtuales a } \\
\text { distancia que } \\
\text { ofrece el mercado. }\end{array}$ \\
\hline & & \multirow{3}{*}{$\begin{array}{c}\text { Activación de Puestos } \\
\text { Claves: Proceso mediante } \\
\text { el cual se capta y/o retiene } \\
\text { a los puestos claves para } \\
\text { desempeñar funciones } \\
\text { críticas que garanticen el } \\
\text { éxito de toda la } \\
\text { organización. (Roig, } \\
\text { 2006). }\end{array}$} & \multirow{3}{*}{$\begin{array}{l}\text { Reclutamiento: Es la } \\
\text { atracción de candidatos } \\
\text { para un puesto específico } \\
\text { dentro de la organización, } \\
\text { reconociendo e } \\
\text { identificando sus } \\
\text { características y } \\
\text { procedimiento para su } \\
\text { activación y/o retención } \\
\text { (Roig, 2006). }\end{array}$} & $\begin{array}{l}\text { Reconoce cuáles } \\
\text { son los puestos } \\
\text { claves dentro de la } \\
\text { organización. }\end{array}$ \\
\hline & & & & $\begin{array}{l}\text { Identifica quiénes } \\
\text { son los } \\
\text { colaboradores más } \\
\text { talentosos de su } \\
\text { institución. }\end{array}$ \\
\hline & & & & $\begin{array}{c}\text { Reconoce el } \\
\text { procedimiento y/o } \\
\text { políticas de la } \\
\text { institución para la } \\
\text { contratación de } \\
\text { personal nuevo. }\end{array}$ \\
\hline
\end{tabular}




\begin{tabular}{|c|c|c|}
\hline & \multirow{3}{*}{$\begin{array}{l}\text { Sistema de incentivos } \\
\text { personalizados: Es la } \\
\text { política organizacional o } \\
\text { sistema que permite o } \\
\text { facilita la obtención de } \\
\text { incentivos salariales a } \\
\text { través de la propuesta de } \\
\text { una nueva banda salarial } \\
\text { que vaya acorde al margen } \\
\text { financiero de la institución y } \\
\text { las necesidades del } \\
\text { personal (Roig, 2006) }\end{array}$} & $\begin{array}{c}\text { Propone una } \\
\text { banda salarial para } \\
\text { los colaboradores } \\
\text { de la institución } \\
\text { educativa. }\end{array}$ \\
\hline \multirow{5}{*}{$\begin{array}{l}\text { Validar la modelación } \\
\text { de un Programa de } \\
\text { Formación Continua de } \\
\text { Directivos para Activar } \\
\text { a los Puestos Claves } \\
\text { en una institución } \\
\text { educativa privada de } \\
\text { Educación Básica } \\
\text { Regular. }\end{array}$} & & $\begin{array}{c}\text { Reconoce el } \\
\text { margen financiero } \\
\text { que le permita } \\
\text { aplicar un sistema } \\
\text { de incentivos } \\
\text { personalizados. }\end{array}$ \\
\hline & & $\begin{array}{l}\text { Identifica las } \\
\text { necesidades } \\
\text { económicas de los } \\
\text { colaboradores. }\end{array}$ \\
\hline & Capacitación: Es el & $\begin{array}{c}\text { Reconoce la } \\
\text { importancia de la } \\
\text { capacitación en el } \\
\text { proceso educativo. }\end{array}$ \\
\hline & $\begin{array}{l}\text { proceso educativo corto } \\
\text { que permite aprender } \\
\text { nuevos conocimientos a } \\
\text { través del reconocimiento } \\
\text { de las debilidades, la } \\
\text { identificación de funciones y } \\
\text { el logro de nuevos saberes }\end{array}$ & $\begin{array}{l}\text { Identifica los } \\
\text { puntos débiles de } \\
\text { su gestión que } \\
\text { podrían ser } \\
\text { reforzados a través } \\
\text { de una } \\
\text { capacitación. }\end{array}$ \\
\hline & educativo (Roig, 2006). & $\begin{array}{l}\text { Logra nuevos } \\
\text { conocimientos } \\
\text { durante el proceso } \\
\text { de capacitación. }\end{array}$ \\
\hline
\end{tabular}




\section{Anexo 3. Cuestionario a estudiantes}

\section{CUESTIONARIO A ESTUDIANTES}

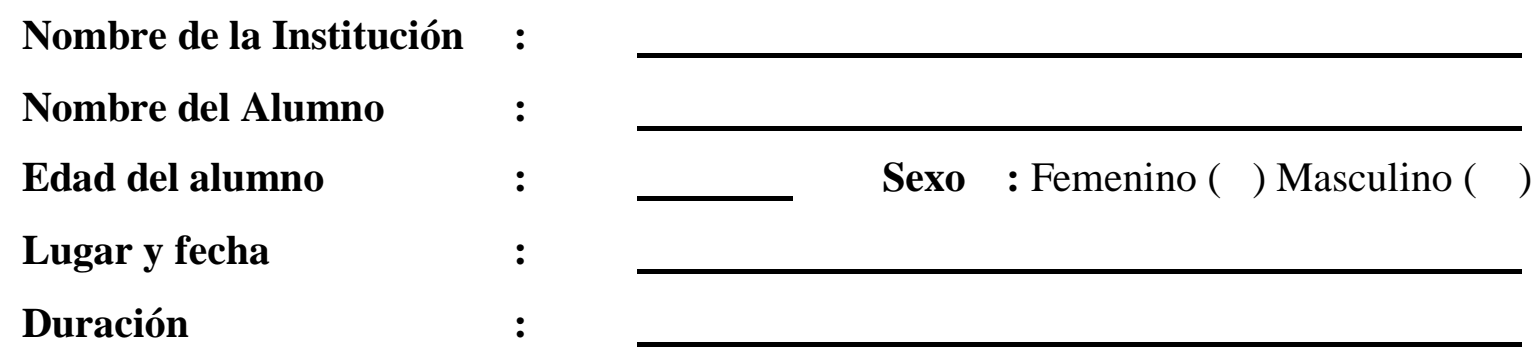

OBJETIVO : Conocer si los estudiantes reconocen a los puestos claves en la institución educativa y si la misma aplica procedimientos para su activación y retención en el tiempo.

\section{Instrucciones:}

Estimado estudiante, como parte de una investigación para conocer su opinión sobre los puestos claves que laboran en su institución educativa, necesitamos que responda a las con sinceridad a las siguientes preguntas:

1. ¿Considera que los directivos que laboran en su institución están debidamente capacitados para ejercer sus funciones?

Siempre ( ) Casi siempre ( ) A veces ( ) Pocas veces ( ) Nunca ( )

2. ¿En la institución se premia o reconoce el trabajo de los colaboradores talentosos? Siempre ( ) Casi siempre ( ) A veces ( ) Pocas veces ( ) Nunca ( )

3. ¿Considera que las mejoras aplicadas en la institución por parte de los directivos después de asistir a encuentros de redes educativas han sido favorables para mejorar el aprendizaje de los estudiantes?

Siempre ( ) Casi siempre ( ) A veces ( ) Pocas veces ( ) Nunca ( ) 
4. ¿Considera que los directivos de su institución hacen uso de las TICS para potenciar su gestión?

Siempre ( ) Casi siempre ( ) A veces ( ) Pocas veces ( ) Nunca ( )

5. Reconoce Ud. ¿Cuáles son los puestos claves dentro de su institución?

Siempre ( ) Casi siempre ( ) A veces ( ) Pocas veces ( ) Nunca ( )

6. ¿Siente Ud. mayor identidad y/o apego con los puestos claves que laboran en la institución?

Siempre ( ) Casi siempre ( ) A veces ( ) Pocas veces ( ) Nunca ( )

7. ¿Considera adecuados los procedimientos que emplea la organización para la contratación de personal nuevo?

Siempre ( ) Casi siempre ( ) A veces ( ) Pocas veces ( ) Nunca ( )

8. ¿Ha escuchado alguna vez si los docentes que laboran en su institución han tenido o tiene problemas económicos?

Siempre ( ) Casi siempre ( ) A veces ( ) Pocas veces ( ) Nunca ( )

9. ¿Se les reconoce de alguna manera el trabajo del personal más talentoso en su institución?

Siempre ( ) Casi siempre ( ) A veces ( ) Pocas veces ( ) Nunca ( )

10. ¿Considera Ud. que sus docentes están bien capacitados para ejercer sus funciones? Todos ( ) La mayoría ( ) Algunos ( ) Muy pocos ( ) Ninguno ( )

11. ¿Considera que los docentes presentan mejoras considerables en su gestión después de recibir capacitación?

Siempre ( ) Casi siempre ( ) A veces ( ) Pocas veces ( ) Nunca ( ) 
Anexo 4. Ficha de entrevista a directivos

\section{ENTREVISTA A LOS DIRECTIVOS}

Nombre de la Institución ：

Nombre del Entrevistador :

Nombre del Entrevistado :

Cargo del Entrevistado :

Lugar y fecha :

Duración :

OBJETIVO : Conocer si el directivo conoce los Programas de Formación Continua que ofrece el mercado y si identifica correctamente la vinculación y/o relación de los mismos con la promoción de los puestos claves y/o personas talentosas dentro de su organización.

Preguntas:

1. ¿Cuáles considera Ud. que son los principales beneficios para el directivo de una organización al inscribirse en Talleres de Formación Continua?

2. ¿Qué características deberían tener los Talleres de Formación Continua para que Ud. se interese en inscribirse en alguno de ellos?

3. ¿En qué medida los encuentros de redes educativas le podrían ayudar en su gestión como directivo?

4. Desde su punto de vista ¿Cuáles son las actividades virtuales a distancia más importantes que permiten potenciar la formación de un directivo? ¿Por qué?

5. ¿Considera que el uso de las TICS representa un aliado estratégico en su labor como directivo? Coméntenos ¿Cuáles son las herramientas tecnológicas que más utiliza en su gestión?

6. El mercado ofrece un sinnúmero de actividades virtuales a distancia para directivos ¿Qué tiempo al mes estaría dispuesto a invertir de inscribirse en alguna de ellas? ¿Cómo le gustaría que fuesen esas actividades? 
7. En temas de gestión del talento humano. ¿Ud. toma en cuenta las buenas prácticas de otras organizaciones para considerarlas en el plan operativo de su institución? ¿Por qué?

8. Identifica Ud. ¿Cuáles son las diferencias que existen entre un puesto clave y una persona con talento? Describa las diferencias.

9. Identifica Ud. ¿Cuáles son las características que tienen los colaboradores más talentosos en su institución? ¿Podría describir alguna de ellas?

10. ¿Ud. considera que los puestos claves deberían estar mejor remunerados? ¿Por qué?

11. En su organización ¿Existe alguna política para retener a los colaboradores más talentosos? ¿Por qué?

12. ¿Identifica Ud. cuáles son las necesidades económicas de los colaboradores que tiene a su cargo? ¿Ha tenido Ud. alguna vez la oportunidad de satisfacer alguna de ellas? ¿Podría contarnos alguna experiencia? 
Anexo 5. Ficha de entrevista a puestos claves

\section{ENTREVISTA A PUESTOS CLAVES}

Nombre de la Institución ：

Nombre del Entrevistador :

Nombre del Entrevistado :

Cargo del Entrevistado :

Lugar y fecha :

Duración :

OBJETIVO : Conocer si los puestos claves están al tanto de la relación que existe entre los Programas de Formación Continua que ofrece el mercado para sus directivos y su activación y/o retención dentro de la institución educativa.

Preguntas

1. ¿En qué medida los directivos de su institución mejoran su gestión después de asistir a Talleres de Formación Continua?

2. ¿En qué medida los directivos de su institución mejoran su gestión después de asistir a Encuentros de Redes Educativas?

3. ¿Considera que los directivos de su institución hacen uso de las TICS para potenciar su gestión? ¿Qué herramientas digitales son las que más utilizan?

4. Identifica Ud. ¿Cuáles son las diferencias que existen entre un puesto clave y una persona con talento? Describa las diferencias.

5. ¿Qué características tienen los colaboradores más talentosos dentro de su organización?

6. Describa Ud. ¿Cuál es el procedimiento que emplea su organización para la contratación de puestos claves?

7. ¿Siente que su remuneración va acorde a sus funciones y responsabilidades? ¿Por qué? 
8. ¿Existe una política clara de incentivos personalizados en su institución? ¿Quiénes deberían recibir tales incentivos?

9. Si recibiera un bono en efectivo importante. ¿Qué gastos cubriría en el corto plazo?

10. ¿Sus ingresos mensuales le permiten llevar un nivel de vida adecuado? ¿Por qué?

11. Desde su punto de vista. ¿Es importante capacitarse? ¿Por qué?

12. Si recibiera una capacitación en los próximos días ¿Qué temas le gustaría recibir?

13. ¿Ha sentido o siente que las capacitaciones que le ofrece la organización son de utilidad en su labor cotidiana? ¿Qué le han parecido las últimas capacitaciones? 


\section{Anexo 6. Tabulación de encuesta a estudiantes}

Tabla

¿Considera que los dicectlvos que laboran en su institución estan debidamente capectados pera ejercer sus hunciones?

\begin{tabular}{|c|c|c|c|c|c|}
\hline & & Finouencea & Pancertive & $\begin{array}{c}\text { Porcentaje } \\
\text { ntiliso }\end{array}$ & $\begin{array}{l}\text { Porcontsis } \\
\text { acumilade }\end{array}$ \\
\hline \multirow[t]{6}{*}{ Vwido } & NLNECA & 2 & 8.3 & a, 7 & 8.7 \\
\hline & POCAS veces & 3 & 13,0 & 13,0 & 21.7 \\
\hline & A veces & 5 & 21,7 & 25,7 & 49.5 \\
\hline & CASI SEMPJeE & 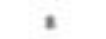 & $34, \mathrm{~s}$ & 4.11 & 763 \\
\hline & SIENDAE & 5 & 21,7 & $25, y$ & 100.0 \\
\hline & Total & 2 & 1000 & 1000 & \\
\hline
\end{tabular}

Figura 1

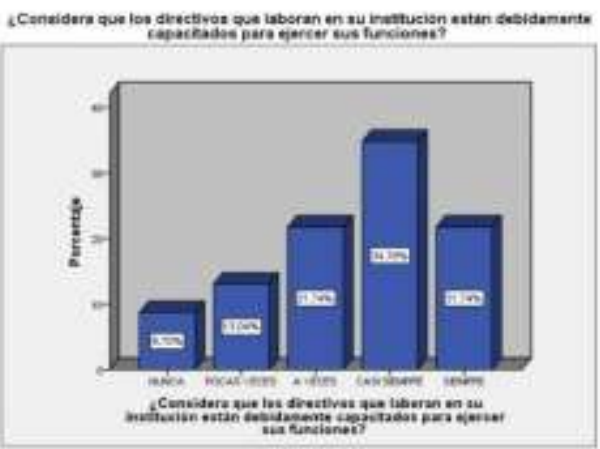

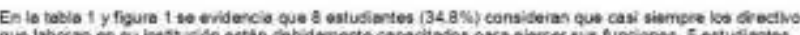

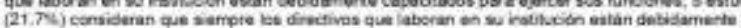

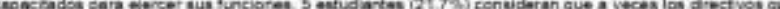

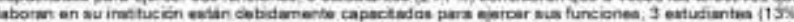

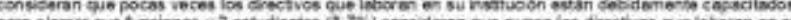

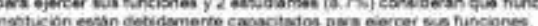

Tabla 3

¿Consibera que ins mejoras apticadas en la imathveson por perte de los itrecttros

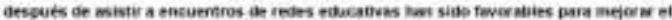

\begin{tabular}{|c|c|c|c|c|c|}
\hline & & frovienos & Astroming & $\begin{array}{c}\text { Portentase } \\
\text { Venose }\end{array}$ & $\begin{array}{l}\text { Porcentapi } \\
\text { scumindo }\end{array}$ \\
\hline \multirow[t]{6}{*}{ vause } & NUNCA & 2 & 13,0 & 120 & 120 \\
\hline & ACCNA VECEA & $=$ & 130 & 13.0 & 26.1 \\
\hline & A veces & to & 82,4 & 42.5 & 60.6 \\
\hline & CA8I SENPPEE & 8 & 26,1 & 56,1 & $16 ?$ \\
\hline & MEMPRE & , & 43 & 43 & 109,5 \\
\hline & Trent & 23 & 1000 & 1000 & \\
\hline
\end{tabular}

Figura 3

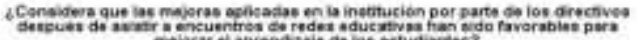

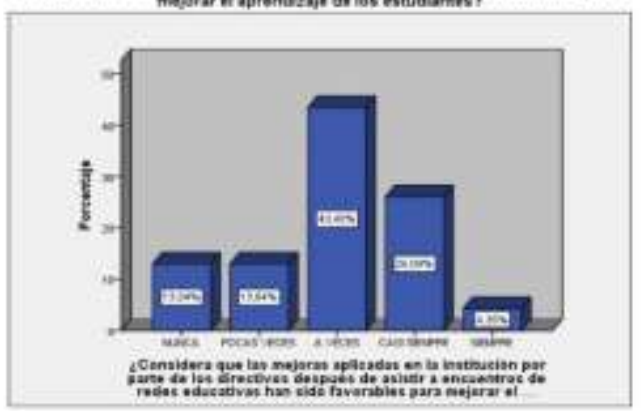

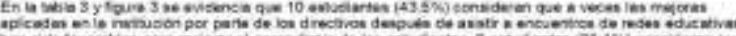
(a)

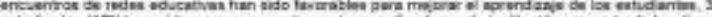

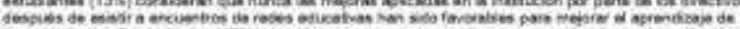

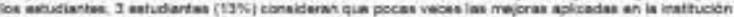

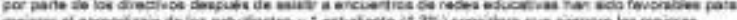

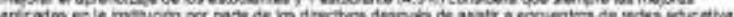

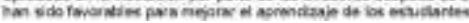

Tebia 2

EEn is insotución se premis o reconoce ef trabajo de los colaboradores talentosos?

\begin{tabular}{|c|c|c|c|c|c|}
\hline & & Fivouracie & Poncentelo & $\begin{array}{c}\text { Porcertaps } \\
\text { vasido }\end{array}$ & $\begin{array}{l}\text { Porcentape } \\
\text { ncumulado }\end{array}$ \\
\hline \multirow[t]{6}{*}{ Vatio } & NUNCA & 2 & 8.7 & 8.7 & 3.7 \\
\hline & POCAS veces & s & 130 & 130 & $2 t, y$ \\
\hline & A veces & a & 34,2 & 34.al & 58,5 \\
\hline & CABi sEUPAE & 8 & 34,8 & 348 & $n+3$ \\
\hline & tcupae & 2 & a.7 & et & 1000 \\
\hline & Totes & 23 & 1000 & 100,0 & \\
\hline
\end{tabular}

Figure 2

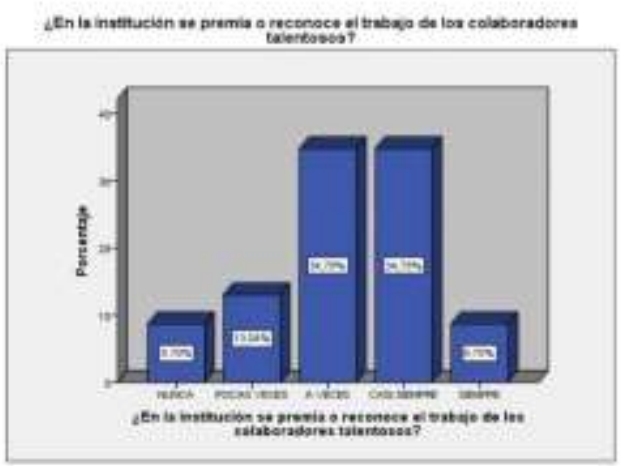

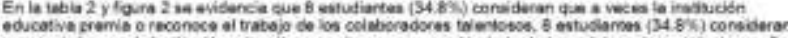

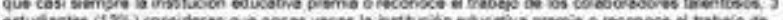

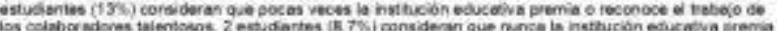

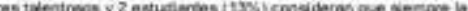

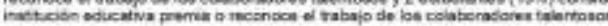

Tebin \&

\begin{tabular}{|c|c|c|c|c|c|}
\hline & & Fasouenca & Parzenteys. & $\begin{array}{c}\text { Percerive } \\
\text { nesise }\end{array}$ & 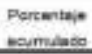 \\
\hline \multirow[t]{6}{*}{ venton } & NLNCA & 2 & RT & 27 & 6.7 \\
\hline & ROCAS VECES & 2 & B) & 87 & 17,4 \\
\hline & A veces & 1 & A3 & 4.3 & 217 \\
\hline & CASI SKUPRER & is & $\cos 2$ & 65,2 & $a v 0$ \\
\hline & DESUPFE & 3 & 136 & 13,0 & 100.0 \\
\hline & Totel & 2 & 100.8 & 1900 & \\
\hline
\end{tabular}

Figura 4

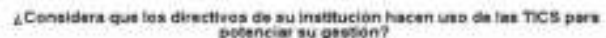

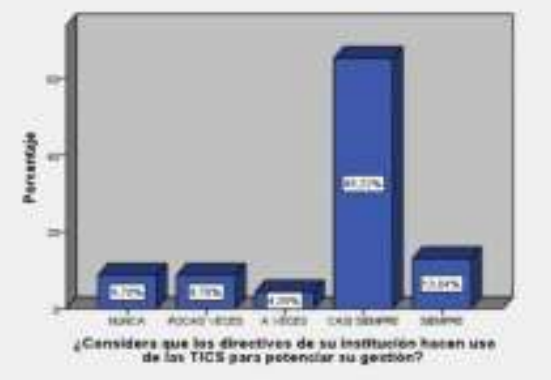

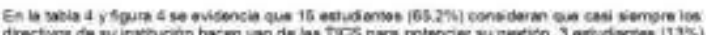

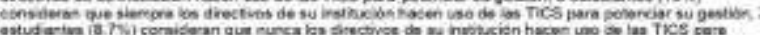

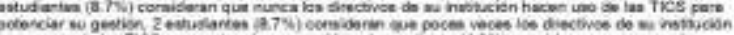

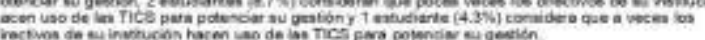


Tabla 5

Aeconoce Ve, Cudies son los puestos ciaves dentro de su instutudion?

\begin{tabular}{|c|c|c|c|c|c|}
\hline & & Frovieno & Porcenteis & $\begin{array}{c}\text { Porcentaje } \\
\text { valids. }\end{array}$ & $\begin{array}{l}\text { Partoncaje } \\
\text { acamiade }\end{array}$ \\
\hline \multirow[t]{6}{*}{ vatos } & NUNCA & 1 & 4,3 & 4.3 & 4,3 \\
\hline & POCAS VECES & 2 & a.7 & e.7 & 12,0 \\
\hline & A VECEES & 1 & 4.2 & 43 & $17 / 4$ \\
\hline & CASI SIEMPRE & 8 & 207 & 21.7 & se.t \\
\hline & SEMPPE. & 14 & ea. 9 & abs & 100,0 \\
\hline & Total & 2 & 1000 & $100, a$ & \\
\hline
\end{tabular}

Figura 5

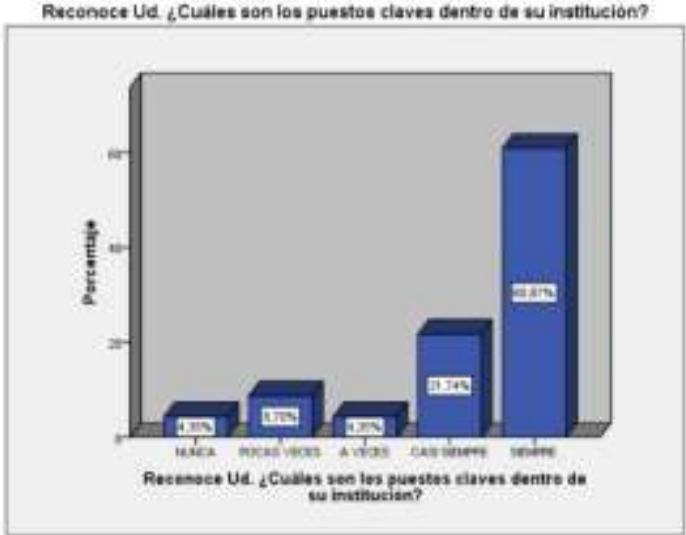

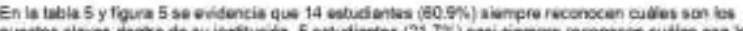

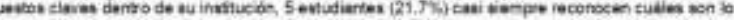

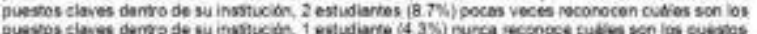

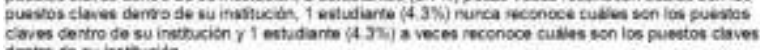

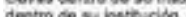

Tabla 7

¿Considera adecusdos los procedimientos que emples la organización para lo

\begin{tabular}{|c|c|c|c|c|c|}
\hline & & Fracuancis & Porcantais & $\begin{array}{l}\text { Porcentapo } \\
\text { wilide }\end{array}$ & $\begin{array}{l}\text { Poncentaje } \\
\text { soimulada }\end{array}$ \\
\hline \multirow[t]{6}{*}{ Vulisto } & RUNNCA. & 3 & 13,0 & 19,0 & 19,0 \\
\hline & POCAS VECES & 2 & 8.7 & 8,7 & 21,7 \\
\hline & A VECEs & a & 39,1 & 39,1 & 60,9 \\
\hline & CASI FEUPRE & 7 & 30,4 & 20,4 & 91,3 \\
\hline & SEM,PRE & 2 & 8,7 & 8,7 & 1000 \\
\hline & Totai & $2 a$ & 1000 & 1000 & \\
\hline
\end{tabular}

Figura 7

¿Censidera adecuados los procedimientos que empiea ia organizacion pars io
contratacion de persanal nuevo?

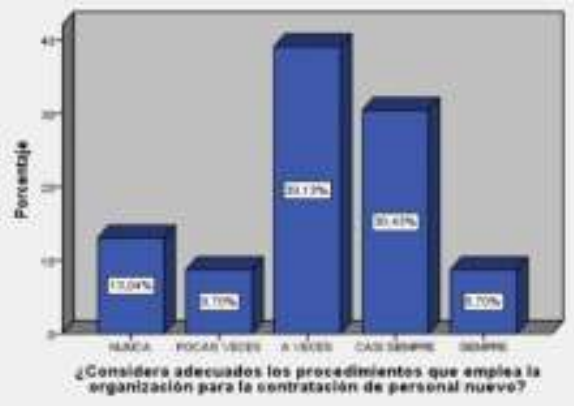

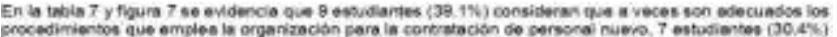

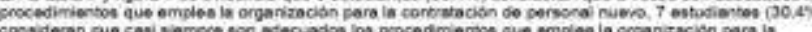

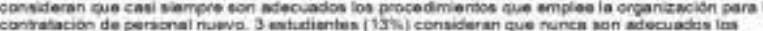

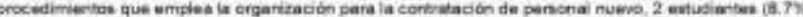

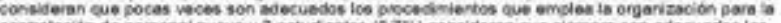

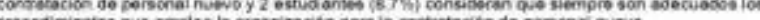

Tabia 6

L5erte Ue mayer idectidisd yo apego ton los puestos claves que iaboran en in instrucicen

\begin{tabular}{|c|c|c|c|c|c|}
\hline & & Finourcia & Furcentese & $\begin{array}{l}\text { Porestan } \\
\text { vilito }\end{array}$ & $\begin{array}{l}\text { Pertentap } \\
\text { gcumule }\end{array}$ \\
\hline \multirow[t]{6}{*}{ veido } & ALNECA & t & 43 & 4s & 43 \\
\hline & POCAS VECEG & 2 & 27 & et & 39,0 \\
\hline & A VECES & $z$ & $8 \pi$ & $B T$ & 21,7 \\
\hline & CAS SEISRE & 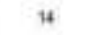 & 62.9 & 60.9 & 42,8 \\
\hline & SEMPRE & 4. & 17,4 & 97,4 & 2000 \\
\hline & Tosal & 23 & 100,0 & 1020 & \\
\hline
\end{tabular}

Figura 6

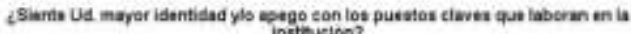

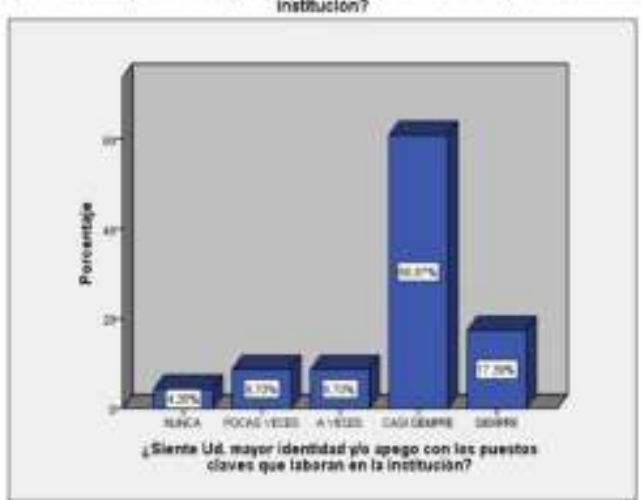

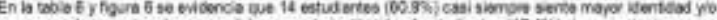

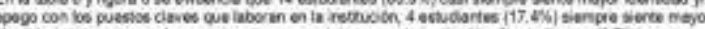

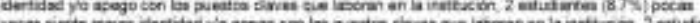

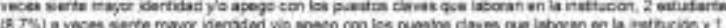

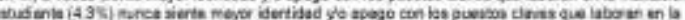
nusicion

Tathla 8

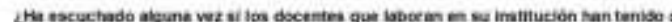
clene probiemos econdemicos?

\begin{tabular}{|c|c|c|c|c|c|}
\hline & & Frecuencie & Porcentere & $\begin{array}{l}\text { Povesertaio } \\
\text { velado }\end{array}$ & $\begin{array}{l}\text { Porcentaie } \\
\text { acumidode }\end{array}$ \\
\hline \multirow[t]{6}{*}{ vavie } & nanea & 2 & 87 & 0.7 & a.7 \\
\hline & POCAS VECES & 1 & 4 & 43 & 19,0 \\
\hline & A VECES & 2 & 27 & e. 7 & 21,7 \\
\hline & CASI \&EMPAE & e & 28,1 & $28: 1$ & 478 \\
\hline & SEMPAE & 12 & 52,2 & 622 & 100.0 \\
\hline & Tesai & 22 & 1008 & 108.0 & \\
\hline
\end{tabular}

Figura 8

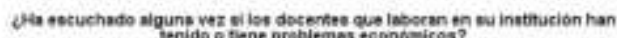

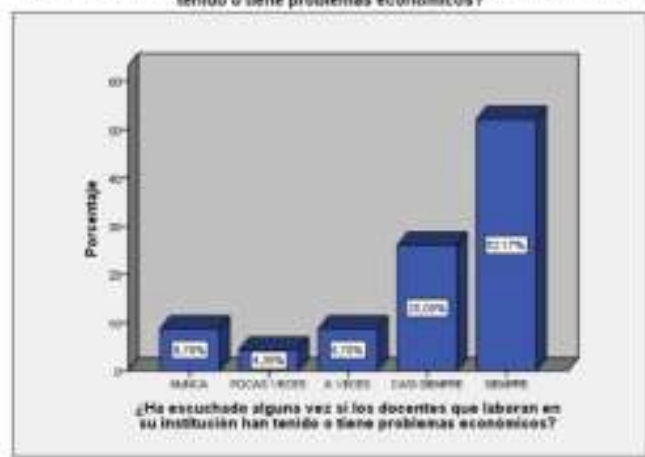

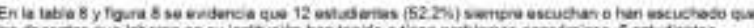

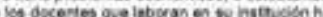

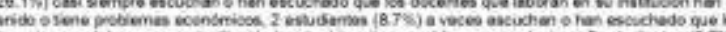
Wrea ocustan

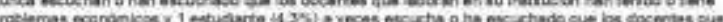

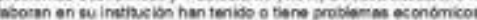


Tabia 9

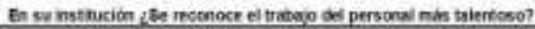

\begin{tabular}{|c|c|c|c|c|c|}
\hline & & Frouendis & Porrenize & 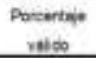 & Portamap \\
\hline \multirow[t]{6}{*}{ Veisto } & musch & 2 & 47 & 0.7 & 5.7 \\
\hline & POCAS VECES & , & 43 & 4,3 & 13.0 \\
\hline & A VECER & 5 & 217 & 21.7 & 34,8 \\
\hline & ChSI SIEMPFE & 14 & 80.9 & 50.8 & 95.7 \\
\hline & SENAPEE & + & 4.3 & 4,3 & 100.0 \\
\hline & Toten & 조 & 1000 & 1080 & \\
\hline
\end{tabular}

Figura 9

En au mathution ¿se foconoce al trajajo del personal mas tasentosot

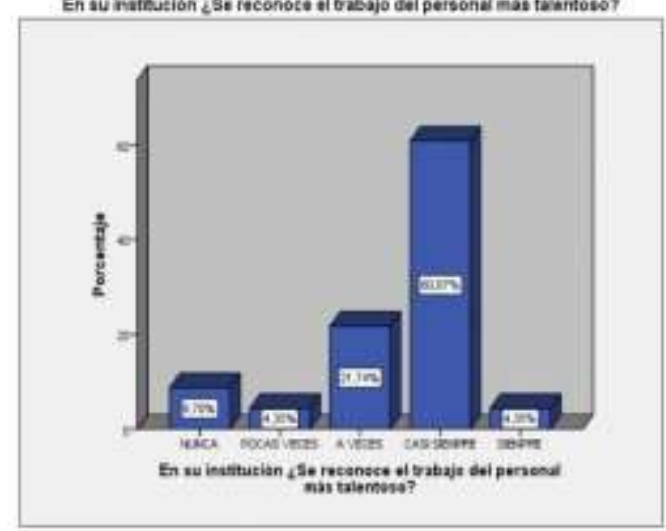

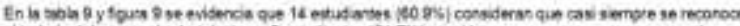
a leses se reconoce ed

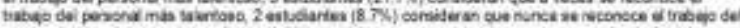

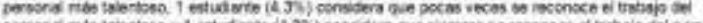

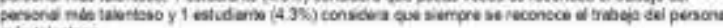

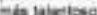

Tatib 11

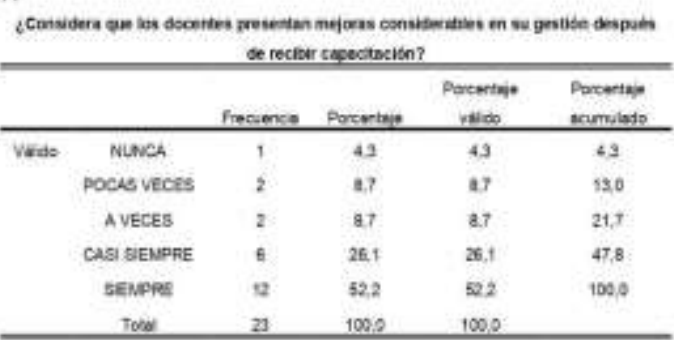

Figua 11

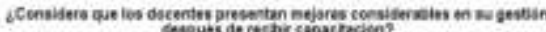

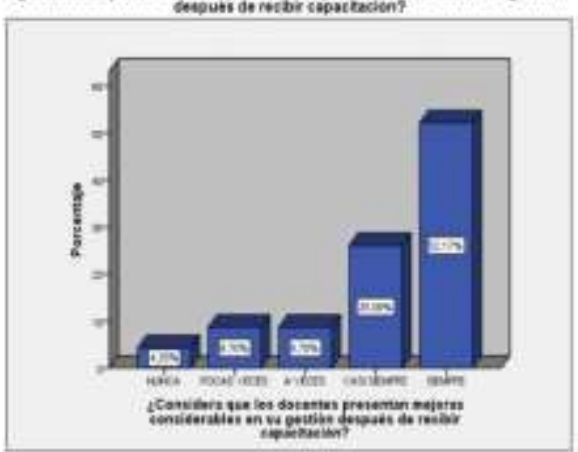

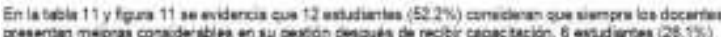

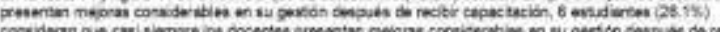

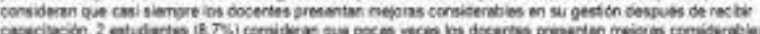

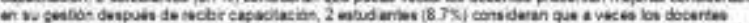

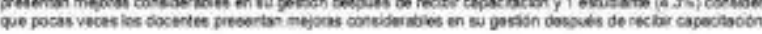

Tabla 10

\begin{tabular}{|c|c|c|c|c|c|}
\hline & & Firsancia & Percertaje & $\begin{array}{c}\text { Percentiaje } \\
\text { valids }\end{array}$ & $\begin{array}{l}\text { Porcertase } \\
\text { vermindo }\end{array}$ \\
\hline \multirow[t]{6}{*}{ Wilos } & Nheivo & 3 & 13,0 & 12.0 & 130. \\
\hline & Mur pocos & 1 & 43 & 4,3 & $17 / 4$ \\
\hline & Acaunos & 1 & 43 & 4.9 & $2 \pi 3$ \\
\hline & LAMAYORIA & II & 34,5 & se.s. & res \\
\hline & 70006 & 5 & 21,7 & 20.7 & 109,0 \\
\hline & Tolai & 23 & 1000 & 1000 & \\
\hline
\end{tabular}

Figre 10

¿Considers Ud, que sua dotentesestan bien capactados pars cjercer sua
Ninoones?

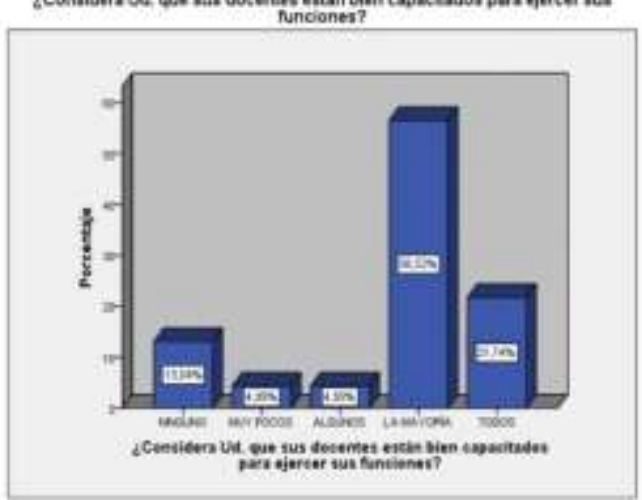

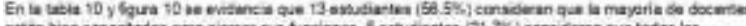

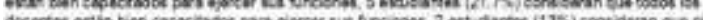

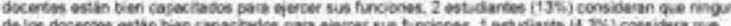

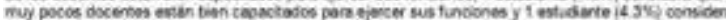

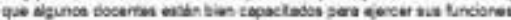




\section{PROGRAMA ACADÉMICO DE MAESTRÍA EN EDUCACIÓN CON MENCIÓN EN GESTIÓN EDUCATIVA}

La Molina, 30 de noviembre del 2020

\section{CARTA DE PRESENTACIÓN}

\section{Señor:}

Dr.

Presente:

Asunto: Validación de instrumentos, por criterio de especialista.

De mi especial consideración:

Es grato dirigirme a Usted, para expresarle un saludo cordial e informarle que como parte del desarrollo de la tesis del Programa Académico de Maestría en Educación con mención en Gestión Educativa, estoy desarrollando el avance de mi tesis titulada "Programa de Formación Continua de Directivos para Activar a los Puestos Claves en una Institución Educativa Privada de Educación Básica Regular”, motivo por el cual, se hizo necesaria la elaboración de una matriz de categorización, construcción del instrumento y ficha de validación.

Por lo antes expuesto y con la finalidad de darle el rigor científico necesario, se requiere la validación de dichos instrumentos a través de la evaluación de Juicio de Expertos. Es por ello, que me permito solicitarle su participación como juez, apelando a su trayectoria y reconocimiento como docente universitario y profesional.

Agradeciendo por anticipado su colaboración y aporte en la presente me despido de Usted, no sin antes expresarle mis sentimientos de consideración y estima personal.

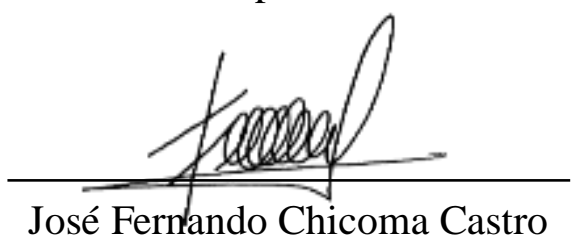

PD. Se adjunta:

- Matriz de Categorización

- Instrumentos de recolección de la información

- Ficha de validación de instrumento 


\section{PROGRAMA ACADÉMICO DE MAESTRÍA EN EDUCACIÓN CON MENCIÓN EN GESTIÓN EDUCATIVA}

La Molina, 3 de diciembre del 2019

\section{CARTA DE PRESENTACIÓN}

\section{Señor:}

Lic. Renato Boggio Quezada

\section{Presente:}

Asunto: Solicito autorización para validación de instrumentos de tesis

De mi especial consideración:

Es grato dirigirme a Usted, para expresarle un saludo cordial e informarle que como parte del desarrollo de la tesis del Programa Académico de Maestría en Educación con mención en Gestión Educativa, estoy desarrollando el avance de mi tesis titulada "Programa de Formación Continua de Directivos para Activar a los Puestos Claves en una Institución Educativa Privada de Educación Básica Regular”, motivo por el cual, resulta necesario validar instrumentos en una institución educativa.

Por lo antes expuesto y con la finalidad de darle el rigor científico necesario, solicito su autorización para ingresar a su prestigioso COLEGIO CLEMENTE ALTHAUS en la fecha y hora que Ud. crea conveniente a fin de aplicar instrumentos de evaluación a 3 directivos (encuestas) , 5 puestos claves (encuestas) y 15 alumnos (cuestionarios). Cabe precisar, que los resultados de dicha investigación serán confidenciales y entregados a su persona en el mes de marzo del año 2020 (fecha referencial).

Agradeciendo por anticipado su colaboración y aporte en la presente me despido de Usted, no sin antes expresarle mis sentimientos de consideración y estima personal.

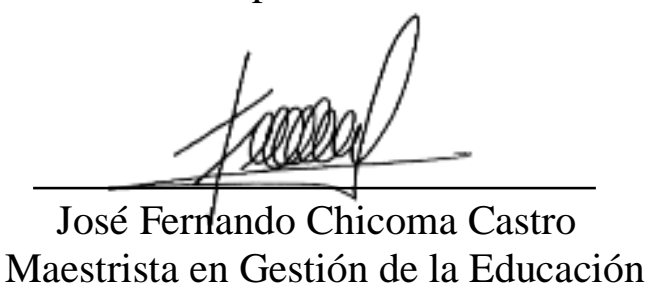




\section{Anexo 9. Validación de instrumentos por criterio de expertos}

Dr. Félix Fernando Goñi Cruz - Metodólogo USIL
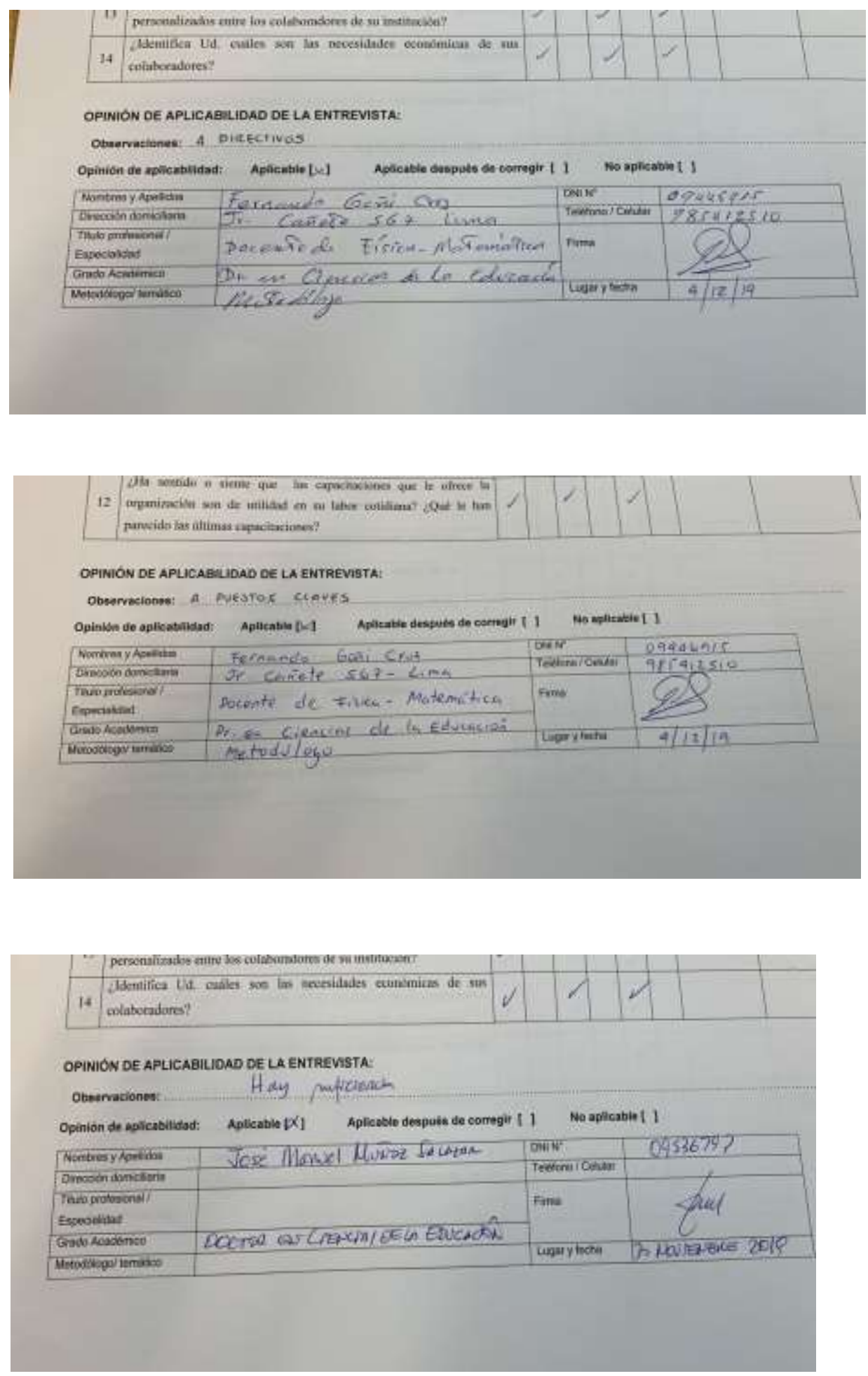
Dr. José Manuel Muñoz Salazar - Metodólogo USIL

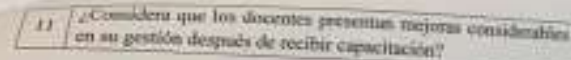

OPINION DE APLICABILIDAD DEL CUESTIONARIO

Obeervaciones:

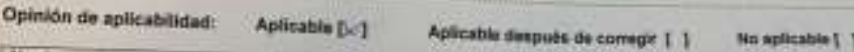

\begin{tabular}{|c|c|c|c|}
\hline & Aplicabie ferputs de cameole 1 & Mn aplieat & \\
\hline Nomicias , Aveldos & Furninde Goini Grut & mentw & 04446715 \\
\hline 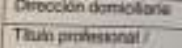 & If Ciñcte s67- Lima & Tawher Cential & \\
\hline Eacocialitat & Dobento de tisica- Mafomaticas & Fima & \\
\hline Crosonocodemico & Df of Cirabiny de is Edotución & & \\
\hline Wincodicop' termites & Nectaislog = & Gapriven & $4 / 2 / 19$ \\
\hline
\end{tabular}

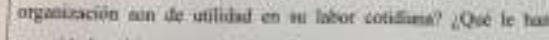

parnckbo las ultimat capecitaciones?

OPINIÓN DE APLICAEILUDAD DE LA ENTREVISTA.

Obovrationes:. Hoy pufiererick

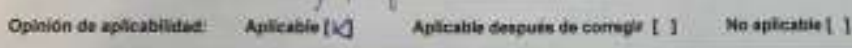

\begin{tabular}{|c|c|c|c|}
\hline 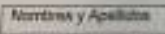 & MuNTER InLEZar & DWIF & 0.5536793 \\
\hline 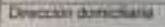 & & Teithroricontar & \\
\hline 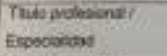 & & noms & \\
\hline 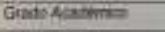 & 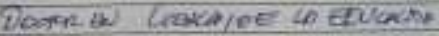 & & \\
\hline 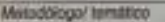 & & Lupreriecte & \\
\hline
\end{tabular}

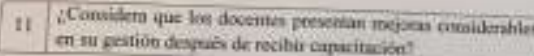

OPINION DE APLCABILIDAD DEL CUESTIONARIO

Oberracione: Hay Mfitiole

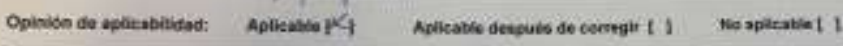

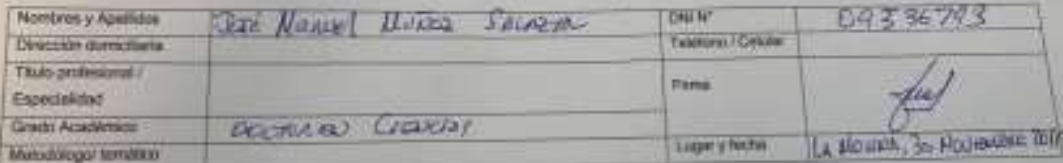


Dr. Ronal Garnelo Escobar - Metodólogo USIL
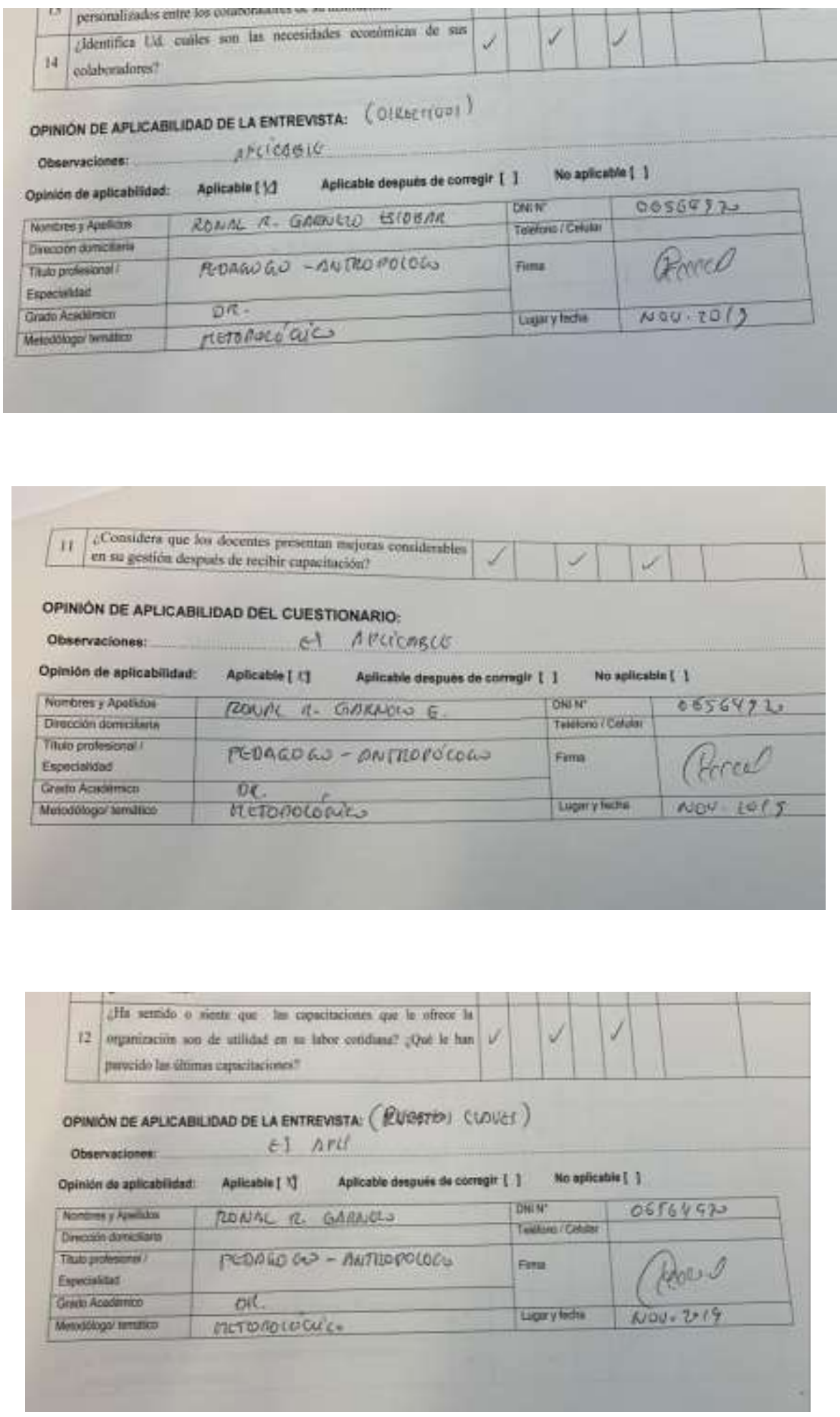


\section{Anexo 10. Validación del programa de formación continua}

Dr. José Manuel Muñoz Salazar - Metodólogo USIL

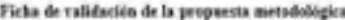

Denuming

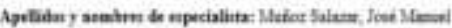

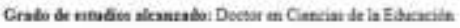

Resaltads eirnatere en valerncise.

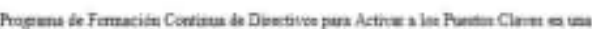

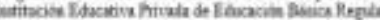

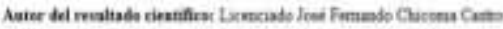

Apectes a chernar

Valiateite imierse

\begin{tabular}{|c|c|c|c|c|}
\hline \multirow[t]{2}{*}{ 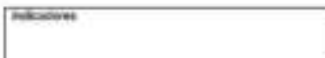 } & \multirow{2}{*}{$\tan$} & \multicolumn{3}{|l|}{ necose } \\
\hline & & Rent & nem & 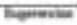 \\
\hline 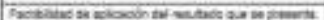 & ta & & & \\
\hline 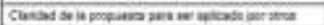 & 8 & & & \\
\hline 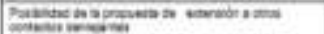 & $x$ & & & \\
\hline 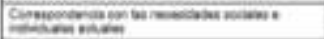 & $\mathrm{t}$ & & & \\
\hline 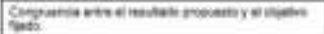 & 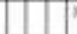 & & & \\
\hline 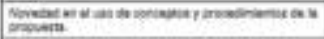 & $\mathrm{z}$ & & & \\
\hline 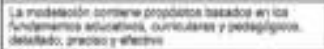 & & & & \\
\hline 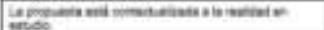 & it & & & \\
\hline 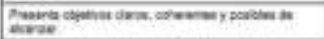 & $x^{\prime}$ & & & \\
\hline 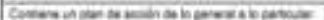 & I & & & \\
\hline
\end{tabular}

Fias do valdacite entras thras

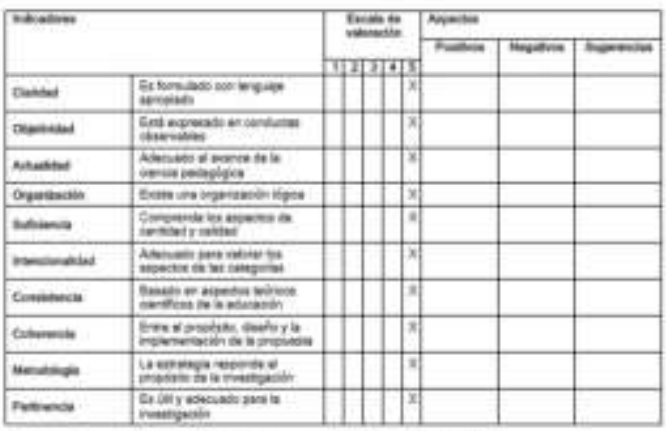

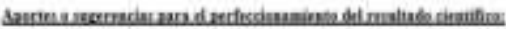

Opinim to apliratilital

Le prepsete de modelasinats ensplicatte

Henaliadn

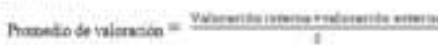

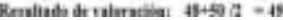

Escala de volanacide

\begin{tabular}{|c|c|c|}
\hline Escols & Forop secusca & Fingoprom the \\
\hline Dotcieris & $\mid 70-17$ & 1205-355 \\
\hline Dealo & 18.29 & $136 \mathrm{~s}-51 \mathrm{~s}$ \\
\hline Reopier & {$[26-390$} & $52 x-67 y$ \\
\hline Bins & {$[34-41]$} & pess - $83 \mathrm{~N}$ \\
\hline Muy tien & $(42-50)$ & 134 - 100 1 \\
\hline
\end{tabular}

Opinión de aplicatilidad:

a) Deficiente ( ) b) Bajo ( ) c) Regular ( ) d) Bien ( ) Muy bien (X)

\begin{tabular}{|c|c|c|c|}
\hline Nombies y Apelididos & Josu Manoel Munhoz Sahzal & DENIN N & 08536793 \\
\hline Drecobin tomicliaria & & Telblone / Cervir & \\
\hline 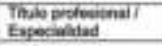 & \multicolumn{3}{|l|}{ Ingeniuno Ekectrdenco } \\
\hline Grado Acasthico & \multicolumn{3}{|l|}{ Doctur en Ciencas de la Educoción } \\
\hline $\begin{array}{l}\text { Coupacibn y ato do } \\
\text { experiancie }\end{array}$ & \multicolumn{3}{|l|}{ Dacome. 35 años } \\
\hline Metodidogotomatico & \multicolumn{3}{|l|}{ Mascdolega } \\
\hline
\end{tabular}

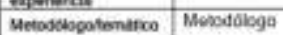

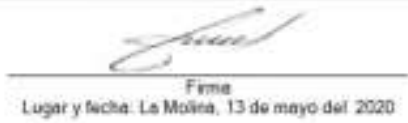


Mg. Hélwis César Moreno Bardales - Temático USIL

Fids de talibatien de la peppenta antiedaligira

\section{Dentarain}

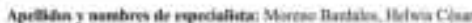

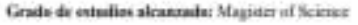

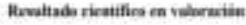

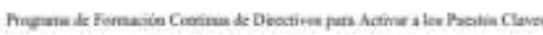

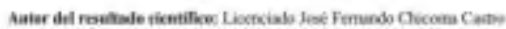

Sentinualumat

Validacian imterns

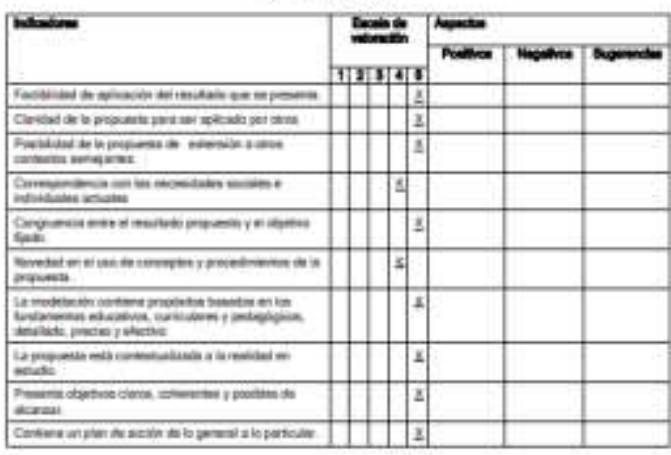

Ficta de validaction enterna (forment

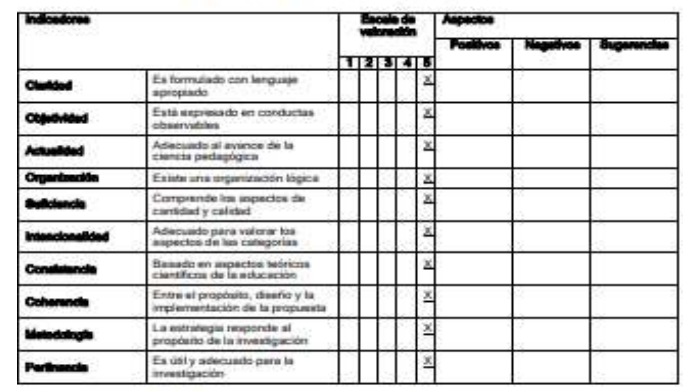

Apartes a sugerendas para el perfeceioeamikato del resultado cientifice:

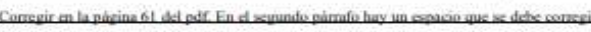
enor de formal. Posde confundirse somo que fathan dinas

Opininie de aptikatilitant

Muy interesante Se pseate aplicur a miversidades y de nuanera soecial a emprosas del sosties

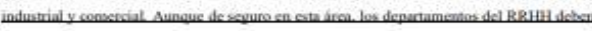
sestar implementades

Resulterdas

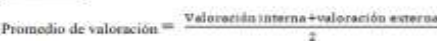

Resultado de valeración: $\quad 49$

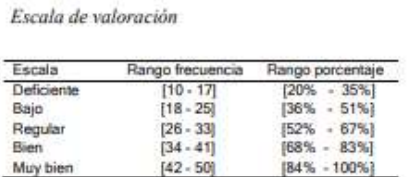

Opinión de aplicabilidad:

a) Deficiente ( ) b) Bajo ( ) c) Regular ( ) d) Bien ( ) Muy bien ( x )

\begin{tabular}{|c|c|c|c|}
\hline Nombres y Apelaldidon & Helwis Cesar Moreno Bardales & DWIN & 09618132 \\
\hline Diveceliten domidellerta & $\begin{array}{l}\text { Jr. Eloy Espinoza 415. Urb. Ingeneiria } \\
\text { SMP }\end{array}$ & Tellatono / Calular & 993140237 \\
\hline 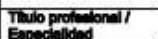 & Licenciado en Administración de Empre & & \\
\hline Gredo Acadionico & Magister of Science & & \\
\hline Coupedicn y wo do & Docente Universitario y Consultor Solu & nes Tecnologicas & \\
\hline Motodollopolhmmillios & Temático & & \\
\hline
\end{tabular}


Dra. María Teresa Herrera Montoya - Metodólogo USIL

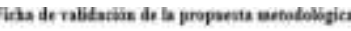

Datas gonolish

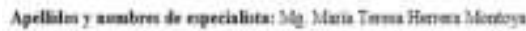

Grabo de enadiar alraasade: Maentra en Rtucacien

Reoshato dientilice ea nharardie

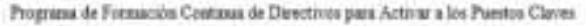

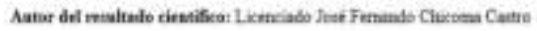

Aspestonsoburvar

\begin{tabular}{|c|c|c|c|c|c|}
\hline \multicolumn{6}{|c|}{ Tulalaciten interns } \\
\hline \multirow[t]{2}{*}{ Fastion } & \multirow{2}{*}{\multicolumn{2}{|c|}{$\operatorname{tgn}$}} & \multicolumn{3}{|l|}{ Anestion } \\
\hline & & & Ren & 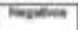 & Tasences \\
\hline 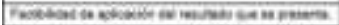 & & $A$ & & & \\
\hline 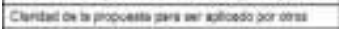 & & 8 & & & \\
\hline 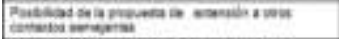 & & 8 & & & \\
\hline 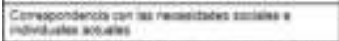 & & 8 & & & \\
\hline 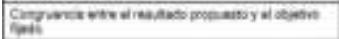 & & a & & & \\
\hline 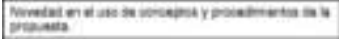 & & I & & & \\
\hline 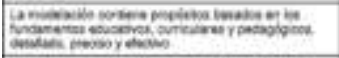 & z] & & & & \\
\hline 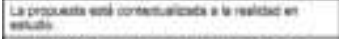 & & I & & & \\
\hline 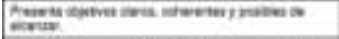 & & I & & & \\
\hline 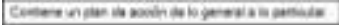 & & 4 & & & \\
\hline
\end{tabular}

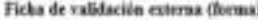

\begin{tabular}{|c|c|c|c|c|c|}
\hline \multicolumn{2}{|l|}{ Hatem } & \multirow{2}{*}{ bes } & \multicolumn{3}{|l|}{ 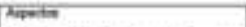 } \\
\hline & & & Powa & Taghen & The \\
\hline onewat & 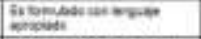 & 8 & & & \\
\hline chentiat & 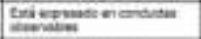 & 2 & & & \\
\hline nates & 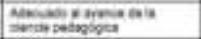 & $\bar{\alpha}$ & & & \\
\hline$a m$ & 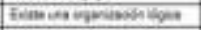 & 8 & & & \\
\hline atames & 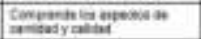 & 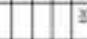 & & & \\
\hline mendirantal & 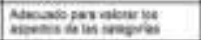 & 2 & & & \\
\hline Conmentas & 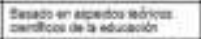 & $\bar{z}$ & & & \\
\hline arande & 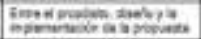 & 2 & & & \\
\hline Henters & 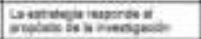 & 2 & & & \\
\hline Nowede & 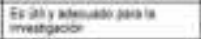 & 1 & & & \\
\hline
\end{tabular}

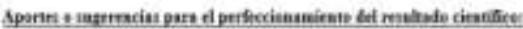

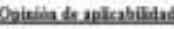

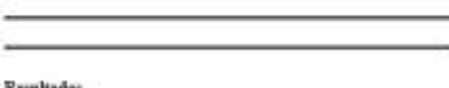

Thuthote

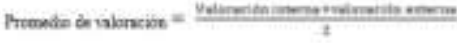

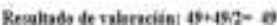

Ërcaláa de valonación

\begin{tabular}{|c|c|c|}
\hline Eala & 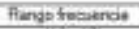 & Raros perantion \\
\hline & $(0-17)$ & Wos-301 \\
\hline Espo & {$[18-29$} & $D 0 t-518 d$ \\
\hline Alegular & {$[2 \pi$} & [art i end \\
\hline then & {$[34-41]$} & $1035-a+4$ \\
\hline Martien & $142-50 \mid$ & ises -100 s! \\
\hline
\end{tabular}

Opiatión de applicabilisdad:

a) Deficiente ( ) b) Byjo ( ) e) Regular ( ) d) Barn ( ) Muy turn ( X )

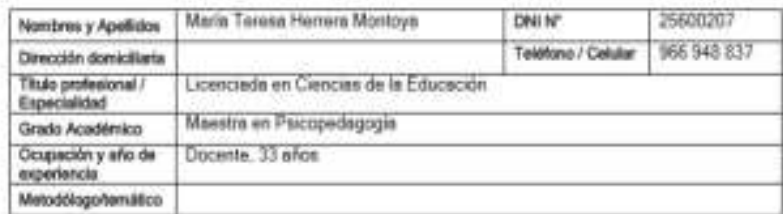

Punis.

Lugar y tocha: La Motina 14 de mavo 2025 